\title{
Clashing Concerns: Multi-Agency Policing, Technology and Rights Implications
}

By

Lidvina Rajabalan, Hon.B.A.

A thesis submitted to the

Faculty of Graduate Studies and Research

in partial fulfillment of

the requirements for the degree of

Master of Arts

Department of Law

Carleton University

Ottawa, Ontario

August 1, 2006

(C) 2006, Lidvina Rajabalan 


$\begin{array}{ll}\begin{array}{l}\text { Library and } \\ \text { Archives Canada }\end{array} & \begin{array}{l}\text { Bibliothèque et } \\ \text { Archives Canada }\end{array} \\ \begin{array}{l}\text { Published Heritage } \\ \text { Branch }\end{array} & \begin{array}{l}\text { Direction du } \\ \text { Patrimoine de l'édition }\end{array} \\ \begin{array}{l}\text { 395 Wellington Street } \\ \text { Ottawa ON K1A ON4 }\end{array} & \begin{array}{l}\text { 395, rue Wellington } \\ \text { Ottawa ON K1A ON4 } \\ \text { Canada }\end{array}\end{array}$

Your file Votre référence ISBN: 978-0-494-18294-9 Our file Notre référence ISBN: 978-0-494-18294-9

NOTICE:

The author has granted a nonexclusive license allowing Library and Archives Canada to reproduce, publish, archive, preserve, conserve, communicate to the public by telecommunication or on the Internet, loan, distribute and sell theses worldwide, for commercial or noncommercial purposes, in microform, paper, electronic and/or any other formats.

The author retains copyright ownership and moral rights in this thesis. Neither the thesis nor substantial extracts from it may be printed or otherwise reproduced without the author's permission.
AVIS:

L'auteur a accordé une licence non exclusive permettant à la Bibliothèque et Archives Canada de reproduire, publier, archiver, sauvegarder, conserver, transmettre au public par télécommunication ou par l'Internet, prêter, distribuer et vendre des thèses partout dans le monde, à des fins commerciales ou autres, sur support microforme, papier, électronique et/ou autres formats.

L'auteur conserve la propriété du droit d'auteur et des droits moraux qui protège cette thèse. $\mathrm{Ni}$ la thèse ni des extraits substantiels de celle-ci ne doivent être imprimés ou autrement reproduits sans son autorisation.
In compliance with the Canadian

Privacy Act some supporting forms may have been removed from this thesis.

While these forms may be included in the document page count, their removal does not represent any loss of content from the thesis.
Conformément à la loi canadienne sur la protection de la vie privée, quelques formulaires secondaires ont été enlevés de cette thèse.

Bien que ces formulaires aient inclus dans la pagination, il n'y aura aucun contenu manquant.

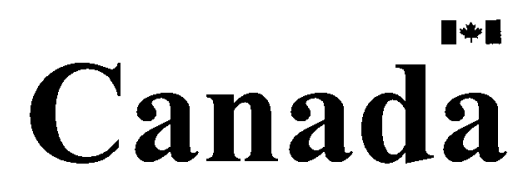




\begin{abstract}
Multi-agency policing refers to the diversified, pluralized and fragmented policing landscape that began to take shape in the $19^{\text {th }}$ century. Today, there is an astonishing level of cooperation among numerous policing actors from around the world. A myriad of technological innovations have had an immense impact on these transformations. The consequences of these developments have had serious implications for rights, specifically the right to privacy, civil liberties and human rights. This is the core tension that this thesis explores. By critically evaluating the changing policing terrain and the corresponding process of technologization, this analysis investigates why rights occupy such a tenuous position today. Key theoretical concepts and an examination of legal rulings, policies and practices are used to inform this analysis. Democratic accountability within multi-agency policing must be enhanced if rights implications are to be effectively addressed. Cooperation among five key actors is essential to fostering greater accountability.
\end{abstract}




\section{Acknowledgements}

A tremendous amount of gratitude goes to Alan Hunt and Pat O'Malley for your encouragement, guidance and insight throughout this research process.

I am deeply thankful to my parents and sister for your steady encouragement and support. Visits home were one of the greatest pleasures during the past two years.

A very special thank you goes to my friend Ayat. Thank you for listening to me and supporting me through all the turbulence.

For all of the other special people in my life, from A-Z, my sincere thanks for being there in so many ways. ' 


\section{Table of Contents}

Abstract

Acknowledgements

Introduction 1

Chapter 1: Laying a Conceptual and Historical Foundation 5

Introduction $\quad \mathbf{5}$

1. Important Terms, Concepts and Developments 6

A. Defining Multi-Agency Policing and Mapping its Territory 7

B. From Police to Policing $\quad 10$

C. Structural Changes to the State and the Impact on Policing 12

D. Unpacking 'Rights': Privacy Rights, Civil Liberties and Human Rights 16

2. The Historical Background of Multi-Agency Policing 18

A. $19^{\text {th }}$ Century Origins of Multi-Agency Policing 18

B. The Early $20^{\text {th }}$ Century and the Bureaucratic Independence of the Police 20

C. The Birth of Interpol: History and Motivating Factors 22

D. The Birth of Europol: History and Motivating Factors 26

E. The Contemporary Policing Landscape 27

3. Policing Technologies, Information and Surveillance 28

A. Technologization of Multi-Agency Policing: A Brief Historical Sketch 29

B. The Rights Implications of Policing Technologies 34

C. The Relationship Between Technology and Transnational Crime 38

4. Factors that Facilitate and Impede Multi-Agency Policing 40

A. Impediments to Multi-Agency Policing 40

B. Factors that Facilitate Multi-Agency Policing 42

$\begin{array}{ll}\text { Conclusion } & 43\end{array}$

Chapter 2: Theoretical Lenses $\quad 45$

Introduction $\quad 45$

1. A Look at Surveillance and the Right to Privacy 46

A. Making Theoretical Sense of Surveillance $\quad 46$

B. The Right to Privacy 49

2. The Surveillant Assemblage $\quad 54$

A. The Surveillant Assemblage: Four Key Components 55

3. Foucault and Deleuze: From Disciplinary Society to Control Society 59

A. The Passage from Disciplinary to Control Societies 60

B. The Relationship Between Control Societies and Multi-Agency Policing 64

4. Digital Rule: A Mode of Exclusion, Control and Surveillance 67

A. Digital Decision-Making: Access and Exclusion 68

B. Digital Rule and the Right to Privacy 70

$\begin{array}{ll}\text { Conclusion } & \mathbf{7 2}\end{array}$ 
Chapter 3: Examining Legislation, Policy and Practices 74

Introduction $\quad \mathbf{7 4}$

1. The Direction of the Courts

A. The First Wave: Rights Implications of Phone-Tapping Technologies 76

B. The Second Wave: Audio-Visual Surveillance and Electronic Tracking 77

C. The Third Wave: Thermal-Energy Detection Devices 80

$\begin{array}{ll}\text { 2. The Convention on CyberCrime } & 87\end{array}$

A. The Need for Greater International Cooperation $\quad 89$

B. The Public-Private Relationship: The Case of Internet Service Providers (ISPs) 93

3. The United Nations Crime Congress $\quad 96$

A. The Early Congresses: Confidence in the Penal-Welfare Model 98

B. The Changing Crime Control Landscape 100

$\begin{array}{lr}\text { Conclusion } & 108\end{array}$

Chapter 4: Responding to Rights Implications 110

Introduction $\quad 110$

1. Democratic Accountability, Multi-Agency Policing and Technology 111

A. Understanding Democratic Accountability 112

B. Accountable to Whom or What? Defining the 'Public' 115

C. Democratic Accountability, Private Policing and Transnational Policing $\quad 117$

D. Democratic Accountability and Multi-Agency Policing 120

2. Avenues for Future Development of Multi-Agency Police Governance $\quad 121$

$\begin{array}{lr}\text { A. The Critical Role of the State } & 122\end{array}$

B. Leaders in the Police Community 127

$\begin{array}{lr}\text { C. The Judiciary and the Courts } & 132\end{array}$

D. Public Participation and the Need for Civilian Oversight 134

$\begin{array}{ll}\text { E. The Role of Non-Governmental Organizations } & 136\end{array}$

F. Tying It All Together Through a Cooperative Strategy 138

$\begin{array}{ll}\text { Conclusion } & 139\end{array}$

$\begin{array}{ll}\text { Conclusion } & 141\end{array}$

$\begin{array}{ll}\text { Bibliography } & 143\end{array}$

$\begin{array}{lr}\text { Cases Cited } & 149\end{array}$ 


\section{Introduction}

In the current era of late modernity, the provision of order and security through the police is undergoing significant change. Arguably the most important of these transformations is that policing functions are now being performed by a wide array of regulatory agencies. This has given rise to a pluralized, diversified and fragmented policing landscape. The concept that I use to capture this ever-evolving network is multiagency policing (MAP). Of especial importance to MAP is technology, particularly those that enhance transportation, communications, information exchange and surveillance. From the $19^{\text {th }}$ century onward, these innovations have powerfully impacted policing, with particular influence on the interactions of policing agencies worldwide. In tracing these developments within the international policing landscape, a discussion of some of the most impactful factors is included to contextualize these changes.

Both the transnational nature of policing and the use of advanced technologies in crime fighting have raised serious concerns about the implications for rights - including civil liberties, privacy rights and human rights. It is this tension between broadening police powers through the use of technologies (specifically those that enhance surveillance and the gathering and exchange of information) and safeguarding rights that forms the core problem that this thesis investigates. In light of this tension, the research question I will be exploring is as follows: to what extent is multi-agency policing and its reliance on technology, surveillance practices and information protecting or undermining rights?

This thesis is comprised of four chapters. Chapter One begins by defining and explaining some foundational concepts. This is followed by an overview and analysis of 
the historical background of multi-agency policing beginning in the $19^{\text {th }}$ century with specific reference to Interpol and Europol. Included here is a discussion of some of the main motivating factors for the formation of MAP. The technological infrastructure of multi-agency policing and the attendant process of technologization are assessed in detail in this chapter. In addition, the rights implications of this process and its role in shaping international crime are also discussed. Finally, a look at some of the main impeding and facilitating factors for MAP highlights the complexity of the policing landscape.

The second chapter undertakes a theoretical analysis of multi-agency policing, technologies and rights implications. The concept of 'surveillance' is explored first because it is a common thread uniting the main ideas used in this chapter. Furthermore, it is deeply connected to the right to privacy. Because this right is significant for the overall analysis of this thesis, I discuss its origins, development and contemporary meanings. Three theoretical models that take surveillance as an important concept are explored in the remainder of this chapter: Ericson and Haggerty's 'surveillant assemblage'; Gilles Deleuze's 'control society' - an updated version of Michel Foucault's disciplinary society construct; and Richard Jones' notion of 'digital rule'. While surveillance is not explicitly discussed in last two of these theories, an argument is advanced that it is a salient concept nonetheless. Throughout this analysis, the rights implications, most notably those affecting the right to privacy, are examined.

Chapter Three moves on to examine concrete examples of policing, technologies and the consequences for rights. Through an analysis of seven Canadian and American legal decisions, it emerges that a gradual increase in police discretionary power in the use of surveillance technologies is apparent. This is explained with reference to the changing 
crime control landscape. Next, the Convention on CyberCrime is investigated to reveal that rights protections are only found on the surface of this treaty. More importance is accorded to establishing greater international cooperation and developing stronger publicprivate relationships to combat cyber-crime. The last portion looks at the UN Crime Congress that has held meetings on crime-related issues since 1955. By examining the documents from each of these sessions, it is held that unique processes are taking place. David Garland's observations on the changing crime control landscape help elucidate these developments. This chapter argues that the changing postures towards safeguarding rights (in the three different contexts) are reflective of broader changes to the field of crime control shaped by political, social and economic factors.

Chapter Four provides a response to the rights implications of multi-agency policing and its dependence on technologies by evaluating the notion of democratic accountability. Especially important here is determining whom or what policing should be accountable to. This requires establishing what is meant by the 'public' within the context of transnational policing. The idea advocated here is that there are multiple publics just as there are multiple policing agencies. The problems of accountability within transnational policing and a key sub-sector - the private policing industry - are explored here also. The second portion of this chapter examines avenues for enhancing transparency and accountability over multi-agency policing. Five agencies in particular, conceptualized as the 'safety valves' of democracy, are identified as crucial for this purpose: the state, leaders in the police community, the judiciary and the courts, the public and non-governmental organizations. The principal strategy advocated is greater cooperation among these actors. 
Lastly, a brief conclusion follows that provides some final thoughts on the intersection between multi-agency policing, technologies and rights implications. The issues covered by this thesis have generated considerable debate among scholars, policy makers, theorists and activists. The events of September 11, 2001 profoundly affected this debate and gave rise to a new set of concerns, especially on the topics of rights protections. Thus, it is hoped that this thesis contributes to the discussion on changes taking place within the worldwide policing landscape, its dependence on technologies and the collective implications for rights protections. 


\section{Chapter 1: Laying a Conceptual and Historical Foundation}

\section{Introduction}

The contemporary policing field is populated by a constellation of policing actors that are collaborating in numerous ways and are aided by a host of technologies. At the same time that these developments have transformed policing, they have also given rise to serious concerns about rights implications. This is the core tension that this thesis explores. This chapter is divided into four sections, each of which discusses various elements that are relevant to the central tension and the thesis as a whole. Section One lays down a conceptual foundation by defining and explaining some of the main concepts, ideas and historical processes that are crucial to this analysis. Section Two examines the historical background of multi-agency policing (MAP) over the past two centuries with reference to the emergence of Interpol and Europol. I argue that a myriad of political, legal and social factors have influenced the evolution of MAP.

The next section focuses on the role of technologies within multi-agency policing. By discussing some of the most significant developments since the $19^{\text {th }}$ century, it is argued that technologies have come to occupy a very prominent place in policing over time. Concomitantly, there has been growing opposition to police uses of technologies because of the threat they pose to rights. The process of technologization and the rights implications it carries are discussed within the context of Interpol and Europol. Another element of this section is the capacity of technologies to facilitate both the internationalization of policing and the transnational reach of crime. Finally, Section Four turns to a discussion of the main factors that impede as well as facilitate multi-agency 
police cooperation. This chapter contends that over time, the increasing collaboration of policing agencies coupled with the expanding use of policing technologies have raised serious concerns about safeguarding rights.

Initiatives to establish closer global police cooperation have occurred in numerous countries throughout modern history but generally they have been sporadic and did not produce lasting results. In recent years, there has been greater international coalescence around specific issues, but the level of involvement by most states still remains irregular. However, European and North American cross-national policing efforts are comparatively more active and have expanded consistently over the past two centuries. It is for these reasons that this thesis concentrates on developments in these two continents.

\section{Important Terms, Concepts and Developments}

The purpose of this section is to define and discuss some of the key concepts, terms, important social transformations and developments that are relevant to this thesis. The first of these is the idea of multi-agency policing itself. Considering that MAP is the main object of analysis for this thesis, a detailed definition of the term, including its main features and constituent parts, is needed. Next, I distinguish between the terms police and policing, each of which have come to assume quite different meanings in the current period. Thirdly, I discuss the key structural changes to the state that have occurred over the last several decades and their impact on the organization and delivery of policing services. Lastly, I provide some brief comments on rights implications because they form a core component of my analysis. 


\section{A. Defining Multi-Agency Policing and Mapping its Territory}

In the present global age, multi-agency policing has become an expanding, diverse and complex field of activity. It is a concept that captures the ongoing pluralization, diversification and fragmentation of contemporary policing. It encompasses local, regional, national and international policing agencies and the interactions that take place between and/or among them. Increasingly, the lines demarcating the operational boundaries of these policing agencies are blurring. For David Garland (2001: 105; 170), this "confusing maelstrom of developments" has brought about a 'third sector' of prevention and security in which various types of policing agencies are acting simultaneously. As such, multi-agency policing does not denote perfect cooperation, but rather strong relationships among policing actors worldwide. Mathieu Deflem's study of international policing strengthens this argument. He found an increasing degree of density in police relationships across states rather than the development of a monolithic global police (Deflem, 2002a: 218).

Some of the many policing agencies active within MAP include the public police, the private police, all branches of the military, transnational organizations such as Interpol, intelligence gathering agencies, hybrid organizations and all types of regulatory bodies. It is important to recognize that this diversification of the policing landscape represents a departure from established modes of delivering security in which the state was the sole provider. As Loader (2000: 324 ) states, fragmented, diverse networked policing is to all intents and purposes here to stay such that it has become sociologically implausible to seek to defend or resurrect a field constituted by one sole state provider. Likewise, Garland (2001: 170) comments that the formal boundaries of the crime control 
field are no longer marked out by institutions of the criminal justice state. The reasons for this are elucidated in detail later in this section.

Among the many policing actors active today, those from the private sector have had a particularly powerful impact on the evolution of this field. Beginning in the late 1960 s or early 1970s, the number of individuals employed in the private industry appears to have overtaken the number of public police officers (LCC, 2002: 9). This trend has occurred in most western states. Some commentators conceptualize this shift as a 'quiet revolution' (Stenning \& Shearing, 1980) that represents a significant historical break because it has altered notions of policing as a state-centred activity. (Sheptycki, 1995: 617). The transformations brought about by private policing will be discussed at various points in this thesis.

Many of these key features of multi-agency policing have been discussed in the literature on policing, albeit under different terms. They include transnational, international, interagency or cross-national policing. As well, 'networks of security' (Bayley \& Shearing, 1996), a 'nodal conception' of policing governance (Shearing, 2001) and 'pluralist policing'(Loader, 2000) have been used. I have selected multi-agency policing because it most accurately captures the phenomenon I would like to investigate. However, since these terms generally refer to a similar idea and have been used interchangeably in the literature, they will be used in this thesis as well.

Although international crime is often cited as the main impetus for the creation of international policing organizations like Interpol, this term is a misnomer because crimes are defined differently by states and so, cannot be considered international. In this thesis, international crime does not refer to activities prohibited worldwide, but rather to crimes 
with cross-national implications. Gerhard Mueller (2001: 13), in his overview of the definition of transnational crime, supports this definition by stating that although this is an amorphous term with numerous international interpretations, its common attribute is transcending the jurisdiction of a given state. Given the logistical and crime-control challenges presented by this main feature of transnational crime, it is understandable that police agencies should have sought closer linkages with their domestic and foreign counterparts. At the same time, many other factors associated with changing organizational and national government concerns and issues linked to the changing nature of economic and political relations crucially influenced greater global cooperation among policing agencies. They are discussed in later portions of this chapter.

There are three main distinctive features of multi-agency policing. The first is the great deal of flexible interaction and cooperation among policing agencies worldwide. Interpol and Europol, two organizations that are focused precisely on promoting this type of cooperation, are illustrative examples. At the same time that greater cooperation is taking place, there is flexibility in these relationships: partnerships can be established just as easily as they can be broken and re-established.

The second characteristic is the process of technologization. This refers to two concurrent developments within policing. The first is the importation or infusion of technologies into policing that have been adapted for policing purposes. The second is the creation of technologies from within policing or by outside agencies specifically for policing activities. The technologies that have influenced MAP the most are those that facilitate communications, transportation and information collection and exchange. The improvements in travel and communications technology, especially in the latter half of 
the $20^{\text {th }}$ century, have brought about what social geographers call the 'time-space convergence' (Sheptycki, 2002b: 2). This phenomenon refers to the breakdown of borders because of technological advancements. As Gary Marx (1997: 484) states, developments in communications and surveillance technology are particularly important in undermining physical, geographical and juridical borders. Deflem (2002b: 458) further remarks that the most critical factor of technologies shaping international policing is their capacity to transcend borders. Although uneven, the process of technologization has propelled worldwide policing interactions in unprecedented ways. At the same time, however, it has also generated serious concerns regarding the protection of rights. Specific examples of key technologies and their rights implications are discussed later in this chapter.

Lastly, MAP is defined by the erosion, both conceptually and concretely, of traditional territorial boundaries. With the multiplicity of policing relationships and exchanges taking place within this terrain, long-held understandings of borders are challenged. As Ian Loader (2000: 329) comments, transnational policing chips away at the presumption that policing is an activity coterminous with traditional territorial boundaries. Importantly, technologization has contributed significantly to this process because it has enabled policing activities outside traditional borders.

\section{B. From Police to Policing}

A relatively recent terminological distinction between police and policing has emerged within scholarly work on policing. There is, however, no real consensus on what the terms mean. Since this thesis focuses on multi-agency policing, it is necessary to give 
both terms definitional consideration by discussing this distinction. In doing so, I explain why the key features of policing are more fitting for this thesis than those of the police.

In a recent report by the Law Commission of Canada (LCC, 2002: 2), the police are defined as institutions and policing is understood as an activity. The police as institutions are creations of government, backed by statue and marked by more or less clearly defined powers. The police engage in the activity of policing, but so do a range of other agencies. Police too often signifies public institutions, for example, municipal or federal uniformed peace officers, without taking into account the myriad of agencies engaging in policing. In other words, the specific legal designation of an organization tells us very little about what they actually do. The idea that the police are institutions tied to the state is consequently too narrow in scope for this analysis.

By contrast, policing as an activity takes into account a wide range of organizations and personnel because it focuses on tasks. The Law Commission of Canada (LCC, 2002: 8) defines policing as the activities of any individual or organization acting legally on behalf of public or private organizations or persons to maintain security or social order while empowered by either public or private contract, regulations or policies, written or verbal. For Robert Reiner (2000: 3), policing is the attempt to maintain security through surveillance and the threat of sanctioning; it implies a set of activities aimed at preserving both a particular social order and social order in general. According to Sheptycki (2002b: 154), policing relates to state capacities as well as terrain and population. It is a set of practices that seeks to order human populations that inhabit or pass through a given territory by simultaneously maintaining control of the space and of the people who inhabit it. Simply put, the concept of policing connotes efforts to provide 
security through surveillance and the possibility of coercion (Sheptycki, 2002b: 7). Based on these definitions, policing involves social ordering activities through legally authorized means and is equipped with the ability to enforce these activities through aggressive action. It is also related to terrain and population and not confined to stateauthorized institutions. In sum, these features of policing are more fitting for this analysis than the idea of the police. As such, multi-agency policing most accurately captures the phenomenon I seek to explore in this thesis.

\section{Structural Changes to the State and the Impact on Policing}

To a large extent, the rise of multi-agency policing is owed to structural reconfigurations of the state that have affected the delivery of policing. This is the first of five key influential factors discussed in this thesis. David Garland's work in this area is useful. Garland (2001: 30) tells us that with the advance of modernity in liberal democracies came the state's capacity to impose 'law and order', a function that was increasingly viewed as a contractual obligation owed by a democratic government to its citizens. In the process (over the course of the late $18^{\text {th }}$ and 19th centuries), the character of crime control slowly shifted from being a generalized responsibility of citizens and civil society to be a specialist undertaking largely monopolized by state-authorized law enforcement. By the middle decades of the $20^{\text {th }}$ century, the public police forces in both the UK and the USA had come to occupy a dominant position in the field of security provision (Garland, 2001: 32). The 1950s and 1960s saw a turning point that changed the perceptions of the public towards the state. This new predicament arose because high rates of crime became a normal social fact and the criminal justice state was perceived as having failed to deliver adequate levels of security (Garland, 2001: 140). In response, the 
late 1960 s and early 1970 s saw the state begin to withdraw its claim to be the chief provider of security and attempt to remodel crime control on a more pluralized, partnership basis.

This created a crime control and security vacuum that was quickly filled by a plethora of policing agencies. The private policing sector in particular, was able to seize the moment. The 1970 s saw the dramatic growth of the private security industry as it increasingly began to sell its services to organizations in need of greater levels of security than the public police could provide (Garland, 2001: 160). The consequence for the state was that it now had to play alongside many other policing agencies on the new pluralized policing field. As Castells (1997: 304) explains, the state - hitherto considered focal to both provision and accountability in the field of policing - has been reconfigured as but one node of a broader, more diverse 'network of power'. Some, such as Loader and Walker (2005: 1), have even argued that states acting alone, or solely within their own borders, are no longer a sufficient means of producing security within those borders. These observations all point to the rise of multi-agency policing that has seen stateadministered policing joined, intertwined and contested by an array of policing actors.

However, these changes did not result in a wholly weakened state. Instead, they have dispersed policing functions, such as the provision of security and the maintenance of order, across the policing landscape. To this, Sheptycki (2002c: 9) adds that entrenched notions of territorial boundaries have been transformed with the consequence that the once assumed radius of social order of a state has begun to disintegrate into many smaller private radii. The result globally is the development of 'bubbles of security' (Sheptycki, 1997). As such, new developments in policing have occurred alongside those 
taking place within the state. Ian Loader (2000: 323) acknowledges this, stating that the policing network continues to encompass the direct supervision of policing by state governments. At the same time, the network also extends to private policing forms secured through government; to transnational police arrangements taking place above governments; to markets in policing and security service unfolding beyond government; and to policing activities engaged in by citizens below government. In outlining the contours of the emergent policing landscape, Loader considers the relationship of its constituent nodes to the state. He specifies five categorizations that are pertinent to this analysis.

Policing by government is the first grouping. It includes state-sanctioned providers of policing as well as the emergence of various police units and other bodies with policing powers such as the British Transport Police. At the local level, there are multiple policing services provided directly by local authorities. These services include the establishment of CCTV systems and the formation of council-run 'community patrols'. The second category is policing through government. This describes situations where policing services are enlisted by government, but provided by others. The most established form that this takes is government agencies purchasing staffed services and hardware for property protection from the security market.

Policing above government captures the defining features of multi-agency policing the closest. Loader explains that this signifies the complex of policing arrangements that are currently unfolding above the level of the sovereign state, either in international fora between states or in novel supranational settings. Having for some 50 years taken institutional shape principally in the form of Interpol, these developments are 
now being fuelled by both the globalization of crime (in field such as drugs and terrorism) and the unprecedented yet uneven progress of policing within the European Union. Although the direction and pace of these developments remain unclear, interagency policing seems set to stay.

Policing beyond government refers to the existence of an enhanced and expanding commercial market in security systems and policing services, a market that now takes multiple forms. These include the employment by public and private organizations of their own 'in-house' security staff, and the purchasing by individuals and businesses of protective hardware such as car and burglar alarms. Loader comments that commercialized policing in residential areas is patchy, but adds that because of the state's incapacity to meet citizen demands for order, it seems poised to become an ever more visible component of local policing networks.

The final category is policing below government and includes three particular typologies. The first is organized surveillance directly engaged in by citizens that are separate, but under the supervision of the state such as neighbourhood watch schemes. The second refers to 'reactive vigilantism' directed at capturing and punishing suspected 'offenders'. The last category includes the mounting of citizen patrols in defence of proactive, preventative control that has been termed 'civil policing'. These numerous types, forms and expressions of policing activities in the modern period point to the broad diversification and pluralization of policing. Collectively, these observations lend further support to the multi-agency policing construct. 


\section{Unpacking 'Rights': Privacy Rights, Civil Liberties and Human Rights}

The features of MAP discussed above, particularly technologization and pluralization, present many rights related concerns. The ones that are most relevant for this analysis are privacy rights, civil liberties and human rights. My focus is on the first of these because it has the most bearing on my analysis - the technologization of transnational policing and the extensive surveillance that these innovations enable has produced widespread concern about the protection of privacy. Civil liberties and human rights are also discussed in the ensuing chapters because they capture broader rights that have bearing on policing practices and also encompass privacy safeguards. Since I discuss the consequences for these rights extensively in this thesis, only a brief summary follows here. The fact that rights concerns are raised within the context of policing seems odd given that police are supposed to guarantee the conditions necessary for the exercise of these liberties. This paradox is significant for this thesis and is explored below.

The right to privacy is a relatively new addition to the law books of many western democracies. Its origins in American law, for instance, can be traced to the late $19^{\text {th }}$ century. Importantly, this evolution is tied to the increasing presence of technologies in everyday life and their intrusive abilities. The technologization that ensued from these early years exacerbated privacy problems. With the advent of the information era, these worries only accelerated. In combination with the spread of multi-agency policing and the technologization of the international policing landscape, privacy has become a prominent issue. Chapter Three provides a more detailed discussion of privacy rights, policing and the legal consequences. 
Civil liberties are fundamental rights and freedoms that are bestowed to citizens under a democratic system. They can vary slightly from state to state, but they generally contain the same basic rights. Human rights is another term used within policing studies. The 1948 Universal Declaration of Human Rights is the primary piece of international law that outlines the human rights all peoples are entitled to and includes many that have bearing on policing. For example, Article 8 guarantees to everyone the right to "an effective remedy for acts violating the fundamental rights granted to him by the constitution or by law" and Article 9 holds that "no one shall be subjected to arbitrary arrest, detention or exile." The right to privacy is also recognized under Article 12: "No one shall be subjected to arbitrary interference with his privacy, family home or correspondence...Everyone has the right to the protection of the law against such interference." Although these rights are guaranteed, most democratic states contain clauses that allow for their suspension under certain conditions. In addition to international agreements, most policing agencies have their own codes outlining standards for rights protections. Those found within the constitutions of Interpol and Europol are discussed in this chapter.

That policing activities can undermine democratically guaranteed rights is the product of its dual role as both enforcers of the law and protectors of rights guaranteed by the law. Fulfilling this twofold role has proven difficult; modern policing is now a balancing act in which police are caught between demands for effective crime control and respect for rights. Loader (2000: 325$)$ describes this as a paradox for the police because they represent both a guarantor of security upon which the exercise of rights depends, and a potent, ever-present threat to those very same liberties. The complexities of multi- 
agency policing and its main defining features outlined above deepen the challenge of resolving this paradox and achieving an appropriate balance.

\section{The Historical Background of Multi-Agency Policing}

The purpose of this section is to provide a historical overview of multi-agency policing itself beginning in the $19^{\text {th }}$ century. In doing so, this discussion focuses on the changes in Europe and the US as well as the emergence and growth of two key agencies: Interpol and Europol. In addition to the structural changes to the state discussed in the previous section, this analysis looks at four other influential factors: the bureaucratic independence of the police, the expansion of transnational crimes, legislation prohibiting 'new' crimes and technological advances. This analysis demonstrates that the evolution of transnational policing has been influenced by a myriad of factors, each of which have made unique impressions on the policing landscape.

\section{A. $19^{\text {th }}$ Century Origins of Multi-Agency Policing}

The emergence of MAP can be located in European and North American history, although both continents followed distinct paths of development. Deflem outlines the evolution of interagency policing in Europe starting in the $19^{\text {th }}$ century. Two key transformations facilitated this trend. First, transnational policing objectives shifted away from political crimes such as those posed by anarchists and socialists against established conservative rule (Deflem, 2005: 1). These criminal problems remained important because they served as catalysts for cross-national police cooperation in Europe. For instance, the police forces of Austria, Baden and several German principalities formed the Police Union of German States in 1851 to unite their efforts to suppress revolutionary activities following the unrests of 1848 (Deflem, 1996: 37). Concerns about politically 
uncertain conditions continued in the following decades and by the $1890 \mathrm{~s}$, violent anarchism became a serious problem in many European countries, prompting national leaders to call for concerted international action (Jensen, 1987: 322).

In response to the violence, a conference was held in Rome in 1898 and is seen today as a crucial step towards greater international police cooperation. As Jensen (1987: 323) explains, the conference became a point of departure for increased intra-European police communication and information exchange, culminating in 1904 with an antianarchist protocol which was signed at St. Petersburg by half of Europe. The accords that came out from both conferences represent the first efforts in recent times to promote official cooperation among the police forces of the world (Jensen, 1987: 323). However, the enactment of legislation following the conferences was encumbered by governments resistant to treating anarchism as a criminal matter (Deflem, 2005: 2). Despite these failures, the conferences left a lasting legacy in terms of techniques of criminal identification. Both the Bertillonage system ${ }^{1}$ and the portrait parlé ${ }^{2}$ (spoken picture) were embraced by police as the most effective methods of recording criminal data (Jensen, 1987: 332) and identifying criminals. From the early $20^{\text {th }}$ century onward, a gradual depoliticization of international policing took place, owing primarily to national

\footnotetext{
${ }^{1}$ Anthropologist Alphonse Bertillon created the system of Bertillonage in the 1890's. Shortly after, it became the primary method for identifying criminals in the late 1800 's. Bertillon based his system on the claim that measurement of adult bones does not change after the age of 20 . A person would go through an exam where they would have various body measurements taken. The results were then recorded and/or compared to a record database.

${ }^{2}$ Deflem (2002: 459) describes the portrait parlé as a refined version of the Bertillonage system that classified identifications of criminals based on measurements of parts of their heads and bodies and the colour of their eyes, hair and skin. These measurements were numerically expressed and transmitted from one country to another by telephone or telegraph, a practice that the Rome conference stressed should be further developed.
} 
sovereignty concerns, sensitivity to political matters and differences in the political-legal ideologies of nations (Deflem, 2002b: 459).

This brings us to the second key transformation. Throughout the $19^{\text {th }}$ century, international cooperation was established by personal contacts among police officials and on an ad hoc basis. This system soon began to change as police established more formal and multilateral forms of cooperation (Deflem, 2002b: 459). This transition can be attributed to many factors. The one that has received the most attention in the literature is the rise of international crime. Although this was an important motivational force, it was by no means the only one. Other key reasons are examined in this section and the next. The point to recognize here is that these two shifts facilitated closer transnational police cooperation in $19^{\text {th }}$ century Europe.

In the United States during the same period, police were concerned with specifically American issues: slavery, immigration and the establishment of national borders. American law enforcement slowly began to address the same crime problems faced by their European counterparts but their efforts were much more limited during this century (Deflem, 2002a: 81). Nadelmann (1993: 15-18) attributes this to factors such as the isolationist approach of US foreign policy, socio-geographical conditions and the slow development of US federal policing agencies. It was not until after World War II that the US emerged as a leader in multi-agency policing.

\section{B. The Early $20^{\text {th }}$ Century and the Bureaucratic Independence of the Police}

In the 20th century, the conditions for greater and more effective multi-agency police cooperation were established. Deflem (2002a: 20) argues that perhaps the most important of these was police attainment of a high degree of bureaucratic autonomy from 
political centres. This allowed policing agencies to move beyond the confines of their particular national jurisdictions and function as relatively independent bureaucracies. It also enabled police to collaborate beyond states with which they were politically akin or aligned (Deflem, 2002a: 215). Additionally, autonomy allowed policing organizations to share systems of knowledge and training on both the changing nature and control of transnational crime.

As police gained increasing autonomy in the opening decades of the $20^{\text {th }}$ century, there was also a substantial rise in efforts to formally organize global police cooperation. Although most of these plans were unsuccessful, they served as important steps towards greater transnational police collaboration. The first initiative in Europe was taken at the 1914 First Congress of International Criminal Police in Monaco. This meeting sought to focus police energies on distinctly criminal law enforcement duties and to set up an international police organization. The Congress failed in both respects because it was not organized by police officials but by politicians and legal officials who did not understand the daily issues police faced (Anderson, 1989: 38). On the American continent during the same period, efforts to increase cross-national police cooperation were the most active in Latin America, resulting in three international police conferences: Buenos Aires in 1905, Sao Paolo in 1912 and Buenos Aires again in 1920 (Deflem, 2005: 796). However, they were all unsuccessful because they were oriented at professional objectives, namely to foster better relations among the police of different countries, and not to control international crime.

Despite these failings, US officials pushed for the creation of a formal organization. Deflem (2005: 797) explains that in 1922, the International Police 
Conference (IPC) was established at a police meeting in New York City but only existed for a few years for two main reasons. Firstly, the IPC was mostly concerned with promoting an ideal of professionalism among local US law enforcement agencies rather than tackling major criminal problems. The second was that the IPC did not have realistic concerns about international crime. An internationalization of crime that could justify the establishment of an international police organization was at this time still missing in the United States. This was especially the case because of the distance with Europe and other parts of the world and because the US did not yet have a well-developed federal police. Consequently, its policing operations at this moment in time still remained insulated from the rest of the world (Deflem, 2005: 1). Importantly, the growing pains associated with these early efforts at establishing international policing associations did not prevent the formation of future organizations with the same mandate. Interpol is a prime example.

\section{The Birth of Interpol: History and Motivating Factors}

The 1914 Congress in Monaco, although unsuccessful in its immediate objectives, is seen as the precursor to Interpol. With the outbreak of the First World War in the same year, any further developments towards the establishment of an international policing body were put on hold (Santiago, 2000: 16). It was not until 1923 that a more permanent organization was formed, when the International Criminal Police Commission (ICPC), the organization currently known as Interpol, was founded in Vienna. Today, Interpol is the world's largest international police organization and has a membership of 184 countries (Interpol, 2005a). But as Deflem describes, the creation of the ICPC did not follow a conventional path. The organization was an independent initiative taken by police officials from various, mainly European, countries. It was set up without the 
signing of an international treaty, convention or legal document (Fooner, 1989: 45). The ICPC activities were planned at police meetings and through correspondence among police officials, without control from their governments (Deflem, 2005: 778). These developments during the early phases of Interpol reflect the increasing bureaucratic independence of the police that started at roughly the same time.

Several factors provided the motivational basis for the creation of Interpol. In addition to bureaucratic independence of the police, the internationalization of crime was highly significant. According to Deflem (2005: 798), this took place at the end of World War I. At this time, new types of crime were emerging that took place across countries undergoing rapid social change and technological progress. Based on previous experience with cross-national crimes (primarily in Europe because of the close proximity of countries), the ICPC responded to these post-war changes by establishing new systems of technologically advanced means for international police communication (Deflem, 2005: 799). Through these efforts, Interpol came to represent an important new avenue for greater international police cooperation.

Although the global spread of crime is often cited as the main impetus for the creation of organizations like Interpol, scholars have cautioned against embracing the simplistic equation that more transnational policing was required because of the growth of this type of criminality. Sheptycki (2002b: 113), for instance, argues that the presumed necessity for transnational policing has rested on the images of a variety of 'folk devils'. These are not myths, but rather the product of definitional choice and institutional thinking. In other words, various social actors are involved in the manipulation and social construction of meanings. These actors also help project meanings via various forms of 
mediated communication, to a larger public audience and they do so partly to ensure that their own actors are portrayed as necessary and noble. In this sense, the term folk devil gains analytical purchase. Moreover, transnational crime can now be seen as an artificial, limited and socially constructed problem. In view of this, Sheptycki (2002b: 114) calls for a more rounded picture of transnational policing, but acknowledges that the simplistic version holds centre stage because it makes sense when seen against the global backdrop. A look at some of the transnational crimes to concern Interpol may help us understand why this may be the case.

In its embryonic phases of the early $20^{\text {th }}$ century, Interpol concentrated on crime that gripped the attention of citizens, governments and the policing community. From fears about violent anarchy in the opening years of this century to concerns about counterfeiting in the interwar years, these cross-national crimes were deeply troubling. The Cold War brought with it new worries, most especially the perceived threat (by most of the western world) of an international communist conspiracy. In the 1970s and 1980s, crime problems related to terrorism, illegal immigration and money laundering fostered police cooperation (Aden, 2001: 105; Anderson, 1989: 138). Clandestine trade in everything from illegal drugs to rare species has formed a substantial part of Interpol's activities since its inception. Today, old crime problems in addition to new ones such as cyber crimes and the trafficking of nuclear and radioactive substances concern Interpol (Occhipinti, 2003: 192). From Sheptycki's social construction perspective, the meanings of these transnational crime problems were manipulated to muster widespread support for intensified international police action. 
While this argument provides for a critical evaluation of a popular argument, it does not adequately consider the practical consequences of international crime (ex. financial losses, human costs, et cetera) that required collaborative state and policing interventions. This shortcoming suggests that a more balanced understanding of the role of transnational crime in propelling greater international police cooperation is needed. Such an understanding must take into account the fact that global criminality did have an impact, but perhaps not as monumental as some have argued. Other influential factors should be considered.

One of these is criminalizing legislation. As certain activities captured police attention, laws were soon created to prohibit them. Nadelmann (1993: 1) agrees, stating that a principal force for this process was provided by statues that criminalized activities previously not regarded as criminal. Among these are insider trading, money laundering and computer fraud. Some of Interpol's crime priority areas also illustrate this dynamic: environmental crimes, financial and high-tech crime and the trafficking of human beings (Interpol, 2005c). Legislation prohibiting 'new' crimes consequently helped foster cooperation among police agencies.

The three motivating factors behind transnational policing discussed here bureaucratic independence, the expansion of transnational crime and the impact of new legislation - have made unique impacts on the growth of the policing field. Collectively, they have transformed institutions such as Interpol into key actors that are part of the complex web of global policing. Today, Interpol facilitates this network by providing channels of communication between police agencies in its member countries (Sheptycki, 2004: 116). It serves as an information router, relying heavily on technologies such as 
databases and systems of global communication. As such, it has no operational role and therefore cannot initiate investigations or undertake judicial enquiries on its own behalf. Nevertheless, Interpol's technical capacity to facilitate exchanges among policing organizations worldwide makes it crucial to multi-agency policing.

\section{The Birth of Europol: History and Motivating Factors}

The creation of Europol in 1992 has behind it a long and colourful history of police cooperation in Europe. According to some authors such as Anderson and Boer (1994: 11), the first concrete steps toward creating Europol were taken within Interpol itself because the message traffic passing through the latter was overwhelmingly European in origin and destination. Though this is likely had an impact, others such as Sheptycki (2004: 116) believe that Interpol's decision not to handle domestic European terrorism in the 1970 s was crucial because it gave rise to a host of other transnational police networks in the region. The police working group on terrorism (PWGOT), the TREVI system and then later Schengen and Europol all sprang up on Europe's fertile ground (Sheptycki, 2004: 116). With respect to Europol itself, Santiago (2000: 43) argues that the main impetus came at the European Council meeting in Luxembourg in 1991. In the following year, these plans were given a substantial boost by the Maastricht Treaty: Europol was created to establish closer police cooperation among authorities of EU member states to address cross-national organized crime (Europol, 2005).

Initially a Drugs Unit, Europol became fully operational in 1999 and has expanded to address crimes such as illegal immigration, terrorism, trafficking in human beings and the smuggling of nuclear materials (Loader, 2002: 292). Its principal mode of operation is through the exchange of information and intelligence (Europol, 1997: 2), an 
activity coordinated through an EU-wide network of liaison officers (Bigo, 2000). Europol has also signed several agreements with many non-EU states, bodies and international organizations. An interesting recent example is an operational cooperation agreement signed by Europol and the Royal Canadian Mounted Police (RCMP), which makes it possible for both partners to exchange personal data and Liaison Officers (Canada, 2005). As the EU expands its crime-control activities in the $21^{\text {st }}$ century, Europol will continue to play a vital role both continentally and globally.

\section{E. The Contemporary Policing Landscape}

The influence of all of these historical factors has produced a highly diversified network of policing actors, a development that Garland (2001: 170) refers to as constituting a 'third sector' - a new apparatus of prevention and security. He explains that this small but expanding sector is made up of crime prevention organizations publicprivate partnerships, community policing arrangements and multi-agency practices that link together the different authorities whose activities bear upon the problems of crime and security. It is this latter observation that I have documented here as it is taking place at the international level. Importantly, similar processes occurring at the local, regional and national levels are all caught up in this diversification and pluralization of policing.

In sum, the divergent nature of European and American policing in the $19^{\text {th }}$ century narrowed significantly in the $20^{\text {th }}$ century. The birth of Interpol and Europol were instrumental in this regard because they helped reconfigure cross-Atlantic linkages between the two continents. Concomitantly, a host of other policing actors, relationships, linkages, networks and practices emerged over the course of these centuries. Structural changes to the state, bureaucratic independence of the police, shared concerns about 
transnational crime and legislation prohibiting 'new crimes' facilitated these changes. Of these four, the rise in international crime has received the most recognition. However, this discussion has highlighted that all of these factors have made separate, significant and lasting impacts on MAP. As a result, a wide range of operational police interactions exist between not only Europe and the US, but among a diversity of states, private organizations and non-governmental organizations, including agreements for mutual stationing of liaison officers, a plethora of bilateral and multilateral agreements, extradition and mutual legal assistance treaties (Norman, 2005: 328). Technological advancements, surveillance practices and information databases have been instrumental in enabling these shifts.

\section{Policing Technologies, Information and Surveillance}

The role of technology in multi-agency policing is recognized as both relevant and uncertain. It is relevant because it is the oil that lubricates the global policing complex and has led to what is today a well-entrenched technological infrastructure. At the same time, these technological advancements have also furthered transnational criminal activity. Scholars have even argued that technology has been instrumental in the creation of international crime; it has improved the opportunities for a new class of criminals to transcend traditional borders (Deflem, 2002b: 464). In response, policing agencies initiated efforts to cooperate more closely with one another. Technologies have and continue to facilitate these global partnerships. In this sense, technology is the fifth key factor driving MAP. Technology is also recognized as ambivalent. This is primarily due to the tension between demands for effective crime control and the potential for technologies to weaken civil liberties and privacy rights. 
This section analyzes the process of technologization that began in the late $19^{\text {th }}$ century. I discuss some of the most influential of these innovations for MAP, specifically those in the area of transportation and communications as well as those that are the product of the 'information revolution'. I also explore the various origins of these technologies. In addition to internationalizing the police function, technologies have also enhanced transnational criminality. I examine the implications of this for MAP. Paralleling the rise of police uses of technology has been growing concerns about the implications for rights. In recent decades, police technologies have come to be viewed as either necessary or deeply problematic, leading to a very polarized debate. The role of technology and the rights concerns they have raised within Interpol and Europol are discussed here as well. This section argues that a more proportionate look at policing technologies, one that recognizes both its relevance and ambivalence, is important.

\section{A. Technologization of Multi-Agency Policing: A Brief Historical Sketch}

Beginning in the late $19^{\text {th }}$ century, technological advances in communications and transportation significantly facilitated the transnationalization of policing. As early as the 1898 police conference in Rome, technological means of identifying criminals were discussed. These included the portrait parlé (spoken picture), the Bertillonage system and various forms of printed materials (Deflem, 2002b: 460). Perhaps the most important of these that influenced the internationalization of policing were the Bertillonage and fingerprint systems.

At the beginning of the $20^{\text {th }}$ century, advances in communication and transportation were increasingly applied in police institutions, with more and more consequential results for international police cooperation. For instance, at the 1914 ICPC 
conference, systems of police information exchange aided by postal, telegraphic and telephonic means of communication were suggested. Also proposed were a universal system of identification of fingerprints and photographs, the distribution of an international publication containing search warrants and the creation of a central clearinghouse (Deflem, 2002b: 460). In the ensuing decades of this century, there has been a striking degree of technological innovations to affect policing. Some examples within law enforcement are the motorization of police patrol, the installation of two-way radio communication in patrol cars and developments in forensic science such as polygraph tests. Other salient inventions include the radio, the car and the airplane.

Technologies that permit and enhance surveillance, a term that is given detailed consideration in Chapter Two, are of especial importance to MAP. Nunn (2003: 456) believes that these technologies were developed to cater to the increased level of public surveillance in western society and forms part of a larger trend towards the 'surveillance society'. He contends that this type of surveillance and the technologies that support it have four main layers ranging from simple human perception in the most basic layer to extremely complicated devices in the deeper layers. It is useful to discuss each of these in turn. The first layer deals with human surveillance methods such as direct observation of and involvement in investigations by policing personnel. Spying, informants and domestic intelligence practices are some examples. The second consists of the collection of data about citizens and organizations from primary observation and secondary sources such as credit card records. The technologies of this layer are particularly relevant to multi-agency policing because they enable the collection, analysis and exchange of information around the world. Bennett (1996: 238) describes this process as 
'dataveillance', a term that refers to surveillance practices facilitated by the massive collection and storage of vast quantities of personal data.

The third layer deals with more sophisticated and complex electronic monitoring and imaging systems such as CCTV networks, global positioning systems and satellite photography. The last layer enters the visible surface of targets to reveal invisible electromagnetic radiation that are believed to indicate criminal activity. One example is passive millimeter imaging (PMI) technology that uses waves transmitted from the body to build an image of that body and everything that is carried on it (Nunn, 2003: 456-463). Collectively, these tiers reflect both the complexity and vastness of policing technologies used for surveillance purposes.

The technological advances of the 20th century, including all of the ones found in Nunn's four layers, depended heavily on information - gathering it, processing it, storing it and exchanging it. This is indicative of the 'information era' in which police now operate. Brandl (2003: 137) suggests that this phase is the latest of three 'waves of change' that have occurred in Western society, which in turn affected policing: the agricultural wave, the industrial wave and the information wave. Presently, Western states are in the information wave that began in the 1960 s. It is characterized by an electronics explosion, the growth of high technology and a major concentration on information technologies (Brandl, 2003: 137).

The information wave has produced 'intelligence-led' policing that relies on surveillance systems and databases and focuses on knowledge-work including gathering information, collating data and analytically storing, retrieving and processing this material (Manning, 2000: 181) For Brodeur (2003: 43), these features of intelligence-led 
policing are the hallmark of 'high policing'. These technological advances of the information era have been a major force for organizational change within transnational policing. Sheptycki (2002b: 82-83) shares this view, stating that the role of communications, information management and surveillance technologies are particularly pertinent to an understanding of transnational policing because it is intimately wedded to such technologies. Today, information-based technologies and the technical infrastructure they have created are vital to transnational policing.

Both Interpol and Europol have been significantly aided by policing technologies, particularly those that enhance the collection, organization and exchange of information and augment global policing communications. To illustrate, one of Interpol's core functions is creating secure international communications systems in order to exchange data and information related to combating crime ${ }^{3}$. Indeed, this objective has been a key aspect of Interpol's operations since its establishment. For instance, between the $1920 \mathrm{~s}$ and the 1970 s, an international radio network was the principal means of transnational police communication. During the 1980s, state-of-the-art telecommunications technologies such as high-frequency radioteletype networks, automatic message switching and telex replaced the radio network (Fooner, 1989: 150-151). Thereafter, electronic and digital technologies enhanced communications. Today, the I-24/7 webbased communication system is the chief form of communication used by Interpol.

Europol has been dependent on technology from the start and, like its European policing counterparts, emphasizes intelligence instead of casework (Heiner, 1995: 3). In view of this, Europol is charged with handling criminal intelligence and relies on data

\footnotetext{
${ }^{3}$ This is one of Interpol's three core functions. The other two are (1) providing operational data services and data bases for police and (2) operational police support services.

$<$ http://www.interpol.int/Public/icpo/about.asp $>$
} 
networks to perform this function. It provides its members with technical support by facilitating the exchange of information between police organizations and European Liaison Officers, generating strategic analyses and providing expertise for investigations. These tasks are aided by The Europol Computer System (TECS), which allows the input, access and analysis of data (Europol, 2005). Europol also relies on networks such as the European Intelligence System and the Schengen Information System to coordinate its activities (Lyon, 2001: 98). Technologies, especially those innovated during the current information era, are therefore essential to the operation of Europol.

Many of the technologies identified here were imported into or adapted by the police because of their purported ability to increase communications and other interactions. In more recent decades, technologies have increasingly been developed by the police themselves or by private organizations catering to growing police demands for such technologies. Some examples of the latter include companies such as Visionics, Viisage Technology (both develop facial recognition systems) and Millivision (sensory enhancement technologies), all of which are currently marketing their products to state policing agencies (Nunn, 2003: 466). A third source of policing technologies is the military. Haggerty and Ericson (1999: 234) argue that this is part of the larger 'militarization of policing' process in which technologies developed for military purposes are transferred to law enforcement agencies. A more recent development, they observe, is that these technologies are being introduced directly to domestic agencies in a 'dual use' format (military and civilian usages) rather than gradually 'trickling down' from military to police usage. Some examples include photonics technologies, thermal imaging, 
satellite monitoring and retinal scans (Nunn, 2003: 458). Today, policing technologies originate from a combination of these sources.

\section{B. The Rights Implications of Policing Technologies}

Alongside the explosive growth in policing technologies documented here has been increasing criticism regarding their implications for a host of rights including civil liberties, privacy rights and human rights. Deflem (2002b: 454) explains that soon after technologies were introduced and applied by the police, suspicions mounted against an excessive and unbalanced reliance on technology. This has been the case with the introduction of new policing technologies over the course of the $20^{\text {th }}$ century. Lyon (2001: 20) echoes this argument, stating that the unprecedented growth of surveillance practices during the $20^{\text {th }}$ century has generated calls for the protection of privacy. For example, computer matching technologies and profiling operations have raised issues of privacy, civil liberties, uses of information, unauthorized access, and the rights of persons about whom information is gathered (Marx, 1986:4).

These worries have only increased since the opening of the $21^{\text {st }}$ century, propelled dramatically by the aftermath of the September $11^{\text {th }}, 2001$ terrorist attacks. These events initiated an intensive overhaul of legislation, policy and strategies regarding the uses of technologies within policing. Paralleling these changes has been growing concern about their implications for civil liberties and privacy, the surveillance practices they enable and the massive amounts of personal data they are able to collect and exchange. According to Paul De Hert (2005: 69), we are witnessing the widening use of data mining activities whereby the use of information-based systems facilitates data gathering and sharing between multiple sources. He adds that these measures have reinforced the 
powers of law enforcement bodies to access individuals' personal data for purposes different from those for which they were originally gathered, supplied and processed (De Hert, 2005: 69). This is best demonstrated by the USA PATRIOT Act. Philip Thomas (2002: 206) argues that the Act undermines the privacy protection of the Fourth Amendment by eroding the line between intelligence gathering and collecting evidence for criminal proceedings. For instance, the Act expands the ability of the government to spy by wiretaps and computer surveillance and allows secret searches of homes and offices (P. Thomas, 2002: 96).

Privacy concerns are also heightened because of the multiple registration and surveillance systems that are in use today since they contain highly sensitive and personal data. According to Mathieson Thomas (2000: 203), as these networks are further integrated, factors such as the rapid development of technology make data protection very vulnerable. As a result, most police scholars today have criticized high-tech strategies of policing because of their pervasive powers to erode civil liberties (Deflem, 2002b: 455). Because these challenges can weaken civil liberties in fundamental ways, achieving a balance between policing priorities and safeguarding rights takes on added significance. However, it is important to recognize that many of these rights-related problems stem from how and for what purposes police make use of these technologies. In this sense, new technologies used in policing are not inherently problematic for rights. A look at Interpol and Europol will help contextualize these arguments.

Rights protections, with a special focus on the use of technologies and datagathering practices, have played a defining role in the formation of Interpol and Europol. Mirroring the inclusion of these safeguards has been criticisms about their weaknesses 
and the frailty of accountability measures. These criticisms form the crux of my analysis in Chapter Four so only a short discussion follows here. Beginning with Interpol, its founders concluded that it would be based on principles of universal human rights (Fooner, 1989: 178). In the spirit of these principles, the General Assembly sessions in 1949, 1979 and 1994 discussed rights and set out resolutions, codes of conduct and promoted human rights training in police colleges. Today, Article Two of Interpol's Constitution codifies the protection of human rights: "To ensure and promote the widest possible mutual assistance between all criminal police authorities within the limits of the laws existing in the different countries and in the spirit of the Universal Declaration of Human Rights"" (Interpol, 1996a). Interpol asserts that it is especially concerned with privacy rights and the protection of personal data. Several rules and commissions have been created to control access and exchange of such data (Interpol, 1996b).

Despite these claims, critics have expressed skepticism about Interpol's practices regarding the use of technologies and the handling of highly sensitive data. Sheptycki (2004: 122), for instance, explains that the supervision of Interpol's use and transfer of criminal intelligence is largely performed by its own officials such that its supervisory board is only a superficial mechanism of external accountability. Furthermore, some European states have found that Interpol's data protection measures are lacking and scholars generally recognize that any settlement of these issues requires formal treaty provisions (Sheptycki, 2004: 122).

Concerns for rights protections likewise shaped the negotiation and ratification of the Europol Convention. Since then, issues such as political accountability, the protection of privacy and safeguarding personal data have figured prominently on Europol's agenda. 
It established international management and supervisory boards and formalized the role of the European Parliament to address these concerns (Occhipinti, 2003: 75). With respect to technologies, Europol is legally empowered to maintain a computerized data system but must also follow a strict framework for human rights and data protection, control and security (Europol, 1997). Furthermore, several legal documents outlining rules on analyzing files, confidentiality and the transmission of personal data are found on the organization's website.

Though these rules exist in official documents, critics question whether and to what extent they are upheld in practice. One particularly common criticism is directed at information protection practices: collecting and selling highly personal data, plans to create a more 'potent EU surveillance strategy' and the questionable integrity of data exchange practices (Glendening, 2002). Another weakness is accountability. There are 15 member states involved in Europol, all with their own national sovereignty concerns, making monitoring systems diverse and fragmented (Den Boer, 2002: 278). Chapter Four engages in an in-depth discussion of accountability and transparency issues. These examples highlight just some of the concerns with Europol's rights protection scheme.

Policing technologies, while capable of seriously jeopardizing rights protections, should not be understood as entirely problematic. The problems lie in how policing authorities make use of them, what controls and guidelines are in place and the degree of transparency governing their use. Nunn (2003: 468) suggests that two questions are important to bear in mind: (1) whether the technologies actually 'work' in the sense that they accomplish the exact purpose for which they are designed and (2) whether they are 
used in the proper manner. These questions signal the need for a more critical and cautious position towards technologies used in policing activities.

\section{The Relationship Between Technology and Transnational Crime}

As explained in Section One, one of the reasons for greater international policing cooperation has been the growth of transnational crime. This rationale has garnered substantial support in the literature, among politicians and within the multi-agency policing field itself. Many of these actors have credited this growth to technological advances, often arguing that it is the chief driving force behind international crime. Deflem (2002b: 464), for instance, has asserted that technologies created international crime. These arguments highlight the dual impact of technologies: just as they have aided policing activities, they have also enabled the global spread of crime. Unlike Deflem, I take a less drastic view that technologies have been and continue to be an important catalyst for transnational crime since it is highly plausible that such crime was being committed prior to the invention of many of the technologies identified here. For instance, the close proximity of many European countries made it feasible for criminals to enter foreign countries by foot. Nevertheless, the police feared that criminal elements were capitalizing on technological innovations of the day to further their ends, communicate with one another and expand their territorial reach.

These concerns prompted increased demands for technologies by policing agencies. The primary argument police make is that technologies are needed to combat the technological sophistication of criminals - many police agencies now feel 'outtech'd', not 'outgunned' (Nunn, 2001: 12). This view gained popularity in the $19^{\text {th }}$ century when it was believed that technological developments in communication and 
transportation aided political opponents (recall the earlier discussion on anarchist violence during the second half of this century) (Deflem, 2002b: 459). Among the communications technologies that caused concern were the press, the telegraph, the telephone and the radio since they fostered exchanges among geographically distant peoples and locations (Deflem, 2002b: 464). In terms of transportation, the expansion of railways in the 1800 s and the invention of cars and airplanes in the following century were considered to expand the mobility of criminals beyond the jurisdiction of national police (Deflem, 2002b: 465).

Today, information technologies are seen as vital tools in transnational criminal activity. For instance, Barry Rider (2001: 332) argues that organized crime has made computers its primary vehicle and the internet an attractive alternative for conducting business. The anonymity of the internet and the confidentiality of data make criminal forgery, counterfeiting and telecommunications crimes serious problems for policing (Rider, 2001: 332). The fears and perceptions resulting from these technologically supported crimes served, and continue to serve, as important motivational factors for policing organizations to beef up their store of technologies.

This section has demonstrated that the rapid expansion of technologies since the $19^{\text {th }}$ century has been crucial for transnational policing. Innovations in the areas of communication, transportation, and most recently, information technologies, have been highly impactful. Two organizations that have undergone the process of technologization are Interpol and Europol. Today, they employ a vast corpus of technologies in their daily practices. Having discussed some of the many sources of these technologies, it can be stated that a complex network of providers are essential to policing. Concomitant to 
technologization has been growing criticism about rights implications. Both Interpol and Europol have faced intense scrutiny on these issues. Although technologies present challenges for safeguarding rights, it is necessary to recognize the human aspect of technologies, that is, the purposes for and the way in which they are used by policing authorities. Also examined here was the view that technologies are the chief driving force behind transnational crimes, prompting policing agencies to likewise embrace technologies. My argument was that technologies, while immensely important, cannot be wholly credited with creating these offences. Nevertheless, the popular perception from the $19^{\text {th }}$ century onward has been the opposite, consequently providing a main impetus for technologization within policing. In sum, a myriad of innovations have influenced multi-agency policing and criminal activity, simultaneously raising many rights concerns.

\section{Factors that Facilitate and Impede Multi-Agency Policing}

The foregoing sections have traced the rapid acceleration of multi-agency policing over the past two centuries. However, this has not always been a smooth process. The very nature of transnational policing, as a conglomeration of various regulatory bodies from around the world, predisposes it to numerous obstacles. This final section explores some of these barriers followed by a look at the factors that can break them down.

\section{A. Impediments to Multi-Agency Policing}

One particularly challenging obstacle is the diversity of national legal frameworks. Let us take the variations in law enforcement style as an illustrative example. According to Anthony Balzer (1996), different countries, based on their respective histories and customs, have markedly different ideas about what constitutes 'properly administered' state justice. For example, the U.S.'s common law tradition 
heavily emphasizes individual rights, due process of law, lawyer-intensive adversary proceedings and the use of judicial precedents as a source of law. In contrast, most of Continental Europe follows the civil law tradition that emphasizes the interests of the community/state, informal, neutral, efficient inquisitorial proceedings, legislative superiority in declaring the law and consistency of legal philosophy (Balzer, 1996). These fundamental differences in law can generate confusions, misunderstandings and tensions that even the most cooperatively inclined of officials find difficult to circumvent.

A second impediment is uncertainty about the limits of state sovereignty. A fundamental precept of international law is the prohibition against interference in the internal affairs of other sovereign states by foreign actors (Sheptycki, 2000: 3). As contact between police forces of sovereign states has intensified, it has provoked sensitivities and suspicions precisely because it touches the core of state sovereignty; foreign police intrusions or direct influence on state territory are usually regarded as blatant infringements of sovereignty (Anderson, 1989: 14). This particular issue was raised at the 2005 UN Congress on Crime Prevention and Criminal Justice held in Bangkok, Thailand. According to the delegate from Chile (Mr. Pablo Glasinovic), a strong cultural premium on national sovereignty in his country is a key obstacle to the growth and development of the justice system. Glasinovic commented that this lag served as a barrier to mutual legal assistance and police cooperation both in Chile and the region.

Thirdly, policing technologies that usually serve to enhance multi-agency policing can also present barriers. As Sheptycki (2002b: 120) explains, the 'intelligence cycle' produced by the global transmission of information does not allow for the free flow of information since it is predicated on secrecy. This is attributed to the fact that knowledge 
is considered so sensitive it can only be disseminated on a 'need to know' basis. Another problem posed by technologies is the sheer volume of data that is generated. Additionally, policing organizations can quickly find themselves at the mercy of technologies - a system failure or a security gap within a network can be very detrimental. For these reasons, Sheptycki (2002b: 112) cautions that the process of technologization that drives transnationalization is uneven as are its consequences. Taken together, these impediments indicate that differences within legal systems, organizations and technological infrastructure can inhibit closer cross-national police linkages.

\section{B. Factors that Facilitate Multi-Agency Policing}

There are also several factors that can break down these barriers. One is the convergence of methods of policing in the highly industrialized democracies (Anderson, 1989: 12). Some illustrative examples are the 'Americanization' of European drug enforcement (Nadelmann, 1993: 194), the provision of training facilities and the exchange of information about policing techniques. All of the agencies discussed thus far engage in these activities, which take place on bilateral and multilateral bases at the local, regional and global levels.

Liaison officers also facilitate multi-agency policing. These representatives are posted abroad and play the crucial role of informational gatekeeper between their respective agencies (Bigo, 2000: 74). For instance, the Drug Liaison officer network consists of various police and customs officers from various European countries who are not only posted to other European states, but also to strategically important non-European countries (Santiago, 2000: 23). Another example is the International Operations Branch of the RCMP, which provides support through the liaison officers to Canadian law 
enforcement agencies and also liaises with foreign criminal police agencies and related institutions (Canada, 2003).

A myriad of legal tools that permit information flows have enhanced multiagency police cooperation. Sheptycki (1998: 61) explains that the complexities of criminal law at the international level have prompted the development of key legal instruments: the exchange of Memoranda of Understanding, Extradition Treaties and Mutual Legal Assistance Treaties (MLAT). In North America, MLATs have provided for the routine exchange of crime data and criminal intelligence between multiple police agencies (Sheptycki, 1998: 62). Trevi, the Schengen System and the Maastricht Treaty are the main legal tools for cooperation in Europe (Robertson, 1994: 112). Interpol and Europol also have established relationships with a wide variety of international, intergovernmental and non-governmental organizations. In order to provide a clear legal basis for working together, both organizations have signed a number of cooperation agreements with these partners. Collectively, these various factors that impede and enable multi-agency police cooperation illuminate the complexities of transnational policing.

\section{Conclusion}

From the $19^{\text {th }}$ century onward, the policing landscape has become increasingly pluralized, diversified and fragmented - a set of processes that I have captured by the term multi-agency policing. Two organizations that have been especially affected by these developments are Interpol and Europol. The five main impetuses for this pluralization identified in this chapter are: structural changes to the state, bureaucratic autonomy of the police, the expansion of cross-national crime, creation of 'new' criminal laws and technological innovations. This last motivating factor has been extremely 
important because it enabled surveillance practices and the creation of expansive information systems. Both cross-national policing and transnational criminal activity have benefited from these innovations. In reaction, police have strived to ensure that they are on the cutting edge of new technological advances. At the same time that all of these processes have been occurring, there has been growing concern about their rights implications. The surveillance, data-collection and exchange capacities of new technologies have been especially problematic. Having overviewed some of the main impeding and facilitating factors to multi-agency policing, it can be stated that greater international policing collaboration - a chief goal of transnational policing activities - is a highly complex task. In the next chapter, I undertake a theoretical analysis of some of the issues discussed here by drawing on concepts from the works of Richard Ericson and Kevin Haggerty, Michel Foucault, Gilles Deleuze and Richard Jones. 


\section{Chapter 2: Theoretical Lenses}

\section{Introduction}

The aim of this chapter is to apply key theoretical concepts to analyze the intersection between technology and multi-agency policing and how this relationship affects rights, most notably, the right to privacy. I have selected to focus on privacy because the growth of transnational policing and its reliance on technologies in particular have raised the most concerns about this right. The heart of this unease is located in the surveillance practices enabled by new technologies. The right to privacy and the concept of surveillance, while touched upon in the previous chapter, are examined more closely in Section One. They deserve a more detailed analysis because surveillance is a common theme of the theoretical concepts used in this chapter and it has deep implications for the right to privacy. Because policing activities bear on broader rights encapsulated within civil liberties and human rights, some discussion of these is also included.

Although there is an abundance of theoretical literature on policing, technologies and privacy rights, I have selected four main theorists for this analysis. Section Two continues my evaluation of surveillance by exploring Ericson and Haggerty's idea of the surveillant assemblage. Section Three sketches the contours of Foucault's disciplinary society model of which surveillance is a salient part. This outline is used to set up my discussion of Gilles Deleuze's control society. Section Four analyzes Richard Jones' notion of digital rule, a concept based on Deleuze's control society. I illustrate my discussion in each of these sections by citing examples of current surveillance 
technologies used by policing agencies. Through this theoretical review, I seek to develop an integrated synthesis of transnational policing, technologies and consequences for privacy rights. I argue that intensification of surveillance practices through technologies has given rise to numerous privacy-related concerns. In making these claims, I reiterate my contention that it not always technologies themselves that are cause for concern. Instead, it is their purposes, results and how information is used that is most problematic.

\section{A Look at Surveillance and the Right to Privacy}

As Chapter One demonstrated, the technological infrastructure of transnational policing has experienced tremendous growth since the $19^{\text {th }}$ century, with the most rapid expansion occurring in the latter half of the $20^{\text {th }}$ century. These technologies have strengthened the surveillance capacity of policing agencies and simultaneously enhanced the ability of these actors to gather information on individuals. The computer is the primary apparatus that facilitates the storage, organization and exchange of this data among policing organizations. This section undertakes a closer examination of surveillance by outlining its main features. Mirroring the spread of surveillance has been increasing worries about the protection of privacy. Thus, the second purpose of this section is to sketch the origins, development and present-day meanings of the right to privacy and to offer a working definition of this right. The implications for privacy rights as a result of surveillance practices by policing agencies are also explored in this section.

\section{A. Making Theoretical Sense of Surveillance}

Theorizing on surveillance has yielded abundant literature as well as considerable disagreement on what the term actually means. Nevertheless, many scholars recognize its significance in both modernity and the western world. As Haggerty and Ericson (2000: 
606) remark, surveillance has become a salient topic for theoretical reflection and this interest coincides with the quantitative increase in surveillance in western societies. These authors view surveillance as one of the main institutional components of late modernity. Lyon and Zureik (1996: 3) trace surveillance back much further, commenting that it is as old as social relationships themselves, but it has acquired new and distinctive meanings in the modern era. The theorist who has written some of the most influential work on surveillance is Michel Foucault. An overview of his concept of the Panopticon, as a metaphor for understanding contemporary surveillance, is a useful starting point for this analysis.

Foucault situated surveillance in a distinctive theory of power, with the Panopticon being his major focus. Initially a prison design proposed by Jeremy Bentham, the Panopticon was unique because of its architectural design. The layout was created to maximize the visibility of inmates who were to be isolated in individual cells such that they were unaware of when exactly they were being observed, but always knew that they may be. More than a simple device for observation, the Panopticon sought to transform the prisoner's relation to him or her self. This was done through disciplinary means involving 'soul training', a process in which inmates were encouraged to reflect upon their behaviour in an effort to transform their selves (Ericson \& Haggerty, 2000: 607). Although the Panopticon is based on the Benthamite prison, Foucault (1977b: 205) informs us that it must not be understood as a 'dream building', but rather as a diagram for understanding power relations. The model of power proposed by the Panopticon extended beyond the prison to take hold in other disciplinary institutions characteristic of the era such as the factory, hospital, military and school (Ericson \& Haggerty, 2000: 
607). The meaning of discipline within the Panoptic structure is elaborated later in this chapter. In the years since Foucault theorized on the Panopticon, it has come to assume a dominant place in the literature on surveillance, which has itself grown extensively as a result of Foucault's work.

The breadth of this literature makes defining surveillance a complex task. However, I have selected to concentrate on those offered by Anthony Giddens and David Lyon because they are the most relevant. Giddens outlines that surveillance refers to two connected phenomena. The first is the accumulation of 'information' - symbolic materials that can be stored by a collectivity. The accrual of information is pivotal to transnational policing because it forms the essence of policing work - it feeds databases, is exchanged for crime control purposes and connects policing agencies. The notion of police as 'knowledge workers' and the term 'intelligence-led policing' both take information as a fundamental feature of modern policing. In this sense, information is both symbolic because it links distant policing organizations, and of practical value because of its significance to crime control activities.

The second phenomena is the supervision of the activities of subordinates by their superiors within a collectivity (Giddens, 1981: 169). Within transnational policing, this form of surveillance over populations is essential because of the information it yields. This data, once compiled in electronic or other forms, is then available to policing agencies. Giddens (1981: 169) summarizes that these two phenomena are closely related in principle as well as frequently in practice by virtue of the fact that the collection, synthesis and analysis of information about the public can either be an aid to, or constitute a direct mode of, surveillance over their activities. Lyon's (2001: 2) definition 
of surveillance encompasses the two components that Giddens identifies: "it is any collection and processing of personal data, whether identifiable or not, for the purposes of influencing or managing those whose data have been garnered". The main difference is that Lyon's understanding refers to personal data and its capacity to regulate the individuals from whom this information is gathered. In view of this, the protection of such data through the law, particularly those provisions governing privacy, becomes increasingly important.

However, the collection of information and surveillance over populations does not alone raise concerns for privacy rights. It is the advent of new technologies that enhance surveillance and augment the ability to gather, organize and exchange data that has generated the bulk of these problems. In order to demonstrate these interconnections, it is useful to provide some background on how privacy became a right, why it is so contentious today, what it means in the context of multi-agency policing and a practical example to contextualize these problems.

\section{B. The Right to Privacy}

Historically, the right to privacy in the United States first appeared in the seminal 1890 article by Samuel Warren and Louis Brandeis. They used the term in proposing a new tort, the invasion of privacy, in their complaint about how the press was printing lurid accounts of the social activities of the Warrens, a prominent Boston family (O'Connor, 2004). The aim of this tort was to protect the privacy of the individual from invasion by the press, the photographer, or the possessor of any other modern device for recording or reproducing scenes or sounds in action (Warren \& Brandeis, 1890: 206, 211). It follows then, that new developments in communication technology made it 
important to separately recognize the need for protection as the right to privacy. Warren and Brandeis (1890) distinguished privacy from slander, libel or defamation on grounds that invasion of privacy was a deeper harm, one that caused mental distress, injury to feelings and violations of emotions. In making this distinction, these men made the astonishing claim (for 1890) that privacy was a personal, not a property, right (O'Connor, 2004).

Seventy years later, another crucial work on the right to privacy was authored by William Prosser. In this article, Prosser attempted to more clearly define the new right of privacy based on the legal developments since Warren and Brandeis' piece was written. Prosser believed that four distinct privacy rights materialized during this time: intrusion upon a person's seclusion or solitude, or private affairs; public disclosure of embarrassing private facts; publicity placing one in a false light in the public eye and; appropriation of one's likeness for the advantage of another (1960: 389). Prosser felt that both real abuses and general public demand necessitated this four-part schema. To strengthen this position, the courts had ruled that privacy was a central reason for Fourth Amendment (this protects against unreasonable searches and seizures) protection.

In the years between and after these articles were penned, there has been an explosion of debate and literature on the right to privacy. For instance, during the same time that Prosser was writing, another set of events in the US thrust the right to privacy further into the limelight. As Calvin Gotlieb (1996: 157) describes, fears about government misuse of demographic and other social science data coupled with new evidence on how companies gathered and used data for reporting on consumer 
creditworthiness caused intense debates. These culminated in the passage of the 1974 Privacy Act, which regulated the use of federal government data banks.

In the course of these debates, the definition of privacy has been highly contested. Cultural, social and legal differences between countries as well as varied conceptions, by individuals, governments and institutions, of what privacy means have affected this lack of consensus. Some scholars such as Gotlieb (1996: 156) have even argued that privacy no longer exists because the trade-offs where privacy has been sacrificed are now so common; privacy is a concept whose time has 'come and gone'. I argue on the contrary that privacy has taken on increasing social value in tandem with the expansion of surveillance practices by governments, private industry and of course, policing.

Take the example of airline ticket purchases. Even in the process of surrendering personal information to airlines, most people expect a high degree of confidentiality in how this data is used and for what purposes. Lisa Austin (2001: 252) sheds light on this dynamic, stating that the concern is with a 'new' type of surveillance that depends on collecting, storing, aggregating, sharing and linking vast amounts of information about people and then using this information for screening purposes. She elaborates that this kind of surveillance potentially intrudes on the privacy of individuals and involves cooperation with the private sector (Austin, 2001: 252). Perhaps the best expression of the importance of privacy is the emergence of new non-governmental organizations concerned with the privacy implications of new technologies. Privacy International, Statewatch and the Electronic Privacy Information Centre (EPIC) were all created in the 1990 s in response to growing concerns about data misuse and electronic modes of 
invading privacy. The technological invention that is at the heart of these concerns is the computer, particularly, its integration into and uses within policing.

The computer has caused the most controversy for privacy rights in recent decades, although it is often not thought of as such because of its ubiquitous presence in society. As Bennett (1996: 237) remarks, we tend not to think of computers as surveillance tools, yet in all advanced states, the capacity of computer technology has facilitated a variety of practices for the analysis of personal data. These, he elucidates, may have exactly the same impact on the individual as more physical and direct surveillance measures. David Lyon (2001: 2) concurs, adding that the most important means of surveillance reside in computer power, which allows collected data to be stored, processed and circulated. Even if the data go beyond mere numbers to DNA codes, the technologies that enable surveillance to occur involve computer power (Lyon, 2001: 2). In terms of rights concerns, the computer is problematic for two reasons: it possesses 'memory' and it can 'talk' with other computers (Lyon, 1994: 46). These abilities have facilitated 'dataveillance', a term described earlier as the surveillance practices aided by the massive collection and storage of personal data (Bennett, 1996: 237).

One example that illustrates these awesome surveillance capacities of the computer, and the attendant privacy concerns it has produced, is the creation of DNA databanks. In a recent review of the growth of these databases in the United States, Rosemary Walsh (2006) traces their beginning from the early 1990s when the FBI began to compile a national DNA database. This culminated in the creation of the National DNA Index System (NDIS), a databank that contains samples from convicted offenders, crime scenes and crime victims. To enable states to effectively store and exchange DNA 
profiles electronically and search the NDIS database, the FBI developed a software program called the Combined DNA Index System (CODIS). The creation of this databank resonates with Haggerty and Ericson's (1999: 241) assertion that the proliferation of databases is rapidly transforming the police system into a host of policing systems interconnected to computer networks. The computer is therefore the crucial technical device for connecting disjointed databases and by extension, policing organizations themselves.

Alongside this expansion is concern about their rights implications. As Walsh (2006) describes, thirteen states allow for the DNA profiles in the database to be used for 'other humanitarian purposes'. While this would include circumstances such as the identification in the instance of a major disaster, the broad nature of the provisions infers it is by no means limited to these rare situations. Another problem is posed by the indefinite retention of genetic samples. Although the FBI has not reported any abuse of this data, Walsh (2006) suggests that this increases the risk of uninformed use of stored samples. Whether or not Walsh's suspicions of data misuse are correct remains to be seen. The point to recognize, however, is that the growth of databases containing sensitive information such as DNA is driven by computer technologies that are regulated differently from state to state, leading to variances in the way such data is handled.

In summary, the evolution of the right to privacy is connected with the spread of technologies in daily life. From the intrusions that frustrated the Warren family to the tremendous accrual of personal data in modern DNA databases, technologies that enable surveillance have problematized privacy to the extent that it has become a legally recognized right. While some scholars have disputed the social value or existence of this 
right, I have argued to the contrary that privacy remains both a treasured feature of daily life and an important legal provision. This is especially so in the present technological age, as demonstrated by the data-gathering and storage capacities of computers. Since multi-agency policing activities have been empowered by these same computer technologies, the right to privacy has contemporary significance. The next section continues my analysis of surveillance by turning to Ericson and Haggerty's concept of the surveillant assemblage.

\section{The Surveillant Assemblage}

Surveillance, as I have discussed it thus far, has bearing on both the right to privacy and multi-agency policing. Having discussed the nexus between surveillance and privacy rights, I turn here to discuss the linkages between surveillance and multi-agency policing. The theoretical tool that is most useful for this purpose is the "surveillant assemblage'. By drawing on the work of Gilles Deleuze and Felix Guattari, Ericson and Haggerty (2000: 606) suggest that we are witnessing a convergence of what were once discrete surveillance systems, enabling us to speak of an emerging surveillant assemblage. The assemblage operates by abstracting human bodies from their territorial settings and separating them into a series of discrete flows. These flows are then reassembled into distinct 'data doubles' which can be scrutinized and targeted for intervention. Groups previously exempt from routine surveillance are increasingly being monitored because of the surveillant assemblage (Ericson \& Haggerty, 2000: 606). Four elements of this model are relevant here: its unstable nature, its tendency to integrate practices and technologies, the construction of data doubles and its rhizomatic form. The privacy implications of these components are incorporated into this discussion as well. 


\section{A. The Surveillant Assemblage: Four Key Components}

Ericson and Haggerty (2000: 609) caution that when they speak of the surveillant assemblage, they risk fostering the impression that it is a stable entity with its own fixed boundaries. In contrast, the surveillant assemblage exists as a potentiality, one that resides at the intersections of various media that can be connected for diverse purposes. It is an emergent phenomenon, unstable and lacking discernible boundaries (Ericson \& Haggerty, 2000: 609). These features of the surveillant assemblage can be likened to the contemporary policing field because it too, is evolving, undefined and without clear borders. These similarities make the surveillant assemblage a highly useful theoretical tool for analyzing multi-agency policing.

Secondly, the surveillant assemblage is driven by the desire to bring systems together, to combine practices and technologies and integrate them in to a larger whole. It is this tendency that provides for exponential increases in the degree of surveillance capacity. This process is precisely what is taking place within interagency policing as well because of the convergence of technologies, information systems and policing techniques. Indeed, Ericson and Haggerty (2000: 611) state that the coalescence of discrete surveillance systems has lead to the institutionalization of "various forms of 'multi-agency' approaches to policing". One illustrative example can be recalled from the foregoing discussion of DNA databases, which as I have described, are being brought together through computers and unifying systems such as CODIS. For Philipikoski (1998), this exemplifies the fact that police are continually looking for ways to integrate their different computer systems and databases. 
In addition to convergence among electronic systems, integration is also taking place at the practical level of police organization. Europol is demonstrative of this because it is no longer limited to working with EU member states even though its crime control activities are directed toward the protection of these countries. It has signed agreements with states such as Turkey and Columbia, EU bodies such Eurojust and the European Commission and with international organizations such as the UN Office of Drugs and Crime and Interpol ${ }^{4}$. Not only are these relationships bringing diverse actors together, they are also facilitating the convergence of surveillance systems. As with the case of DNA databanks, the amalgamation of data systems can problematize the protection of sensitive information and by extension, privacy rights.

Thirdly, the human body is the object of a great deal of surveillance. The observed body is broken down by being abstracted from its territorial setting and is then reassembled in different settings through a series of data flows (Ericson \& Haggerty, 2000: 611). Various 'centres of calculation' such as financial institutions and police stations perform this process of abstraction and reassembly. The information is then scrutinized in hopes of developing strategies of governance, commerce and control. The monitored body is a new type of body that transcends human corporeality and reduces flesh to pure information. As such, the body is increasingly a cyborg; a flesh-technologyinformation amalgam that can be conceived of as a 'data double' (Ericson \& Haggerty, 2000: 613). The surveillant assemblage therefore works to produce a new type of individual, one comprised of pure information.

\footnotetext{
${ }^{4}$ These are just some of the operational and strategic agreements Europol has signed. More information can be found at http://www.europol.eu.int/index.asp?page=agreements.
} 
The body is important to policing activities in numerous ways. The most relevant of these for my analysis is the body as a source of information, transformed and manipulated into a 'data double'. Crucial to this process are technological tools that enable the breakdown, reassembly and digitization of data derived from the human body. One example that highlights these developments is the 'Sentor', a device currently used by US drug enforcement and border control agents. Richard Julie describes how this apparatus works:

The Sentor relies on scientific principles...to analyze samples taken from the bodies of suspected drug smugglers. The device is pointed at the suspect and vacuums in large quantities of air from the area surrounding his or her body. It is then inserted into a larger machine, which heats the samples and through high-speed gas chromatography, separates the chemical compounds contained therein, including those found in cocaine, heroin and other narcotics (Julie, 2000: 137).

The data, once gathered from the body, creates what is essentially a data double of the suspected smuggler. Because this is crime-related information, it is most likely stored in a police database. Transnational policing organizations such as Interpol and Europol make significant use of the digitized body, the 'data double'. They also rely on member states to share this type of information in order to facilitate informational exchange activities. In this sense, partner organizations, member states and Interpol and Europol themselves are 'centres of calculation'.

Accompanying the rise in data doubles are privacy considerations regarding their use and functions. The Sentor, for instance, is frequently used without a warrant - no court has ruled on whether its use violates the Fourth Amendment's 'reasonable expectation of privacy' standard (Julie, 2000: 138). Additionally problematic is the type of data the Sentor can expose. Julie (2000: 138) explains that a Sentor scan can reveal 
fragmentary particles of prescription drugs used to treat someone with HIV, possibly leading to the conclusion that the suspect is HIV-positive. As the secrecy of one's HIV status is protected by statute in many states, such information gleaned through a data double bears heavily on privacy issues. Aside from this specific case, there are more general privacy-related dangers associated with data doubles. For instance, Ericson and Haggerty (2000: 613) contend that there is a growing trade in the sale of this information, with governments especially keen on selling their data. This movement of data doubles between agencies heightens concerns about the protection of such sensitive information.

The fourth defining feature of the surveillant assemblage is rhizomatic surveillance. Rhizomes are plants that grow across a series of interconnected roots which throw up shoots at different locations. A rhizome may be broken, shattered at a given spot, but it will start up again on one of its old lines, or on new lines (Deleuze \& Guattari, 1987). Ericson and Haggerty (2000: 614) state that surveillance has comparable expansive and regenerative qualities and provide the proliferation of CCTV surveillance cameras in Britain as an instructive example. The study by Norris and Armstrong (1999) of British CCTV demonstrates how this apparently unitary technology is in fact an assemblage that aligns computers, cameras, people and telecommunications in order to survey public streets (Ericson \& Haggerty, 2000: 614).

The metaphor of the rhizome and the concept of rhizomatic surveillance are both features of multi-agency policing. Rhizomatic patterns of growth, death and re-growth are characteristic of transnational policing patterns, which I earlier characterized as pluralized, fragmented, flexible (readily established as they are dismantled) and diverse. With respect to rhizomatic surveillance, a similar process takes place within the cross- 
national policing field. Although this network aims to facilitate closer exchanges among diverse policing agencies, it is not set back by the withdrawal of these actors because they will reappear in the network at another point.

The collective effect of these four elements of the surveillant assemblage is what Ericson and Haggerty (2000: 619) call the 'disappearance of disappearance' - a process whereby it is increasingly difficult for individuals to maintain their anonymity, or to escape the monitoring of social institutions. Efforts to evade the gaze of these systems involves an attendant trade-off in social rights and benefits. With the rapid expansion of surveillance practices and technologies in the social field and especially within policing, the disappearance of disappearance is likely to become a real outcome.

\section{Foucault and Deleuze: From Disciplinary Society to Control Society}

Michel Foucault's theoretical work on the disciplinary society has had a powerful impact on scholarly work on policing. Gilles Deleuze, a close friend of Foucault's, is another theorist who has made important contributions to this literature. Deleuze believed that the disciplinary model was essentially correct but that it needed updating in order to account for new technological innovations. In this sense, Deleuze's model of the control society provides a more current framework for analyzing transnational policing and its technological infrastructure. Although Deleuze does not provide much commentary on surveillance within the control society, it is arguable that it is a key feature that acts alongside control. This section begins by sketching the contours of Foucault's disciplinary society followed by discussion of the control society and its relationship to multi-agency policing. 


\section{A. The Passage from Disciplinary to Control Societies}

The control society model was first proposed by Gilles Deleuze as a theoretical adjunct to and modification of Foucault's disciplinary society thesis. Deleuze based his ideas on the observation that during the postwar era, power had undergone important transformations, including contemporary developments in surveillance technology. Written as it was before the widespread availability and use of these technologies, Deleuze believed that although valuable, Foucault's disciplinary diagram needed updating (R. Jones, 2000: 9). The model he saw emerging to account for these postwar changes was the control society. Deleuze (1995: 174) indicates, however, that Foucault was actually one of the first to say that we are moving away from disciplinary societies, that we have left them behind.

For Deleuze, discrete institutions, bounded space and rigid categories characterized the disciplinary diagram. He observed that the principal technology of the disciplinary society was confinement within institutions such as hospitals, prisons, schools, factories and barracks. With the end of the Second World War, Deleuze (1995: $178 ; 182)$ observed a breakdown of discipline within these sites and the widespread progressive introduction of a new system of domination: "we were no longer in disciplinary societies, we were leaving them behind," he remarked. In place of the disciplinary society came the control society - a transition that even Foucault observed was "fast approaching" (Deleuze, 1995: 178).

Before detailing the key differences between the disciplinary and control models, it is useful to set out what Foucault meant by 'discipline'. In Discipline and Punish, Foucault situates his ideas in a distinctive theory of power of which discipline is an 
important component: "Discipline," he says "may be identified neither with an institution nor with an apparatus; it is a type of power, a modality for its exercise, comprising a whole set of instruments, techniques, procedures, levels of applications, targets; it is an 'anatomy' of power, a technology" (Foucault, 1977a: 215). The Panoptic structure was important to the exercise of this power because it was supposed to make this process "lighter, more rapid, more effective". Discipline was also conceptualized as spread throughout the social body, giving way to 'generalized surveillance' and an overall disciplinary society. Crucial to this process were a host of disciplinary institutions for which discipline was the essential instrument. These included 'specialized' institutions such as prisons, institutions that use discipline as a tool for a particular end (schools, hospitals), pre-existing authorities that find discipline as a means of reinforcing internal mechanisms of power (families) and state apparatuses whose major, if not exclusive, function is to assure that discipline reigns over society as a whole (the police) (Foucault, 2003: 209). It was this collectivity of institutions that facilitated the spread of discipline throughout the social field.

According to Deleuze's understanding of Foucault's model, the control society differed in many important ways. One of these is the relationship between individuals and institutions. Unlike in the disciplinary society where you were always starting all over again, by going from school to barracks to factory, 'one is never finished with anything' in control societies (Deleuze, 1995: 179). In this sense, confinements are molds while controls are a constant modulation; things are continuously changing (Deleuze, 1995: 178). Control, as Deleuze (1995: 181) conceptualized it, is continuous, immanent, 'designed in' to society and unbounded, whereas discipline was long-term, infinite, 
discontinous, localized and individualizing. That is, instead of disciplinary power fixed inside special institutions, control is embedded in an array of regulatory practices. Within the control society, then, one is always in continuous training, life-long learning and assessment (Rose, 2000: 325). Some examples are the rise of outpatient therapy, work-athome schemes, continuing education and house arrest (Bratich, 2006: 69).

The notion of surveillance can be paralleled to control because it too is embedded into the social field and interlaced with the practices of regulatory agencies. As Lyon (2001: 89) explains, developments that took place in the latter half of the $20^{\text {th }}$ century, including capitalist restructuring and new relationships between the economy, state and society, caused surveillance to 'go global'. These changes opened the door to further interchange, not just between different sectors, but also between different countries and international agencies. Surveillance data quickened its international flow, as did technology, information, people, images and symbols (Lyon, 2001: 89). More similarities between surveillance and control are explored here.

Another difference between the disciplinary and control societies is the way in which we understand others and ourselves. No longer are we dealing with a duality of mass and individual, a prominent aspect of disciplinary society. Instead, we are encouraged to see ourselves differently and encourage organizations to do the same ( $R$. Jones, 2000: 10). The key thing is no longer a signature or number but a code: codes are passwords. The digital language of control is made up of codes indicating whether access should be allowed or denied. Individuals become 'dividuals' and masses become samples, data, markets or 'banks'(Deleuze, 1995: 180). The dividual, as Deleuze meant it, is a further breakdown of the individual made possible by the digital language. 
An example is the electronic card, particularly those used to open barriers and gain access (Deleuze, 1995: 182). These cards contain data on individuals but are connected to a larger databank. Here, then, is the link between the dividual and the turning of masses into banks: the multiplicity of dividuals, after being converted into their digital form as 'samples' or bits of data, are entered into databases. The electronic card, encoded with specific information on the dividual, represents a portion of this information. As Rose (2000: 325) summarizes, the control society is concerned with identifying subjects not by their distinct personality, but by unique codes, identification numbers, profiles of preference and so on; a 'record' containing a variety of bits of data on our credentials, activities and qualifications for entry into a network.

The example of the electronic card highlights the importance of surveillance to the control society because it fits within its definitional parameters. In Section One, I stated that the accumulation of information or data is one defining feature of surveillance. Likewise, a major aspect of the control society is the accrual of data through the breakdown of the individual into the dividual. The second component of surveillance is the collection of this data for the purposes of influencing or managing those whose data have been gathered. The electronic card, for instance, is used in a similar sense because it regulates and manages the movements - entry and exit - of those whose information has been stored into a databank. From these comparisons, it is arguable that surveillance is interwoven with the control society diagram.

The digital and technological dimensions of the control society described here deserve further commentary. These societies function with a 'third generation of machines', the most important of which are information technologies and the computer. 
The computer, in particular, is responsible for determining access or egress, "for making sure everyone is in a permissible place" (Deleuze, 1995: 182). Because of these broad entry and exit-granting capabilities, the computer and related technologies can be seen as the primary tools supporting control societies. In addition to advancing control, these technologies are also important because of their surveillance capabilities. As Lyon (2001: 89) comments, computer-enhanced surveillance has created fine-meshed net to keep track of global flows of data, people and symbols. Facilitating these capacities is the digital language that allows computers to 'talk' with one another. Jones (2000: 9) argues further that this language is not only a distinctive element of the control society, but it is also used to unify the social system. From this overview, it can be stated that the mode of articulation of control is what distinguishes the disciplinary and control societies - the former works through disciplining the individual within sites of confinement while the latter seeks to control continuously through a variety of means spread across the social field and aided by technologies. Surveillance is a key feature of these means and technologies, an assertion that I will illustrate below with specific examples.

\section{B. The Relationship Between Control Societies and Multi-Agency Policing}

These features of the control society are related to multi-agency policing. Let us explore some of these linkages here. The first is the nature of control as continuous, immanent and embedded in society. I add here that surveillance is likewise integrated with control societies. Within the field of transnational policing, continuous control and surveillance are achieved by the concurrent performance of policing functions by a diversity of regulatory agencies. Since these actors are so wide-ranging in form, type and objectives, control is not only continuous, but also multifaceted and dispersed across the 
social field. Through this dispersal, both control and surveillance are an inherent part of the social fabric.

Take Europol's network of liaison officers as an example. In addition to collecting and transmitting information between Europol and their host state, these officers also work on special projects with international specialists (Santiago, 2000: 49). In this instance, various policing actors are the mode(s) through which control and surveillance is articulated. Another illustrative example is closed-circuit television camera (CCTV) systems. For instance, 'Cromatica', a subway security system first tested in London Underground train stations connected CCTV cameras with an 'intelligent' computer system that alerts watchers (policing actors) to cases of deviant behaviour (Lyon, 2001: 60). Here, control is expressed through an integrated technological system that is intertwined with and dispersed across time and space. Surveillance is also a central objective of CCTV systems - their deployment in public spaces is intended to "watch over' the population. The purpose of a system such as Cromatica is to control flows of bodies and information rather than carrying through disciplinary intervention against individuals. These observations resonate with Rose's (2000: 325) contention that surveillance is 'designed in' to the flows of everyday existence. These examples point to the continuous and dispersed nature of control and the attendant concept of surveillance in the contemporary policing landscape.

A second salient feature is the technological capacity of control societies and the different understanding of people they enable. Through a digital language, individuals are deconstructed into 'dividuals'. This data is then rearranged and converted into electronic information stored in databanks. Actors in the multi-agency policing field depend 
crucially on these twin processes for crime fighting purposes. Interpol, for instance, has pushed for the creation of a global DNA database since Resolution No. 8 of the $67^{\text {th }}$ General Assembly in 1998 in Cairo ${ }^{5}$. This resulted in the Interpol DNA unit that was set up to collate DNA profiles provided by member states and make these available to investigators globally. In 2002, Interpol introduced its I-24/7 system to give police officers the ability to search different databases by using a single gateway. This range of databases includes the DNA profile database and fingerprint database. The genetic information contained in the I-24/7 system exemplifies features of the control society detailed here: it is run by a digital language that disassembles the individual into the dividual (in this case, the molecular dividual found in DNA evidence) and then records this sample into a database. This build up of DNA profiles also permits and enhances the surveillance of these individuals.

Thirdly, the exclusionary capacity of control societies is found within MAP. The I-24/7 system is again a useful example because it only allows access to member states and authorized policing institutions. Another case in point is Europol's electronic data network, The Europol Computer System (TECS), because it only allows input, access and analysis of data by member states ${ }^{6}$. Just as the computer is the chief technological device of the control society, it is also the primary tool that facilitates the exchange of data found in I-24/7 and TECS. More importantly, the computer is responsible for regulating entry to these databases. In Deleuze's words, it is charged with "making sure

\footnotetext{
${ }^{5}$ Privacy International, "UK leads the way in development of a Global DNA Database".2006. Date accessed: July 2, 2006. http://www.privacyinternational.org/article.shtml?cmd\%5B347\%5D=x-347-508149 ${ }^{6}$ Europol. "Fact Sheet on Europol." 2005. Date accessed:4 Jan. 2006.

$<$ www.europol.eu.int/index.asp?page=facts $>$.
} 
everyone is in a permissible place." This capacity also points to the surveillance features of the computer that assist in making these determinations of access.

In sum, the disciplinary and control society models provide different understandings of how regulatory practices (or modes of articulating discipline/control) play out in the social field. Those detailed by the control diagram are most relevant to transnational policing practices, therefore making it a more fitting construct for this analysis. It is important, however to recognize that the disciplinary society is the theoretical basis from which the control society was developed. By comparing surveillance, as it has been discussed and defined in this chapter, to control, it is arguable that surveillance is a parallel and essential concept to the control model. The next section turns to Richard Jones' digital rule construct, an idea that is based on the control society model. For this reason, surveillance is a salient feature of digital rule. In exploring this theory, I discuss the privacy implications of digital rule with reference to specific examples. Given the similarities between Jones and Deleuze's ideas, these privacy problems can be linked to the control society as well.

\section{Digital Rule: A Mode of Exclusion, Control and Surveillance}

The concept of digital rule is developed by Richard Jones, who comments that it is an idea that 'usefully broadens' Deleuze's thoughts on the control society. As such, many of Jones' ideas are very similar to those of Deleuze. The aspects of digital rule that are salient here are digital decision-making, access and exclusion. Just as surveillance is a part of control societies, it is also an important component of digital rule. I evaluate these features with reference to two examples of digital rule in action: electronic access cards 
and Facial Recognition Systems (FRS). The privacy implications of digital rule as they pertain to these examples are also explored.

\section{A. Digital Decision-Making: Access and Exclusion}

Digital rule is a new form of at-a-distance monitoring that becomes possible with the advent of certain electronic technology. This form of monitoring enables decisionmaking based on electronically produced information that a rule has either been followed or violated. This is an algorithmically-based process that involves the removal of certain system 'access privileges' (R. Jones, 2000: 11). These elements of digital rule can be paralleled to the control society because both concepts are underpinned by a digital language that is used to determine or deny access. Jones (2000: 14) comments that different types of electronic access systems can be seen as conceptually similar approaches to the governing of access to places, whether these be real or 'virtual'. Built into these ideas of monitoring and electronic access is surveillance. Two illustrative examples are electronic access cards and Facial Recognition Systems.

Electronic access cards are widespread in today's technological age. They are used to access a host of places and networks including residential complexes, workplaces and bank accounts. Although some of these require the entry of a private numerical code, others simply require a swipe through a card reader. At the same time, networks are being developed to integrate these multiple functions of the electronic access card into a single entry/exit system. For instance, the 'Mondex' scheme presently in use in six British universities acts as a combined matriculation card, library card, door 'swipe' card and electronic purse (R. Jones, 2000: 15). Independent and integrated card access systems fit within the digital rule framework because they govern access to places, both real and 
'virtual', based on electronically stored information. With the entry of a code or a swipe, both of which serve as passwords, an electronically-based decision is made to either allow or deny access. Surveillance of activities, movements and transactions is a key component of these electronic pass cards.

A second example of digital rule is found in Facial Recognition Systems (FRS). These systems are biometric tools used for crime control, entry/access and surveillance purposes. Among the numerous companies developing FRS technology, one that is particularly well known for its 'Facelt' program is Visionics. This software, once built into a computer and connected to video cameras, can pick a face out of a crowd, extract it from the rest of the scene and compare it to a database of stored images ${ }^{7}$. FRS technologies have been used as surveillance tools for crime control purposes, most notably at large events and in public spaces. For instance, the Tampa Police used FaceIt at Super Bowl XXXV in January 2000 to search for potential criminals and terrorists at the event. The London borough of Newham in the UK has also built FRS technology into their CCTV network. Additionally, this software has been used by casinos to catch card counters and other blacklisted individuals ${ }^{8}$. In short, FRS technology is a form of digital rule because of the process it follows to determine access: a facial image is scanned through 'at-a-distance' means, matched against a database of other images and a report is produced determining whether an individual should be able to enter a venue or not. Surveillance practices over particular groups are important to this process.

Both electronic access cards and FRS software are mechanisms of digital rule and surveillance that fit within the control society framework. Their exclusionary capacity is

\footnotetext{
${ }^{7}$ http://computer.howstuffworks.com/facial-recognition.htm

${ }^{8}$ Details and examples taken from: http://en.wikipedia.org/wiki/Facial_recognition system
} 
one reason for this. In addition, they depend on data from the deconstructed individual the 'dividual' - to be converted into electronic form and entered into a databank. FRS, for example, requires an extensive database of faces and associated identities, hardware with a large storage capacity and software to perform data searches and suggest potential matches (Nunn, 2001: 16). Once a card is swiped, a PIN is entered or a face is scanned (each of these are variations of passwords), the evidence is compared to the data stored in a database. Based on this electronic matching, access is determined. Furthermore, the computer is the primary technology in both of these cases because they store, process and produce reports detailing who should and should not be allowed entry. Likewise, the code and the computer are key elements of the control society. In sum, both of these technologies represent digital rule 'in action', correspond with the features of control societies and make possible surveillance practices important to both of these constructs.

\section{B. Digital Rule and the Right to Privacy}

Alongside their increasing use in daily life, electronic access cards and FRS software present a host of privacy-related concerns. Those brought about by Facial Recognition Systems are explored here. This software has generated opposition from citizens on the grounds that it is highly invasive. For instance, shortly after the Tampa Bay police installed cameras equipped with FRS technology in the city's nightlife district, it produced widespread resistance by citizens, ultimately prompting the removal of the cameras ${ }^{9}$. In this instance, unwanted and intrusive surveillance of public activities was a key reason for this opposition.

\footnotetext{
${ }^{9}$ Lisa Bowman. "Tampa drops face-recognition system." 21 August 2003. Date Accessed: July 2, 2006 $<\mathrm{ttp} / /$ news.com.com/Tampa+drops+face-recognition+system/2100-1029_3-5066795.html>
} 
Policing authorities also cited problems with FRS software, primarily because it was found to be an ineffective crime-fighting tool, a consequence that has implications for privacy rights. Captain Bob Guidara, a spokesman for the Tampa Police Department commented that, "We never identified, were alerted to, or caught any criminal. It didn't work". This may be due to the high rate of 'false positives' (wrongly matching innocent people with photos in the database) and 'false negatives' (not catching people even when their photo is in the database) that FRS software yields. Unlike our fingerprints or irises, our faces do not stay the same over time. FRS systems are easily tripped up by changes in hairstyle, facial hair, or body weight, by simple disguises and by the effects of aging ${ }^{10}$. A study by the US government's National Institute of Standards and Technology (NIST), for example, found false-negative rates for face-recognition verification of 43 percent using photos of subjects taken just 18 months earlier. According to the American Civil Liberties Union, the Tampa trials failed to identify a single suspect from the database and had many false alarms.

In the wake of the September 11, 2001 attacks, FRS technologies have increasingly found their way into border security measures. For instance, the United States Visitor and Immigrant Status Indicator Technology (US-VISIT) program requires visitors of the US to provide fingerprints and a digital photograph at their port of entry. US-VISIT then interfaces with the IDENT database to check and see if the visitor is a "person of interest" ". In a recent audit report of US-VISIT, the US Government Accountability Office pointed out some of the privacy-related faults of the system. They

\footnotetext{
${ }^{10}$ From the American Civil Liberties Union website at: http://www.aclu.org/privacy/spying/14875res20030902.html

11 Information on these and other uses of facial recognition technology and their privacy implications are found at: http:/www.epic.org/privacy/facerecognition.
} 
stated that although the system underwent a 'privacy impact assessment', it did not satisfy all aspects of the Office of Management and Budget (OMB) guidance for such an assessment (GAO, 2005: 2). This included the failure to fully address privacy issues in relevant system documentation. Another problem was with access to the IDENT database. The report asserted that this system is to be limited to authorized users only, a consideration that was not found in its access requirements (GAO, 2005: 4).

Collectively, these flaws in FRS technology raise some worrying questions about digital rule mechanisms, their surveillance capabilities and privacy rights within multiagency policing: what is the purpose of new techniques of digital rule? What do their surveillance practices seek out and reveal? And perhaps most importantly, how will the information be used? As the FRS example demonstrates, the technical apparatuses that facilitate digital rule are being applied for broad surveillance purposes to gather intimate data. This information is in turn being used to make powerful decisions about the movements (entry/access) of people.

\section{Conclusion}

The theoretical concepts discussed in this chapter have broadened and enhanced our understanding of the nexus between multi-agency policing and technology and its implications for privacy rights. At the heart of privacy matters is the broadening scope of surveillance made possible by new policing technologies. The most problematic aspect of these surveillance tools is the danger they pose to the protection of sensitive personal data. This was illustrated by the discussion of DNA databanks and FRS software. Surveillance was also a common theme uniting the theoretical tools employed here. Haggerty and Ericson's concept of the surveillant assemblage captured what they 
observed to be the convergence of disparate surveillance systems. Section Three took Deleuze's control society model, an updated version of Foucault's disciplinary society diagram, as the main focus. Surveillance practices, although varied in nature, object and type, underpinned both models. Importantly, surveillance is found to work alongside control within the control society. Finally, Jones' concept of digital rule emphasized the changes in control methods necessitated by the technologization of society. These ideas also enabled a closer examination of the problems associated with the protection of privacy rights. Surveillance was also shown to be an integral aspect of digital rule. In summary, intensification of surveillance practices, aided primarily by technological tools, has given rise to numerous privacy-related concerns. These, I have argued, are mainly attributable to the uses, functions and results of information-gathering practices. In Chapter Three, I contextualize some of the theoretical issues identified in this chapter by examining relevant Canadian and American rulings, the treaty from the Council of Europe's Convention on CyberCrime and the evolution of the United Nations Crime Congress. 


\section{Chapter 3: Examining Legislation, Policy and Practices}

\section{Introduction}

The ever-expanding reach of transnational criminal activity and the growing technological sophistication of offenders has been identified in Chapter One as the most widely accepted justification for more aggressive and strategic policing action. In this chapter, I examine three different types of official responses to transnational crime and the technologization of policing through an analysis of legislation, policies, practices and strategies. Section One evaluates seven Canadian and American cases that deal with police technology, the right to privacy and the related right against unreasonable search and seizure. The background on the right to privacy from the previous chapter is very relevant to this section. I argue that over time, the courts are gradually moving towards greater latitude in favour of the police and their use of high-tech surveillance tools. This, in turn, has implications for privacy rights. These developments are explained with reference to David Garland's observations on the changing institutional arrangements that characterized the field of crime control from the 1970s onward. Much more detail on Garland's ideas are provided in the final section of this chapter.

Section Two examines the treaty of the Council of Europe's Convention on Cybercrime. Although the treaty accords importance to rights protections, I argue that this is not reflected in the provisions of the legislation. Instead, far more significance is placed on establishing greater international police cooperation and a stronger publicprivate nexus. Lastly, Section Three examines the shifting crime concerns of the United Nations Crime Congresses. Through a synopsis of these priorities since the start of these 
sessions (in 1955 and held every five years thereafter), I draw on David Garland's ideas to argue that the decline of the penal-welfare model and the emergence of a redefined crime control landscape fostered greater international cooperation, technologization and also gave rise to a fluctuating rights framework. For this reason, the UN Crime Congress does not exhibit the same pattern of diminishing rights protections that is found in the previous sections. This chapter argues that the changing postures towards safeguarding rights (in the three different contexts) are reflective of broader changes to the field of crime control shaped by political, social and economic factors.

\section{The Direction of the Courts}

Seven Canadian and American Supreme Court rulings are examined here to reveal that as police technology has become more sophisticated over time, courts have experienced great difficulties in following precedents, remaining consistent and arriving at decisions that can both safeguard rights and permit reasonable uses of surveillance technologies. These challenges, combined with a rapidly shifting social and political landscape, have seriously weakened rights protections in both jurisdictions. R.v. Duarte [1990], R. v. Wong [1990], R.v. Wise [1992] and R.v. Tessling [2004] are the Canadian cases that are analyzed. Katz v. United States [1967], United States v. Penny-Feeney [1991] and Kyllo v. United States [2001] are the American rulings examined. Since these cases all deal with the right to privacy, Chapter One's discussion on the history, evolution and controversy of this right is important to bear in mind. This section proceeds chronologically in order to demonstrate the increasingly latitudinal shift in the law's position toward police surveillance technologies. There are, however, broader social factors at play that bear on these legal rulings. I provide insight into what these may be by 
drawing on some of Garland's ideas. Let me begin with the Katz case, arguably the most significant in the history of the right to privacy as it pertains to policing and technology.

\section{A. The First Wave: Rights Implications of Phone-Tapping Technologies}

In the 1967 Katz v. United States decision, the accused was arrested for illegal gambling after using a public phone to transmit wagering information across state lines. Without obtaining a warrant, the FBI recorded conversations from a public telephone booth from which the accused placed such calls. They argued that this was a legal action since they never actually entered the phone booth. The Court, however, ruled in favour of Katz, stating that the Fourth Amendment allowed for the protection of a person and not just a person's property against illegal searches. Justice Stewart, in delivering the majority opinion, held that "whatever a citizen seeks to preserve as private, even in an area accessible to the public, may be constitutionally protected."

The crucial outcome of Katz was the 'reasonable expectation of privacy' standard, embodied in a two-prong test: (1) Subjective Privacy: whether the person exhibited a personal expectation to be left alone from state intrusion? (2) Objective Privacy: is that expectation one that society is willing to accept as reasonable? If the answer to both questions is 'yes,' any police infringement upon that expectation is considered a search. This test is significant because it balanced the interest in protecting individuals from state intrusion with the interest in protecting society from criminals ( $\left.\mathrm{O}^{\prime} \mathrm{Connor}, 2004\right)$ and is now used to determine the scope of the Fourth Amendment's protections.

Despite these crucial steps forward for privacy law, it was not long before things began to change. As Julie (2000: 131) states, courts in recent years have tended to find that, "the effect of modern life, with its technological and other advances, serves to 
eliminate or reduce a persons' expectation of privacy." By consequence, state regulation has also been found to weaken this expectation. This author's observations deserve further exploration - what factors influenced these negative outcomes? and why were they so impactful? First, however, I would like to examine the changing position of the courts toward privacy protections in light of new surveillance technologies. Sharing Julie's view, I argue that after Katz, the courts have granted police increasing latitude in their use of these tools. This has lead to diminished privacy protections and weakened safeguards against unlawful searches and seizures. The technologies that come before the courts in the next six cases are video surveillance, electronic tracking and thermal energy detectors. With the exception of the Kyllo decision, the evolution of technologies is accompanied by lowered rights protections by the courts.

\section{B. The Second Wave: Audio-Visual Surveillance and Electronic Tracking}

In the Canadian ruling of R.v. Duarte, both the right to be secure against unreasonable search and seizure under Section 8 of the Charter of Rights and Freedoms and privacy rights were at issue. I begin with the facts of the case. As part of an investigation into drug trafficking, the police rented an apartment for a police informer who was working with an undercover police officer. The apartment was equipped with audio-visual recording equipment installed in a wall. Prior to the installation of the equipment, the informer and the undercover officer consented to the interception of their conversations under s. 178.11(2)(a) of the Criminal Code. During the investigation, the appellant discussed a cocaine transaction and was subsequently charged with conspiracy to import a narcotic. At trial, the accused challenged the validity of this section of the Code, arguing that it violated his s. 8 rights. 
At the Supreme Court, the judges had to first determine whether unauthorized interception by police, even if not a criminal offence, would violate s. 8 . The Court concluded that this right had indeed been violated. The second point to be determined was whether the admission of evidence, if obtained in breach of the Charter, would bring the administration of justice into disrepute under section 24(2) of the Charter. This provision requires the exclusion of evidence at trial if it was obtained through the violation of a Charter right. To this second question, the Court stated that the actions of the police were, "in no way deliberate and it stemmed from an entirely reasonable misunderstanding of the law by the police officers who would otherwise have obtained the necessary evidence to convict the accused in any event" and therefore did not violate s. 24(2). Consequently, it was concluded that the admission of this evidence would not bring the administration of justice into disrepute.

In the same year, $R$. v. Wong reached the Supreme Court. In this case, police installed a video camera without a warrant and monitored activities in the accused's hotel room for the purposes of investigating a 'floating gaming house'. The Court held that the degree of privacy reasonably expected in a free society would be seriously diminished by unrestricted police video surveillance, a person occupying a hotel room has a reasonable expectation of privacy and that hotels and motels may be considered homes away from home. Thus, a warrantless video search is contrary to s. 8. Justice La Forest then turned to the statement in Duarte that unauthorized electronic audio-visual surveillance violated s. 8 and extended it, maintaining that "all existing means by which the state can electronically intrude on the privacy of the individual violate s. 8." In the end, however, the Court followed Duarte and concluded that the videotape evidence was obtained in violation of 
s. 8 , but did not bring the administration of justice into disrepute under s. 24(2) because the police acted in good faith, had reasonable and probable grounds for suspicion and there was a measure of urgency. Wong's appeal was dismissed.

The conclusions in these cases weaken s. 8 protections and question the integrity of the statement that all unauthorized means of electronic intrusion of privacy by the state violate s. 8 . With respect to Wong, the decision to admit the evidence on the grounds that it would not bring the administration of justice into disrepute is especially problematic because the search was warrantless. The justifications for the search provided in both Duarte and Wong - good faith, reasonable and probable grounds and urgency - cannot sufficiently account for police actions. Both rulings have the reverse effect of bringing the administration of justice into disrepute.

The third relevant case is $R$. $v$. Wise. The accused was charged with mischief to property and at the time of the offence, he was under police surveillance for recent murders in the area. A warrant was obtained to search his car and home and after the warrant expired, the police installed an electronic tracking device (a 'beeper') in his vehicle. Evidence from the beeper was used to charge the accused with mischief after he crashed into a telephone tower. The majority held that the search was only minimally intrusive because there is a reduced expectation of privacy in a vehicle. An interesting contrast is apparent between this position and the American one in Delaware v. Prouse where the court recognized an increased expectation of privacy for automobile passengers (Julie, 2000: 131). The Court added that the beeper was unsophisticated and inaccurate, concluding that the admission of the evidence the beeper produced would not 
bring the administration of justice into disrepute and the evidence as to the location of the car would not affect the fairness of the trial.

Some important parallels can be drawn to Duarte and Wong. Similar to the latter case, the technologies were used by the police without a warrant but the courts admitted the evidence nonetheless, stating that justice would not be impaired. Second, it was held that in all three cases, the police acted in good faith. Thirdly, the judges in both Wise and Wong argued that there was a sense of urgency that warranted the use of the respective technologies: Wong was running a gaming house and Wise was a suspected serial killer.

The court's justifications in Wise are replete with shortcomings. First, it is arguable that the search was not minimally intrusive because, as Justice La Forest stated in his dissent, an individual has a reasonable expectation of privacy in both the communications s/he makes and in her/his movements, even when traveling on a public road. Next, by deeming the beeper unsophisticated and then admitting the evidence to convict the accused, the process of justice can be seen as severely undermined. Lastly, the rationalization that the police acted in good faith is weak because, as Justices Sopinka and Iacobucci assert, good faith does not include the knowing commission of an illegal trespass by the police. This shortcoming is a feature of Duarte and Wong as well. The reasons given for upholding the search and admitting the evidence in these three rulings calls into question the integrity of s.8 rights as well as the administration of justice.

\section{The Third Wave: Thermal-Energy Detection Devices}

The latest police technology that has caused widespread controversy is ForwardLooking Infrared Radar (FLIR) devices. These tools detect thermal energy and are frequently used in determining heat patterns consistent with indoor marijuana 
growhouses. In United Sates v. Penny-Feeney, the court adopted an even more latitudinal approach to the use of police surveillance tools than in all of the previous cases discussed. The facts of the case are as follows. Upon receipt of information that the accused was growing marijuana in her home, the police flew over the property using FLIR and observed heat patterns indicating marijuana growth. No warrant was obtained for the flight. The Court deemed FLIR to be a passive, "non-intrusive device" because it measured escaping heat from well beyond the perimeter of the home. Using the Katz test, the Court concluded that the defendant had no subjective expectation of privacy because the FLIR only analyzed "abandoned/waste heat." Moving onto the second prong of the Katz test, the Court held that even if the defendant had a reasonable expectation of privacy, it was not an expectation society was willing to accept. In comparing this 'voluntary' emanation to the placing of garbage bags outside one's home, the Court pointed out that "both cases involve a homeowner's disposing of waste matter in areas exposed to the public." Such a justification rests on a weak equation of visible waste such as garbage to 'waste' such as heat that can only be detected by an FLIR device. It was concluded that the use of a device to detect surface heat waste from a home does not amount to a Fourth Amendment search (Colbridge, 1997). Reacting to this conclusion, Julie (2000: 136) states that the assertion that heat is potential evidence of crime places a sinister cast on a by-product of the daily life functions of every American.

The last American ruling for this analysis is Kyllo v. United States. Kyllo is the only decision among those examined here in which the court ruled in favour of safeguarding rights from advancing technologies. An FLIR device was used to detect hot spots around Kyllo's residence. A warrant was obtained to search the accused's home 
based on these photographs, where the agents found marijuana growing. The Court held that a minimal and reasonable expectation of privacy exists in the home and to withdraw such protection would permit police technology to erode the privacy guaranteed in the Fourth Amendment and "leave the homeowner at the mercy of advancing technology." Thus, they argued, “obtaining by 'sense-enhancing' technology any information regarding the home's interior constitutes an intrusion into a constitutionally protected area." Based on these arguments, the Court recognized the potential rights implications of surveillance technology as well as the importance of stepping in early to define the limits of the government's power to invade citizen's privacy.

Although this decision marks a victory for the protection of rights, it is important to note that it was delivered in July of 2001. Two months later, the events of September $11^{\text {th }}$ resulted in the USA PATRIOT Act, a hastily crafted piece of legislation that granted police agencies considerable freedom and discretion to exercise their powers. A particularly odious aspect of this legislation for the purposes of this analysis is the breadth of this discretionary power in terms of surveillance. For instance, under Title II: Enhanced Surveillance Procedures are found numerous provisions that expand the power of federal authorities to intercept, share and use telecommunications to investigate activities relating to terrorism (Sec. 201) and computer fraud (Sec. 202). In Thomas' (2002: 206) view, the Act as whole undermines the privacy protection of the Fourth Amendment by eroding the line between intelligence gathering and gathering evidence for criminal proceedings. The Canadian Anti-Terrorism Act similarly broadens the scope of police surveillance capabilities and rehashes the justification that police need to keep 
up with technologically sophisticated criminals. The Department of Justice's website states that:

Terrorist groups are increasingly able to take advantage of sophisticated techniques to further and conceal their activities. Law enforcement and national security agencies must have the ability to effectively investigate individuals and groups who may pose a threat to the safety and security of Canadians (Canada, 2001).

In view of this, the ATA provides new investigative tools to allow security, intelligence and law enforcement agencies to more effectively gather knowledge about terrorist groups. Turning now to the latest Canadian Supreme Court ruling on police technologies in $R$. v. Tessling, it emerges that police have substantial discretionary authority in their use of surveillance technologies.

The Tessling judgment was delivered in October 2004 and so it reflects the current position of the Supreme Court on the tension between police technologies and civil liberties. The RCMP used an airplane equipped with an FLIR camera to overfly the accused's home. A warrant was obtained to search the accused's home based on the results of the FLIR image and information from two informants. This search produced a large quantity of marijuana and several guns. The accused was charged with multiple drug and weapons offences. The majority judgment emphasized the importance of limiting the ability of police power from unlawfully invading the privacy of Canadians, but tempered this concern by outlining the competing demands of social life: the community wants privacy but it also insists on protection.

The Court's analysis of the thermal technology was strikingly similar to that in Penny-Feeny. Because FLIR imaging is characterized as an external surveillance of the home, it is not equivalent to entry and therefore did not intrude the accused's reasonable sphere of privacy. The FLIR heat profile did not expose any intimate details of the 
accused's lifestyle or part of his 'core biographical data'. It only showed that some of the activities in the house generate heat. In sum, the Court held that FLIR technology was both non-intrusive in its operations and mundane in the data it is capable of producing. The Court went on to state that as technology develops, the protections offered by property rights diminish. Especially worrisome is the lament that previous courts were reluctant to accept this idea.

There are three problems with this decision. The first relates to nature of the search itself. By arguing that it was an external search that did not invade the accused's reasonable expectation of privacy, the Court adopted a problematic understanding of the home. For most, heat emanating for their homes does not automatically qualify it for open scrutiny. The Court in Kyllo expressed a similar concern, stating that, "imaging technology capable of discerning activity in the home leaves the homeowner at the mercy of advancing technology". A second and related problem has to do with the argument that no intimate details of the accused's lifestyle were revealed but only that some activities generated heat. In my view, this is flawed because that which happens in the home is inherently intimate. Likewise, the Kyllo decision argued that in the sanctity of the home, all details are intimate details. Thirdly, in ruling that FLIR imaging is not equivalent to physical entry, the court overlooks a controversial aspect of new police surveillance technologies - they are no longer constrained by a dependence on physical space and can thereby access many new domains. In this case, the majority seems to be of the view that although technologies can now access locations and individuals without physical contact, there is no need to re-evaluate them. These weaknesses highlight both the contentious place of technology within the law and the Courts' problematic understanding of its 
consequences and outcomes. Paul De Hert (2005: 78) has likewise observed that even in countries with a 'legality requirement' (this basically means 'no technology without law') such as the Netherlands, judges give too much leeway to law enforcement authorities trying out new technologies. Judges do not like to say 'no' to human rights-infringing technologies that help combat crime but which lack a proper legal basis.

These seven cases indicate that with the growing sophistication of surveillance technologies over time, the courts have adopted a more latitudinal approach towards their use by policing agencies. The implications of this have been most heavily felt in the protection of privacy rights. I return here to my two queries above: what factors influenced negative outcomes for rights and why were they so impactful? It is arguable that these consequences are tied to broader social factors as well as unique issues surrounding each of the technologies that have come before the courts. For instance, FLIR devices seem not to be conceptualized as particularly invasive today whereas wiretapping was perhaps more controversial during the time Katz was decided. In my view, this points to larger social changes and attitudes toward surveillance technologies that are being reflected in judicial decisions. In many urban areas, for example, citizens are aware that they are likely to be captured by CCTV surveillance in the course of their movements. Another case in point is the security procedures in airports - travelers generally understand that in the present period, surveillance is an integral aspect of airports. In this sense, the decisions examined here are reflective of the times.

David Garland's work in Culture of Control provides useful insights into these observations. In detailing the shift away from the 'penal-welfare' framework in the 1970s followed by a reconfiguration of the crime control landscape, a set of ideas that will be 
elaborated in greater detail below, Garland argues that the dominant theme underpinning this transition was the protection of the public (2001: 12). Evidence for this is found most clearly in community notification laws that publicly mark released offenders highlighting past misdeeds and possible future dangers. Most relevant for this analysis is Garland's assertion that as a result of these changes, there has been a relaxation of concern about the civil liberties of suspects and the rights of prisoners accompanied by a new emphasis on crime control and enforcement. What is more, procedural safeguards have been partrepealed and surveillance cameras have come to be routine presence on city streets. Garland believes that this represents the public as 'risk-averse' and fearful of the consequences of unrestrained criminals in the public sphere. The consequences of these developments are that the risk of unrestrained state authorities, arbitrary power and the violation of civil liberties no longer seems to figure so prominently in public concern.

The negative aspects of these shifts are that the right to privacy, and privacy protections more generally, has come to be interpreted in different and problematic ways. In Katz and later in Kyllo, the Court affirmed citizen's Fourth Amendment rights against intrusions on reasonable expectations of privacy and against unreasonable searches and seizures. However, Duarte, Wise, Wong, Penny-Feeney and Tessling departed from Katz to reflect the current state of the tension between surveillance technologies and protecting rights. This shift served to undermine Section 8 Charter rights in Canada, Fourth Amendment protections in the US and privacy rights in both countries. What is most problematic about this observation is that courts are essential to the interpretation and protection of these basic rights. Due to the larger forces at play detailed in the foregoing paragraphs, these decisions have come to increasingly undermine privacy protections but 
have not yielded the level of public disapproval that past surveillance technologies may have elicited. In the following sections, I discuss policy, legislative and practical changes at the global level to argue that a similar weakening of rights is taking place in the first instance but a more complex picture emerges in the second. These processes can be attributed to many of the same broader shifts identified here and is complicated by the challenges of tackling transnational crime through an international network.

\section{The Convention on CyberCrime}

The technological era has both transformed the way policing is performed and introduced a new and complex category of crime: cyber-crime. As one of the most pressing crime problems of the present period, cyber-crime has generated an immense international response. Greater international cooperation, intensified uses of technologies and involving more non-police actors have been the main solutions advocated. One body that has taken particularly aggressive action is the Council of Europe (COE). In 2001, the Council held the Convention on Cybercrime (CC) in Budapest. Both members and nonmembers of the COE, including Canada, the United States and Japan, attended the Convention. Described by Pocar (2004: 30) as the first multilateral treaty on cyber-crime, the Convention's goal was to pursue a common criminal policy aimed at protecting society against cyber-crime, especially by adopting appropriate legislation and fostering international co-operation (COE, 2001). This treaty came into force on July 1, 2004.

I choose to examine this convention rather than other aspects of transnational crime because the role of technology in both criminality and policing is a key focus of this thesis. Considering that technology is the primary medium for the commission of cyber-crimes, analyzing this Convention is fitting. This section evaluates two prominent 
themes of the Convention: intensified international police cooperation and a stronger nexus between the state and private industry. Although emphasis is placed on the theme of safeguarding rights, I argue that it is not translated into any substantial provisions in the treaty. Based on these observations, I contend that state interests in combating transnational crime take priority over rights protections, which have only a perfunctory place in the accord. First, however, I address the problem of defining cyber-crime.

One of the most vexing tasks for lawmakers, politicians and state authorities involved in the legal regulation of cyber-crime is defining it. Many factors account for this problem: the array of activities that can qualify as cyber-crime, and lack of international agreement on its constituents and the unclear use of different terms to refer to a range of computer-related offences. For Pocar (2004: 32), the lack of consensus on the elements of cyber-crime, which is a central prerequisite for criminal prosecution, are substantive and can impact the effectiveness of international cooperation. Podgar (2002: 273) adds that definitional problems arise partly because computers can serve many different roles in criminal activity: they can be the 'object' used to commit the crime, the 'target' of the criminal activity or tangential to the crime. Another complication is posed by the interchangeable use of terms such as 'computer crime', 'high-technology crime' and 'cyber-crime' because each covers different offences (Pocar, 2004: 32). It follows that establishing an internationally acceptable definition, even one that is quite broad, is a thorny and complex task. Considering that even the Convention does not set out such a definition, an effective international response is likely to be a veritable challenge.

Although these impediments are substantial, I propose a working definition of cyber-crime for this analysis. Cyber-crime refers to all kinds of criminal activity that 
takes advantage of and expands as a result of the opportunities offered by the Internet and information and communication technologies, including the evolution of e-commerce, the growth of multi-national commerce and the ease and speed with which information can be passed around the world (Pocar, 2004: 28). I have selected this definition for two reasons. Firstly, it encapsulates the principal mediums and technologies used in the commission of cyber-crimes and secondly, it is broad enough to capture the range of criminal activities committed through these technologies. In the following pages, I argue that definitional problems aside, the two main themes of the Convention seek to dramatically expand the global police network, a goal that has corrosive implications for rights protections.

\section{A. The Need for Greater International Cooperation}

One of the chief priorities of the Convention is to foster international cooperation and stronger ties among member states to combat cyber-crime. Not only is cooperation advocated among states, it is also needed between states and private industry, which is the second theme I examine. Commentators such as Pocar (2004: 34) argue that this is the most feasible strategy because the worldwide dimension of the Internet and its illegal uses require concerted efforts from all relevant domestic and international authorities. Articles 23 to 35 of the treaty outline the specifics of international cooperation most conducive to combating cyber-crime. Through an analysis of some of these articles, I argue that the Convention accords only outward importance to rights protections while top priority is given to combating international crime, strengthening international police networks and expanding this network by including private non-state actors. This is best illustrated by the absence of a specific rights provision within the treaty. 
Chapter III sets out the eight articles that pertain to international cooperation. Principles relating to extradition are covered in Article 24. A fundamental problem of the treaty is found in Subsection 3 of this article. It outlines that if a particular state does not have its own domestic extradition law, it can consider the Convention as the legal basis for extradition. Coleman (2003: 135) cautions that requiring extradition other than under the terms of existing extradition treaties could weaken processes that have been developed over many years. A parallel problem is evident in Article 27: it sets out procedures for when mutual assistance requests are made but applicable international laws are non-existent. By permitting states to defer to the Convention as the legal foundation for extradition and mutual assistance purposes, a question arises as to why a specific article outlining safeguards for rights could not be included. Through adding such a clause, a state that does not have privacy laws, for instance, could turn to the Convention for guidance. Considering that the preamble of the treaty specifically outlines the importance of human rights, international human rights instruments and privacy law, it is curious that a rights-specific article is absent. Instead, police authorities are referred to both domestic law and dated international law to deal with rights issues. As Article 15(1) states,

Domestic law shall provide for the adequate protection of human rights and liberties, including rights arising pursuant to obligations it has undertaken under the 1950 Council of Europe Convention for the Protection of Human Rights and Fundamental Freedoms, the 1966 United Nations International Covenant on Civil and Political Rights, and other international human rights instruments (COE, 2001).

The consequences of these omissions are already apparent in Canada. The Canadian government recently released a consultation paper entitled "Lawful Access" in response to their obligations under the $\mathrm{CC}$. The paper proposes, among other dubious 
recommendations, the collection of data by Internet Service Providers (ISPs) at the request of law enforcement, without prior judicial authorization, in exigent circumstances (Huey \& Rosenberg, 2004: 599). The collective effect of these shortcomings indicates that rights have only external importance within the Convention.

Schalken and Pronk offer an explanation for the inconsistencies of Articles 24 and 27. Referring to the European context, they state that current treaties on mutual legal assistance are an important step on the road to the harmonization of international police powers but these treaties do not cover everything (Schalken \& Pronk, 2002: 76). This means that several criminal matters remain unstandardized at the European level, such that police cooperation will still have to fall back on the domestic legal system, as long as important differences remain between the countries in the standards of special methods of investigation. Though current treaties do not need to 'cover everything', expanding police powers must be met by adequate accountability schemes and rights safeguards. This is a recurrent point of discussion in the treaty, but rarely does it translate into either law or practice. In this regard, Schalken and Pronk's explanation adds clarity to the situation but does not effectively explain why a treaty such as the Convention fails to include a rights provision but manages to give police such sweeping powers.

Article 28, entitled "Confidentiality and Limitation on Use," is perhaps the closest to a rights directive, but is nevertheless a weak one. It instructs states to provide information to requesting parties only if it is kept confidential and used for the purposes set out in the request. While the inclusion of this article indicates a concern for the sensitivity of data, the interests of the state are the chief priorities, not those of individuals, businesses or others from whom the data is taken. For example, Article 28(3) 
stipulates that the confidentiality requirement is flexible because it grants broad discretion to parties being asked for data. If this party feels that the requesting party cannot comply with the confidentially requirement, they can decide whether or not to provide the information. Having the ability to provide the data if confidentiality cannot be guaranteed suggests that data protection under Article 28 is very narrow in scope.

Articles 31 to 34 seek to make mutual assistance regarding investigative powers a smooth process. Each of these rules require parties to assist one another, within guidelines, through the provision of requested data. The problem, however, is that no mention is made of the individual or organization from which the data is to be taken. It is assumed that each state and party will address these issues through domestic laws. This is troubling because police cooperation in the area of cyber-crime requires the cooperation of these private actors. Although these parties may want to protect their own interests through collaborating with the police, the Convention assumes this participation and does not allow much agency to private actors.

Finally, the purpose of Article 35 is to advance international cooperation by requiring parties to designate a point of contact available on a twenty-four hour, sevenday-a-week basis. The creation of this ' $24 / 7$ Network' is aimed at ensuring the provision of immediate assistance for investigations or proceedings concerning criminal offences related to computer systems and data. By requiring signatories to establish this round-theclock network, the international police network transcends both time and space barriers.

The sections of the Convention intended to facilitate global police cooperation are quite comprehensive in terms of the practical measures needed. By contrast, very few and weak protections of rights are included, although the preamble stresses the importance of 
such safeguards. This omission is further reinforced by the second theme: the need to strengthen the relationship between the state and private industry.

\section{B. The Public-Private Relationship: The Case of Internet Service Providers (ISPs)}

Cross-national police cooperation has been widely advocated as the key strategy for fighting transnational crime. However, Pocar (2004: 35) stresses that this may not be sufficient to cover all aspects of cyber-crime. High priority should also be given to enhancing cooperation between public authorities and private companies involved in the production and commerce of hardware and software. This point is buttressed in a recent United Nations report (UN, 2002) which asserts that strategic and closer relationships could help address some types of cyber-crimes at the policy, legislative and law enforcement levels (Secretary-General, 2001). Strengthening public-private relationships, specifically between police and Internet Service Providers (ISPs), is the second key theme of the Convention on Cybercrime. Articles 16 to 21 bear most directly on issues relating to the role of service providers in facilitating online surveillance, search and seizure of client data. Through an examination of these articles, I argue that ISPs are being co-opted as partners to law enforcement in the fight against cyber-crime.

Among the many worrying measures mandated by the $\mathrm{CC}$ is legislation that grants new powers of search and seizure to law enforcement authorities. Huey and Rosenberg (2004: 597) describe that these powers include compelling ISPs to provide intercept technology to ensure 'lawful access' to data transmissions, to provide assistance to police in the storage and search of data from an investigation target and to release to police general information (i.e. names and addresses) regarding a service's customers. These authors add that the CC places obligations upon ISPs that, in effect, convert service 
providers into internal cogs in the apparatus of online law enforcement. This represents part of a larger trend in policing whereby western states have begun to recognize the limitation of public police services and have started to extend their reach by establishing policing networks with elements of the private sector that have the tools and capacity to achieve desired results beyond the state (Huey \& Rosenberg, 2004: 597).

Under Article 16, parties must adopt laws to permit authorities to order the preservation of specified computer data, including traffic data ${ }^{12}$, that is relevant to an investigation. Huey and Rosenberg (2004: 598) argue that since 'preservation' is not defined, users, ISPs and civil libertarians are worried about the implications of data collection: do governments seek to trap the traffic of a targeted user or the network traffic of all users of a service? These concerns appear to be justified: Belgium, France, Spain and the United Kingdom are among the growing number of states that have instituted data retention schemes (EPIC, 2005). Article 17 raises further concerns. It outlines that state laws must ensure both expeditious preservation and disclosure of traffic data. The preservation requirement specifies that data must be made available regardless of the number of ISPs involved in the transmission of data. In effect, this places service providers at the behest of law enforcement and subordinates their interests to those of the state. As a result, this stipulation relegates the importance of privacy protections that service providers may consider vital to their businesses. The second requirement of 'expeditious disclosure' is even more problematic because it requires that law enforcement must be able to identify the ISP and the path through which the

\footnotetext{
12 "Traffic data" is defined as any computer data relating to a communication by means of a computer system, generated by a computer system that formed a part in the chain of communication, indicating the communication's origin, destination, route, time, date, size, duration or type of underlying service. $<\mathrm{http}: / /$ www.conventions.coe.int/Treaty/en/Treaties/Html/185.htm>
} 
communication was transmitted. It is important, however, to bear in mind that ISPs may welcome legislation of this kind because it can help protect their business interests. The implications, therefore, are felt at the individual client level as well as at the level of commerce to maintain customer loyalty.

Article 18 exacerbates privacy concerns: it obliges parties to adopt laws that permit authorities to order computer data from either an individual or an ISP (in the form of 'subscriber information'). The subscriber information includes the identity and location of subscribers, their telephone number, billing and payment information, type of service used and the length of service. The use of the word 'order' in 18(1) demonstrates that the cooperation between ISPs and the state is more obligatory than voluntary. Article 20 mandates the adoption of legislation to compel ISPs to provide access to police to monitor real-time traffic data or to assist law enforcement in collecting and recording real-time traffic. This would permit authorities to track the means by which targeted data are traveling and to have maximum cooperation from service providers. Article 21 calls for legal measures through which ISPs could be compelled to intercept and store content data such as e-mail messages, or to assist law enforcement in doing so (Huey \& Rosenberg, 2004: 598). Although these capabilities may violate the privacy policies of an ISP, Article 21 essentially forces cooperation with the state.

Collectively, these provisions require signatories of the $\mathrm{COE}$ to grant police authorities quite broad powers of surveillance and interception and to take aggressive action to ensure service providers comply with their objectives. Additionally, parties are required to permit international access to information by governmental authorities in other jurisdictions. Coleman (2003: 4) comments that this makes the Conventions' 
requirements very ambitions indeed. Huey and Rosenberg (2004: 598) add that the articles examined here also cast ISPs in the role of police agents, either by compelling them to perform officially sanctioned surveillance activities - searching for, collecting, analyzing and turning over data to agents of the state - or by ordering them to assist police in these same activities. This lack of agency situates ISPs in a vulnerable position because their objectives, such as protecting the privacy of their customers, are subordinate to those of the state. Although some ISPs may be receptive to these laws for commercial reasons, these same provisions also grant police the opportunity to penetrate beyond the traditional veil of privacy shrouding personal communications, and to do so in a manner that far exceeds the scope of traditional law enforcement techniques used for similar purposes (Huey \& Rosenberg, 2004: 599). The practical result of these provisions is that users of communications technologies are considered 'fair game' in terms of surveillance and for periods of time that state legislatures or governments have the discretion to determine.

\section{The United Nations Crime Congress}

Every five years beginning in 1955, the United Nations Congress on Crime Prevention and the Treatment of Offenders has been held. This Congress brings together a broad spectrum of individual experts, state officials and non-governmental organizations from the field of criminal justice to discuss a wide range of crime-related topics. I have selected to examine this Congress because it allows for an examination of both chronological and worldwide changes in crime priorities. By analyzing the documents of the twelve Congresses to date, this final section has two objectives. The first is to provide an historical overview of the crime priorities since 1955 . The second 
goal is to locate these changes within broader social, political and historical developments. Garland's work is again useful to this discussion, particularly: the decline of the penal-welfare state followed by the reconfiguration of the crime control landscape, the significance of old and new crime matters in successive Congresses, the figure of the victim and the 'third sector' of crime prevention (as discussed in the Chapter One).

In comparison to the transition taking place in the courts and manifest in the Convention on Cybercrime, a more complex set of developments can be observed here: concerns for the protection of rights has fluctuated such that they are more prominent at some Congresses than at others. Because the Congress itself addresses a broad array of crime matters, the focus over time has likewise been on a host of rights and liberties.

Before delving into these issues, I want to discuss why Garland's ideas are significant to an analysis of the United Nations, an international organization, even though Garland himself specified that his observations focused on the USA, UK and other developed countries. One possible reason is that the changes associated with 'late modernity' - a distinctive pattern of social, economic and cultural relations that affected America, Britain and other developed countries - extended their impact beyond industrialized nations. Two such changes are relevant to highlight: (i) the dynamic of capitalist production and market exchange and the corresponding advances in technology and communications and (ii) the rise of the electronic mass media (Garland, 2001: 78). It is arguable that these features of late modernity were increasingly visible in developing countries because of the expansion of global markets, international trade and information and communications technologies. It is further plausible that these changes came to bear on crime control agendas in ways similar to developed countries, albeit with different 
interests and objectives in mind. Whether this pattern unfolded or not, the point I would like to emphasize is that Garland's ideas are valuable for analyzing the evolving global crime control agendas of the UN Crime Congress. At the same time, the differences at the international level do not allow for a total 'match' with Garland's observations. In view of this, some ideas have more application to this analysis than others.

\section{A. The Early Congresses: Confidence in the Penal-Welfare Model}

Following the dissolution of the International Penal and Penitentiary Commission (IPPC) by the General Assembly in 1950, the United Nations continued the former body's practice of holding international conferences on crime control matters (UN, 2006). The UN Congresses on the Prevention of Crime and the Treatment of Offenders replaced the IPPC and took place as follows. The First Congress was held in Geneva in 1955 and was mainly concerned with strengthening and rebuilding society after the Second World War. The key topics at this meeting were humanitarian values and rights protection. Some of the main objectives were establishing standard minimum rules for the treatment of prisoners, regulating prison labour, setting standards for hiring prison staff and the prevention of juvenile delinquency (Secretariat, 1956).

These same themes re-emerged in the 1960 Congress in London, but were modified and joined by new ones. Juvenile delinquency, prison standards and prison labour took on added importance at the meeting. The new issues were post-release care and criminality resulting from social change and economic development (Secretariat, 1961). At the 1965 Stockholm Congress, the central topics were technical assistance in crime prevention, implications of broad social changes for criminality, prevention and treatment for juvenile offenders and alternatives to incarceration (Secretariat, 1967). 
Though the crime problems during these Congresses generally remained the same, the failings of traditional criminal justice practices in areas such as incarceration and the harsh treatment of young offenders were increasingly recognized.

In order to understand why these crime problems were important during the first ten years of the Congress, David Garland's notion of the penal-welfare framework, which was at its zenith during this period, provides useful insight. Garland describes this model as a set of institutional arrangements that increasingly characterized the field of crime control and criminal justice from the 1890 s to the 1970 s. Penal-welfarism shaped the common sense of generations of policy-makers and practitioners and was a dominant model for addressing crime, particularly during the decades following World War Two (2000: 352). This strategy was seen as the appropriate framework for action against the post-war growth in crime because it focused on reforming offenders, targeted the deviant for transformation and adopted a policy of vigorous policing (Garland, 1996: 447, 454).

The penal-welfare strategy was also linked into a broader politics of social change, a vision of social justice and overcoming social divisions (Garland, 1996: 466). With respect to the failures of these measures, they were seen as a problem of resources and knowledge and plans were laid for further research, increased funding and the expansion, for example, of child welfare services. There was no doubt about the state's capacity to deal with these problems. On the contrary, the state was determined to win the war against crime by attacking social problems (Garland, 1996: 447). Confidence in the penal-welfare framework, as expressed in official discourses, reached its peak in the 1960s. By focusing on prison issues, law enforcement standards and preventing juvenile 
delinquency, these early Congresses also embraced this high level of confidence in the penal-welfare model.

\section{B. The Changing Crime Control Landscape}

In the period since the 1960 s, official policies and practices gradually moved away from this position and a reconfigured field started taking shape. Garland (1996: 447) explains that beginning in the 1970 s, commitment to the penal-welfare framework waned and that the state's claims in respect of crime control became more modest and more hesitant, at least in certain contexts. There emerged a new sense of the failure of criminal justice agencies, and a more limited sense of the state's powers of regulate conduct and prohibit deviance. Attention shifted to dealing with the effects of crime costs, victims and fearful citizens - rather than its causes. Above all there was an explicit acknowledgement of the need to rethink the problem of crime and the strategies for managing it (Garland 1996, 447). These changes indicated that the penal-welfare strategy was rapidly unraveling while more punitive measures were gathering support. This shift can be observed within the Congresses, starting with the 1970 Kyoto session.

Kyoto marked a key turning point in the Congress' crime priorities. In the Kyoto Declaration, deep concern was expressed about major social, economic and technological changes that were having an impact on the quality of life and giving rise to the increased seriousness of crime in many countries (Secretariat, 1971). The Declaration made three other crucial points. The first was the recognition of a 'world-wide crime problem' and its ramifications for both conventional crime and more sophisticated types of organized crime. Secondly, new dimensions of crime were perceived as 'far more serious now than at any other time in the long history of these Congresses'. And thirdly, the UN and other 
international organizations were urged to prioritize international cooperation in crime prevention and to ensure the availability of effective technical aid to countries desiring such assistance (Secretariat, 1971). By underscoring the ramifications of transnational crime and identifying the pressing need for a concerted global response, these statements ushered in a new phase in the international response to global criminality and distinguished the Kyoto Congress from its predecessors.

In the six Congresses held after 1970, the ever-expanding threat of transnational crime, the growing technologization of crime and the need for intensified international police cooperation were central themes. The sum of these changes resulted in a move towards a tighter global policing network that depended on technological tools to address global crime. However, given the diversity of policing and state actors involved and the complexity of tackling crime at the international level, this process unfolded at a slower pace than it may have at the domestic level. As a result, crime issues of a penal-welfare quality that were dominant prior to 1970 still continued to be important agenda items in the Congresses, but their presence eventually waned over time. Garland (2001: 167) likewise observes a similar 'carry-over' of crime problems after the decline of the penalwelfare model. He explains that when considering the field of crime control in its entirety, we need to bear in mind that new practices and mentalities co-exist with the residues and continuations of older arrangements. Our focus upon the new and the transformative should not lead us to neglect these older practices and institutions. The intertwining of the established and the emergent is what structures the present.

A second observation that emerges in this next set of Congresses is the growth of a 'third sector'. Recalling from Chapter One, Garland conceptualized the third sector as a 
new way of regulating crime and criminals that focused on prevention. This expanding sector is made up of diverse partnerships and multi-agency working practices that link together different authorities and has a 'fragile, virtual existence' (Garland, 2001: 170). Furthermore, it has begun to alter the balance of the crime control field by exercising a 'small but insistent' pressure that has moved policies towards prevention, harm reduction and risk management. It aims to reduce criminal events by minimizing criminal opportunities, enhancing situational control and channeling conduct away from criminogenic situations. Importantly, it seeks the active participation of the host of actors and agencies that make up civil society. These defining elements of the 'third sector' can be seen within the UN Congresses.

Thirdly, Garland describes an increasing focus on the figure of the victim after the fall-out of the penal-welfare model. He explains that the feelings and interests of victims are now routinely invoked such that the new imperative is to protect victims, make their voices heard, honour their memory and allow them to express their anger (Garland, 2000: 351). In this regard, the symbolic figure of the victim has taken on a life of its own, leading to a situation wherein being 'for' victims automatically means being tough on offenders (Garland, 2000: 351). Within the Congresses, the victim begins to assume prominence from 1985 onward. This 'delay', as it were, is perhaps indicative of the different issues at the top of the international crime control agenda vis-à-vis those occupying the agendas of industrialized countries at the same time.

Beginning with the 1975 Geneva Congress, the principal issues of concern were changes in the forms and reach of criminality, augmenting crime prevention and the scientific and technical revolution. This session also discussed, for the first time, the 
concept of crime as a business (including organized crime). In addition to these 'hard' crime-related issues, special emphasis was placed on the changing expectations of law enforcement, minimum standards of performance, the treatment of offenders, torture and other cruel treatment (Secretariat, 1976). Five years later, the Caracas session focused on the role of international cooperation in criminal justice, shared ideas on guidelines in criminal justice, capital punishment, juvenile justice, problems with the correctional system and rehabilitating offenders. Data collection, analysis and storage were emphasized as key to the prevention of crime. In addition, three types of crime were reported to be on the rise in most countries: organized and premeditated violence, property offences and white-collar crime (Secretariat, 1981).

At the 1985 Milan Congress, the scope of crime concerns expanded significantly and greater attention was placed on the victim. The key topics were greater international cooperation, technical cooperation for crime prevention, terrorist activities, youth crime, codes of conduct for law enforcement, alternatives to imprisonment, extra-legal executions, prisoner and human rights standards. There were also a host of novel issues that emerged at this Congress: domestic violence and victims of crime and abuse of power (over women in particular) (Secretariat, 1986). This diversity of criminal justicerelated issues on the international agenda reflects Garland's observation that even with the waning of the penal-welfare model, past and present topics remained intertwined and existed alongside one another. The focus on 'new' victim groups is indicative of contemporary penality's linkage with the idea of the victim. The victim gains increasing standing in the Congresses to follow. 
The $8^{\text {th }}$ session was held in Havana in 1990 and focused attention on preventing juvenile delinquency; greater international cooperation against organized crimes and terrorist activities; mutual assistance through training and exchange programs; the problem of and alternatives to imprisonment; and setting standards for the treatment of offenders. Technical cooperation, 'clearinghouses' of data and a fortified relationship among science, technology and crime prevention were also emphasized as crucial to the fight against computerized crime. The consideration of both older and newer criminal matters, the focus on crime prevention and the technological considerations all resonate with post-penal-welfare features of crime control.

The Ninth Congress in Cairo likewise concentrated on a blend of past and present crime concerns. Old ones included: juvenile and violent crime; the need for stricter extradition laws, national legislation and international legal instruments; international cooperation and information technologies. Newer issues were strengthening the rule of law, crime prevention in urban areas, transnational economic crime, environmental crime and corruption (Secretariat, 1995). As well, recognition was given to accountability in criminal justice operations and protecting privacy in the course of surveillance activities. The victim also figured prominently at this Congress in the following forms: victims rights, victim impact statements, victim support groups and services, reducing victimization and restitution and compensation were key topics. The focus on crime prevention is indicative of the growth of the third sector.

The Vienna Congress in 2000 focused on four substantive areas that contained both new and old elements. They are: (i) promoting the rule of law and strengthening the criminal justice system, (ii) international cooperation in combating transnational crime (a 
focus on new challenges in the 21 st century), (iii) crime prevention (iv) and offenders and victims: accountability and fairness in the justice process. In addition, workshops were held on women in criminal justice, combating computer crimes and community involvement in crime prevention (Secretariat, 2001). Again, we can see the elements of Garland's observations evident here - the victim is an object of attention and crime prevention, as an important aspect of the third sector, is a core objective. Significantly, fairness and rights protections (including privacy rights) are considered important goals.

In 2005, the $11^{\text {th }}$ Congress was held in Bangkok, Thailand. As this was the first Congress held after the $9 / 11$ attacks, there was a notable shift in the tone, priorities and goals of the delegates. This is best captured in the statements made in the Bangkok Declaration. Entitled Synergies and Responses: Strategic Alliances in Crime Prevention and Criminal Justice, the Declaration concentrated on combating terrorism and its links with other criminal activities (Secretariat, 2006). The parties continually underscored the importance of tackling corruption and the many dimensions of transnational organized crime such as illicit drug trafficking, money-laundering and the smuggling of migrants. As such, the most heavily emphasized theme was the need for more effective concerted global action - on multilateral, regional and bilateral levels - against cross-national crime. The need to strengthen international law in the areas of extradition and mutual legal assistance was also stressed. This theme appears multiple times in virtually every document, panel discussion and working paper.

Technology also occupied a central place. Section 16 of the Declaration is telling: "We welcome efforts to enhance and supplement existing cooperation to prevent, investigate and prosecute high-technology and computer-related crime, including by 
developing partnerships with the private sector." This statement advocates the same strategy pursued by the Convention of Cybercrime: to establish a closer public-private relationship. Previous issues are juvenile justice and the protection of children, upholding the rule of law, international standards in prisons, protecting witnesses and victims, training for law enforcement and rehabilitating offenders. New topics include defining terrorism, tackling all aspects of terrorism, developing restorative justice policies and minimizing the spread of HIV/AIDS in prisons. Thus, we can see the intertwining and coexistence of established and emergent issues, the continued importance of the victim and the focus on the prevention, control and minimization of crime.

The place of rights in these Congresses deserves some further commentary. Unlike the trajectory identified within the courts and the problematic situation of rights in the Convention on CyberCrime, there is a greater degree of fluctuation in terms of how rights were positioned in the Congresses and diversity in terms of how they were manifest. Immediately after the end of the Second World War, the focus was on strengthening and rebuilding society through rights protections and a strong recognition of humanitarian values. In 1975, we see a gradual orientation towards standard-setting in criminal justice. Then in Milan in 1985, the rights concerns are found in codes of conduct for law enforcement, alternatives to imprisonment, extra-legal executions, prisoner and human rights standards. In 1990, recognition was given to accountability in criminal justice operations and protecting privacy in the course of surveillance activities and in 2000, complying with international law, particularly international human rights law, refugee law and humanitarian law, was a key theme. At the most recent Bangkok Congress, alongside a highly diversified list of topics was an affirmation to comply with 
international law, particularly international human rights, refugee and humanitarian law, and act in conformity with the Charter of the United Nations. Over the course of these Congresses then, we can observe both rapid expansion in the issues of concern as well as a fluctuating, yet also expanding, focus on rights. Also significant is the fact that in considering the importance of rights protections, a very broad understanding of what they meant was adopted most notably in the notion of 'human rights'. Consequently, the UN Crime Congress does not exhibit the same pattern of diminishing rights protections that is found in the previous sections. This is reflective of broader changes to the field of crime control shaped by political, social and economic factors.

Based on this overview, there has been a dramatic shift in the United Nations' crime priorities over the past 50 years. These changes were influenced by a host of factors including the decline of the penal-welfare framework followed by a major restructuring of the crime control landscape. Collectively, they have contributed to the rise of a new and relatively comprehensive international crime picture, in terms of both policies and practices. This is indicative of three processes. The first is the increasingly diversified and pluralized nature of the international policing network. The second is the broad scope of the international response to crime. Seeking to address everything from large-scale international coordination schemes to challenges in individual prisons and to work both preventatively and reactively to crime, a more 'holistic' or 'cover-all-bases' response to the world's crime problems is advocated by the Congress. Thirdly, the fluctuating place of rights protections has occurred alongside the diversification of criminal priorities. 
Furthermore, the course of the Congresses reflected many of the same trends Garland identified: the decline of the penal-welfare model followed by a reconfigured crime control landscape, older and newer crime matters were intertwined with one another, the victim came to assume a dominant presence and the rise of a 'third sector' of crime control that focused on crime prevention. In their totality, the Congresses gave increasing importance to international cooperation, the build up of a technological infrastructure and the need to address a vast array of criminal issues alongside changing degrees of emphasis on rights obligations and the need to protect human rights.

\section{Conclusion}

The shifting direction of the courts, and the policies, legislation and practices of the Convention on Cybercrime and the UN Crime Congresses each responded differently to policing practices and technologies, having likewise differing impacts on rights protections. Collectively, they have each augmented the discretionary power of the police, granted a significant new role to surveillance technologies, helped establish new structures of multi-agency policing and widened the scope of the international response to crime. Perhaps the most significant impact of these shifts can be seen in the changes to legislation - internationally, regionally and domestically. Concomitantly, rights protections have also underwent a series of changes that correspond with many of Garland's observations about the changing terrain of crime control. The complex web of influences on the three practical developments examined in this chapter reflects the rapidly changing nature of multi-agency policing. The next chapter responds to the rights implications of this transforming policing landscape by examining the notion of democratic accountability, identifying the key actors that can help enhance such 
transparency and suggesting that cooperation among them can prove advantageous for greater accountability within multi-agency policing. 


\section{Chapter 4: Responding to Rights Implications}

\section{Introduction}

The pluralized and fragmented nature of modern policing and the accompanying technologization of this field have had tremendous impacts on privacy rights and civil liberties most notably. As Loader (2000: 324) comments, the nature of this field has rendered established modes of accountability limited and inadequate. This has lead to demands for greater transparency and more robust mechanisms of accountability. In trying to respond to these concerns, we confront a key question of global governance: how is it possible to render multi-agency policing democratically accountable?

Section One of this chapter examines the notion of democratic accountability as it relates to policing followed by a discussion of potential misuses of accountability measures. Defining the 'public' within the multi-agency policing context as well as identifying the challenges to greater accountability are explored. An analysis of how the technological and information-based environment of policing affects these barriers is also included. Section Two seeks to answer how policing can be held more accountable. I propose that five social actors need to be strengthened in order for meaningful change to occur. Just as cooperation is the central focus of transnational policing efforts, it should also be the guiding principle among these actors in order to effectively address oversight issues. This chapter argues that democratic accountability needs to become a more prominent aspect of multi-agency policing but recognizes that there will be obstacles to this process. The purpose of this chapter is to provide some indication of the future possibilities, particularly those fostering greater coordination, that may enable us to make 
sense of and respond to change in a fragmented, technologized yet clearly still emergent policing network.

\section{Democratic Accountability, Multi-Agency Policing and Technology}

As the basic parameters of the policing field are increasingly left undefined and as the technological capacity of the police continues to expand, concerns for rights implications prompt the need to think more critically about police accountability. For Loader (2000: 340$)$ these processes have led to a condition in which policing actors involved are evading the constraints of the democratic gaze. In view of these developments, efforts to make the police democratically accountable have gained momentum in recent decades. However, these initiatives have encountered many obstacles. One reason is because democracy is a slippery concept and is often used as if its meaning were self-evident (T. Jones et al., 1996: 182). Accountability is another contentious term that has generated substantial debate. There appears, then, to be universal agreement about the desirability of 'democratic policing', but equally universal disagreement about what this would constitute. This terminological ambiguity combined with rights concerns discussed in previous chapters present tremendous challenges to police accountability measures.

This section begins by exploring the meaning of democratic accountability and its potential shortcomings, followed by a discussion of its relevance to this thesis. I then attempt to determine who or what multi-agency policing should be held accountable to by defining the 'public'. The challenges to making democratic accountability a substantial part of transnational policing are discussed next with reference to the private sector and multi-agency policing itself. This section argues that the complexities of multi-national 
policing and the ongoing technologization of this field necessitate a complex understanding of accountability. This requires a range of mechanisms, each oriented to questions of rights protections, regulating the uses of police technologies and maximizing citizen participation.

\section{A. Understanding Democratic Accountability}

Rendering the police democratically accountable is a phrase frequently found in the literature when scholars propose a remedy to police abuses of power. However, there is a dearth of theorizing and analysis on what this term, and its constituent parts, actually means. This discussion attempts to address this gap, beginning with the notion of democracy. Democracy, or 'rule of (or by) the people' in Greek, was first used to describe a form of government found in some of the ancient Greek city-states. It was characterized by the sharing of the right to participate in public affairs amongst 'the people' and denotes a state in which governance is vested in the people as a whole (Held, 1987; Sheptycki, 2002c: 7). Since the $18^{\text {th }}$ century, there have been wide differences among scholars on basic questions of democracy. For instance, there has been disagreement about the priority to be accorded to different values or objectives, and the appropriate role of the people in a democratic system (T. Jones et al., 1996: 183). A common thread uniting the different understandings of democracy is that it is concerned with public participation in political decision-making. In recent years, many policing agencies have recognized the value of public involvement in policymaking and daily practices. At the same time, however, significant gaps and shortcomings remain. These are examined throughout this chapter. 
There are a number of values that arise from discussions on the notion of democracy. It is suggested that the essence of democracy lies in balancing these different values against each other. Five of these are pertinent to this analysis: equity, efficiency, distribution of power, participation and accountability. According to Jones et al.(1996: 190), equity runs through all democratic theory and is placed first in the order of priority here because in practice, other elements of democracy derive from it. Equity is synonymous to fairness and often goes hand in hand with equality. In the policing context, equality consists of equality of service and inclusivity of all members of society in policing (LCC, 2002: 39). Efficiency refers to cost-effective policing practices that are designed to attend to the security needs of a population. Thirdly, the distribution of power, meaning that power should not be concentrated among a few individuals or groups, is a value that underlies democratic theory. A more even distribution is necessary to achieve stable compromises when conflicts of interest arise and to ensure there are sources of countervailing power, particularly in the case of the police who are a key part of the repressive complex (T. Jones et al., 1996: 192). Fourthly, public participation is an important but contentious theme and will be explored in further detail below.

Accountability is the fifth value and is central to democratic policing. This principle requires that the actions of the public police, as an institution and as individuals, are subject to review. Redress is another essential element and refers to the availability of formal channels for individuals to lodge complaints against the police and gain compensation (T. Jones et al., 1996: 192; LCC, 2002: 4). Sheptycki (2004: 112) believes that accountability is also a cultural construct as much as a technique of government. $\mathrm{He}$ explains that accountability is not the simple imposition of a set of requirements, but rests 
rather on shared cultural understandings of what is right, just, fair and proper. A related concept is civilian oversight, which is essentially a process that involves people from outside the police calling the police to account for their actions, policies and organization (Miller \& Merrick, 2002: 2). These broadly interrelated terms capture police obligations and the oversight capacity of the public in democratic societies.

Accountability has also generated disagreement and debate, particularly in the policing literature. Philip Stenning (1995: 5) writes that, "fundamentally, accountability is about no more nor less than requirements to give accounts". Accountability may be rooted in formal legal requirements and rules, or it may be rooted in custom, or power relations. In short, it may be formal or informal. In liberal democracies the ideal has been that the requirement to give account is, at its most basic, a requirement to make matters of institutional and individual practice transparent (Sheptycki, 2004: 109). A further distinction is between internal and external accountability, each of which can affect transparency initiatives in very different ways. Very often, external and internal mechanisms exist alongside one another. In short, transparency and openness of operations are uniting themes of these different understandings of accountability.

At the same time that accountability measures can engender transparency, they can also have the contradictory effect of justifying actions and limiting external control. Sheptycki (2004: 110) explains that this is because accountability mechanisms are resources in the hands of officials who use them to justify actions in ways that, perhaps ironically, often preclude scrutiny and control by outsiders. This 'accountability shield' demands that police organizations place a premium as much on internal accountability as they do on external transparency. Consequently, a paradoxical outcome emerges whereby 
systems of accountability aim at making institutional action transparent but they ultimately tend towards opacity. Although this ironic situation illuminates the detrimental potential of accountability frameworks, it also underscores and augments the pressing need for more comprehensive oversight schemes.

Based on this discussion, democratic accountability can be understood as oversight and transparency of the police performed by different sectors of society. Instituting accountability frameworks are challenging for all types of policing organizations, and arguably more so for those involved in multi-agency policing. At the same time, these obstacles reinforce the need for more critical thinking on accountability irrespective of the forms of police work performed or the relationships engaged in. Since the public constitute a central element of democracy, it is useful to explore its constituent elements more closely.

\section{B. Accountable to Whom or What? Defining the 'Public'}

Given that a key dimension of democracy is public involvement in political affairs, it is important to ensure that the public has a voice in the operation of the police. Although the notion of democracy originally referred to the public police, new forms of policing that can profoundly affect the lives of citizens necessitates public participation in these policing operations as well. Before elaborating on this, it is important to define who or what constitute the public in light of the ongoing transformations to the policing field. One such change is the service orientation of policing that has created the need for a broader understanding of who the 'customers' of policing are (T. Jones et al., 1996: 194). As a result, the reconfigured policing landscape challenges long-held understandings of who or what make up the 'public'. 
Ian Loader takes issue with the role of the public in shaping police accountability standards. He asks on what basis might citizens be able to voice their concerns about the multiple policing forms that increasingly impact upon the quality of their lives? How might the plurality of agencies that constitute the policing field locally, nationally and transnationally adequately be rendered responsive to democratic audiences (Loader, 2000: 324)? From another perspective, members of the public are conceptualized as consumers of policing services. In fact, the private policing industry views their audience precisely in this way and public police are increasingly doing so, as evidenced by the transition from police forces to police services. These issues underscore the complexities of defining the public within the context of multi-agency policing.

In light of these circumstances, it is useful to think of having multiple publics. Indeed, this idea captures what is actually taking place since various policing actors are answerable to different audiences by virtue of their different origins. The difficulty with this, however, is that new policing linkages are constantly being established and dismantled at the transnational level. For instance, Joint Investigation Teams are policing relationships set up for a specific aim and for a specific duration (Schalken \& Pronk, 2002: 71). Europol is another example because it is controlled by the parliaments of its fifteen different Member States and is therefore accountable to each of their respective publics. These examples highlight just a few of the complexities of defining the public within the context of multi-agency policing. A useful conceptual tool then, is to consider the notion of multiple publics. The next two portions of this section discuss the challenges to implementing a more robust framework of accountability into private policing and multi-agency policing. The focus is on these forms of policing because they 
are relatively new and have presented many unique problems for governance and accountability mechanisms.

\section{Democratic Accountability, Private Policing and Transnational Policing}

The incredible growth in the worldwide private policing industry has transformed the face of policing at both the domestic and international levels. Parallel to this development has been the tremendous challenge of regulating private policing. The transnationalization of private policing as well as the multiplication of new technologies within multi-agency policing has further complicated the implementation of regulatory frameworks. Likewise, scholars such as James Sheptycki (2002c: 4) have expressed skepticism about the feasibility of accountability measures, arguing that the democratic control of policing, transnational and otherwise, is problematic in the contemporary period because the policing field is ungovernable through traditional means of democratic accountability. These problems are compounded by the fact that it is increasingly difficult to distinguish between private and public police in terms of what they do and how their activities impinge on the lives of citizens. Collectively, these factors have highlighted the need for a closer evaluation of regulation over the policing field as well as specifically over the private sphere.

The main criticism regarding the regulation of the private policing sector is that it is not subject to the same controls as the public police are. Because each organization within the private sector has the ability to set its own standards, this has lead to wide gaps in the industry. Scott Burbidge is one proponent of this view, suggesting that this discrepancy has caused a 'governance deficit'. Burbidge (2005: 63) argues that it is unacceptable that while the public police (at least in theory) are governed by and 
accountable to democratically elected governmental authority and to the public, private police officers performing the same policing functions are not subject to the same form of accountability. This view has gained popular support: private security officers are much less accountable for their actions than are public police because legislation does not establish independent oversight mechanisms that can be used to hold private security officers accountable (LCC, 2002: 4). With the public and private policing sectors providing similar services, but controlled by and answerable to different entities, concerns about oversight and accountability are bound to arise.

In opposition to these arguments, private security executives believe that the competitive nature of the market and existing regulatory structures place sufficient controls on their industry. Some even argue that these mechanisms make them far more accountable than the public police because they are subject to criminal liability, industry self-regulation, labour legislation, contractual liability and accountability through the marketplace (LCC, 2002). This is a logical argument because, as one of the fundamental rules of the market sets out, if customers do not like the services of a private security firm, they can fire them - an alternative not available to the public police (Bayley \& Shearing, 1996: 596). From an industry perspective, then, market competition accelerates the drive for higher quality and tighter controls.

The problem, however, is that the accountability provided by markets accumulates for buyers of private security and not to all the people who might be affected by it. In view of this, the public police fair higher on the accountability scale because they are, at least in theory, accountable to every citizen. A market-based argument is also problematic because it does not consider the social division that private forms of policing 
can create or further entrench. According to Bayley and Shearing (1996: 596), private policing is more selective in who it protects whereas the public police are required to serve the interests of people territorially and are therefore more inclusive. Though the market may ameliorate some inequalities, it can manufacture and deepen others.

A second source of concern is posed by the use of technologies in private policing. These worries are heightened when it comes to transnational policing activities because it may add another layer of secrecy to private policing. What is more, since private police are competing to secure the most lucrative security contracts, they have an added incentive to be at the cutting edge of technology. In the process, rights considerations are likely to be relegated in importance. Philip Stenning provides some insight into why this may be the case. Through a comparison of technologies used by public and private policing, Stenning (2000: 335) comments that because the latter are employed by private corporations, not only do they have more ready access to technologies, they are also not vulnerable to Orwellian 'Big Brother' fears that the public police are when they express interest in more technologies, especially those that enhance surveillance. Within private corporate environments, greater use of such technologies by private policing seems to be more readily accepted (Stenning, 2000: 335). These perceptual differences towards technologies and the competitive nature of the private policing industry, as it relates to the acquisition of these technologies, can together deepen the governance deficit.

In light of these challenges to holding private police accountable, both at the domestic and transnational level, renewed critical thinking on transparency measures is required. As well, new approaches to managing the interactions between private police 
and other types of policing actors are needed. In combination with existing schemes of accountability in the private sector, oversight schemes must be developed to address the unique problems presented by this industry.

\section{Democratic Accountability and Multi-Agency Policing}

While the private policing sector has been criticized on its accountability measures for quite some time now, it is only in the last decade or so that attention to issues of accountability has come to focus on transnational practices (Sheptycki, 2004: 108). The growing technological infrastructure and novel policing partnerships that characterize multi-agency policing have contributed to this change in focus. In order to understand these concerns and other challenges to transparency over MAP, let us turn to the experiences of Europol.

Returning to the example of Joint Investigation Teams (JITs), Europol's involvement in these initiatives has caused controversy because while the organization can participate in operational actions, it cannot do so in the executive sense simply because it does not have executive or autonomous legal powers (Fijnaut, 2002: 244). However, as Schalken \& Pronk (2002: 75) point out, these rules are more flexible than rigid because Europol can both exercise influence and give direction on the operational execution of a joint action. This raises the question of accountability because Europol is straddling the fine line between policy and practice. In light of Europol's increasing influence on operational activities such as JITs, it is important to intensify supervision, both judicial and democratic, of this police force. A possible solution is to set out a more detailed outline of Europol's involvement and caution that without such parameters in place, serious complications to judicial control over criminal procedures could arise 
(Schalken \& Pronk, 2002: 75). This example illuminates just some of the accountability problems that can arise when operational boundaries are blurred, a dynamic that frequently affects multi-agency policing.

This section has sought to indicate some of the problems of democratic accountability, transparency mechanisms and public participation as they pertain to multi-agency policing. From this discussion, it has emerged that a complex understanding of accountability can be an effective conceptual tool for addressing these issues. This strategy requires a range of mechanisms and actors, each differently oriented to questions of rights protection, controlling police uses of technology and maximizing public participation. By such means it might become possible to generate a transnational policing capacity that is both effective and democratically legitimate. Section Two undertakes an exploration of the key actors that can assist in this process and advocates a strategy of cooperation among them.

\section{$\underline{\text { 2. Avenues for Future Development of Multi-Agency Police Governance }}$}

This section attempts to address some of the problems identified in the previous section by outlining possible avenues for developing a more integrated and comprehensive police accountability model. I propose that this requires the commitment, strengthening and perhaps most importantly, cooperation, of five elements or 'safety valves' of society: state governments, leaders in the policing community, the judiciary and the courts, the public and non-governmental organizations. Since each of these actors can impact accountability practices in unique ways, they must all be strengthened in some form. Cooperation is important because just as policing agencies are collaborating in new ways, these five elements can be more effective if they work together. Technology can be 
an extremely powerful apparatus in this regard. This section offers and evaluates ideas for increasing the transparency of multi-agency policing. Given that some of these ideas are theoretical and others practical, my overall objective is to encourage thinking about the transnational policing field that gives consideration to democratic dialogue.

Recognizing that many police agencies already have oversight mechanisms in place for both domestic and cross-national operations, the proposals advanced here seek to weave these existing controls into new ideas for democratic accountability. Though this section is optimistic that accountability can become a substantial part of multi-agency policing activities, I caution that this process will encounter many challenges as the policing field continues to change and as technology is increasingly integrated into it. This section argues that in order for meaningful oversight and transparency of the police to occur, the safety valves of democracy must not only be triggered, but must work steadfastly and cooperate with one another to lessen the negative outcomes of transnational policing.

\section{A. The Critical Role of the State}

In recent decades, we have witnessed what Loader and Walker (2001: 10) call the de-coupling of police and the state. What remains true as these changes continue to take place, however, is that the state is crucial in bringing the world of dispersed, networked policing under democratic control. In support, Loader (2000: 336) asserts that the challenges to regulating pluralized policing and concerns about accountability require a strengthened posture of government. It also demands a renewed role for institutions of government as active regulators whose task it is to ensure that the public voice is heard. In advancing the argument that the state is the leading force that can make police 
accountability a reality, I evaluate Loader's proposal to reform the police through policing commissions. At the same time, however, it must be pointed out in qualification that the most effective strategy for greater accountability requires cooperation among the state and the other key players identified in this section. Thus, a modified version of Loader's model is useful; this is elaborated below.

Recall that in the previous chapter, I was critical of decision by both the Council of Europe and the United Nations Crime Congress to refer police agencies to the human rights standards of their respective states. Though I stand by this position, my main criticism is towards the weak decision-making processes of these institutions and not the instruction referring police authorities to their governments. In fact, I believe that there is real wisdom in (re-) energizing the role of the state because of its unique position in a democratic context - it is the central authority for regulation, oversight and accountability. Many other scholars share this view, although with a few variations. Ian Loader (2000: 336) maintains that the state alone has the resources to respond to the threats to democratic, equitable and effective security provision that networked policing poses. Similarly, Cyrille Fijnaut (2002: 246) favours the intensification of existing state control over policing because it is more suitable to the intergovernmental character of police cooperation. He adds that the greater the distance at which control of operational activity is being organized, the less effective it will be. State governments are therefore important players in making transnational policing transparent and accountable.

In contrast to this view, Bayley and Shearing (1996: 600) believe that government is fighting a losing battle by trying to retain control over policing and respond to the public's intense desire for security. They argue that the state cannot respond effectively 
through traditional law enforcement programs for reasons such as the dauntingly high cost of increasing police numbers and the Anglo-American tradition of mistrust in government. As a result, western democracies will continue to resort to the market place for security solutions in order to compensate for the deficiencies of governmental control over crime (Bayley \& Shearing, 1996: 601). These arguments call attention to the weakened position of the state in the modern period and also challenge the view that government can effectively regulate today's pluralized policing landscape. However, even with the state in a weakened posture, it is still an essential actor for rendering the police accountable. As Burbidge (2005: 66) explains, the state, as the embodiment of the values of society, is uniquely capable of ensuring public security, characterized by a monopoly on the legitimate use of force, coordinated governance, collective provision and communities of attachment. This is true also with respect to interagency policing because strong state controls can have positive carry-over into international operations.

So, in what specific ways can the state's governing role be reconfigured to foster a more democratically accountable policing framework? One idea that has gained support is policing commissions. These commissions would be responsible for upholding the law and interpreting the general duty of the police. They would be directly elected and able to issue instructions to local police chiefs on matters of policy (Jefferson \& Grimshaw, 1984). Ian Loader suggests a modified version of this concept. His scheme is to create national, regional and local policing commissions, which would essentially be institutions charged with formulating policies and coordinating service delivery across the policing network (Loader, 2000: 337). These commissions would also be responsible for bringing 
to democratic account the various agencies that comprise this network and be governed by the tripartite principle of public justice. It is fruitful to further explore this principle.

The first prong of public justice is the politics of recognition, which requires policing commissions to take account of the views of all individuals and groups likely to be affected by their decisions. This process would equalize the imbalance between paying customers of the private security industry, who have disproportionate influence over the delivery of policing resources, and those who cannot afford to do the same. Although marshaling the views of all affected actors will be a daunting task, the politics of recognition highlights the need to increase the input of those affected by, but outside of, the policing world. This is especially needed given that present arrangements fail to adequately represent the weak and minority groups (T. Jones et al., 1996: 189).

The second element is a politics of human rights. Policing commissions would need to make decisions that have high public support while being careful not to prejudice individuals or groups. Within plural policing, commissioners should ensure that all policing agencies uphold fundamental human rights and cultivate a human rights culture within their organizations. In essence, this requires policing commissions to establish a very narrow, yet balanced, definition of human rights. The difficulties of this include questions such as what constitutes a culture of human rights and how can this be fostered within the diverse police organizations that are active today? At the same time, however, a more serious consideration of rights implications is precisely what this thesis advocates. Indeed, a great number of modern policing agencies have done just this in the course of formulating or amending their policies. Interpol, for instance, places a high premium on ensuring human rights in its various practices. According to the organization's website, it 
has taken several initiatives to promote the observance of human rights in its various fields of activities (Interpol, 2005b). Hence, the politics of human rights is extremely important and deserves further recognition by police agencies.

The final component is the politics of allocation. Essentially, this requires policing commissions to take account of potential inequities in the distribution of policing resources and seek measures to rectify them when making policy/network coordinating decisions. This includes taking seriously the concerns of both overpoliced populations and underpoliced groups. Though Loader does not detail how these categories are to be determined, his point does not hinge on this. What he seeks to underscore is the need to both recognize and do something concrete about the uneven distribution of policing resources. Considering that the state is the central coordinator, distributor and overseer of public resources in a democracy, this strategy is quite fitting. With the advent of new forms of policing such as private security, however, traditional methods of distribution are disrupted. A further consequence of this is that the resource divide between the overpoliced and the underpoliced has deepened. These features of the contemporary policing field challenge the task of rectifying the resource imbalance that Loader has assigned to these commissions. However, because members of these commissions would be from diverse agencies, their influence in these institutions may be able to address resource inequities.

The principle of public justice and its three constituent parts seek to bolster the position of the state through the creation of policing commissions. These boards would be responsible for regulating various police organizations with a view to gain control over the policing field more broadly. Although some of Loader's ideas about the functions of 
these commissions are perhaps more effective in theory than in practice, they generally point to strategies that if not already taking place, are feasible to make practical. Importantly, the theoretical considerations that Loader's ideas encourage can foster new ways of thinking about police accountability. Given the fact that multi-agency policing is a continually transforming form of policing, this may be more effective than immediate overhauls of police operations. At the same time, practical changes must occur alongside debate and dialogue. A particularly useful approach to balancing these two considerations, and one that is a feature of policing commissions, is coordination and cooperation. Especially important is promoting cooperation among the state and the other significant actors discussed below. The first of these is the police community, and more specifically, leaders from various sectors of policing.

\section{B. Leaders in the Police Community}

Regardless of which sector of the policing field they are from, leaders in the policing community have the capacity to make their operational policies more transparent and receptive to accountability. It is important to note that these measures exist within most policing agencies but are often weakly enforced or not at all. Nevertheless, I argue that police leaders can bring about substantial internal change, which is arguably more effective than externally imposed regulations. A further contention is that cooperation among these actors, particularly those from the private and public sector, is key to fostering transparency. Similar to Loader's scheme to establish police commissions, I evaluate the Law Commission of Canada's proposal to create policing boards.

International organizations such as the United Nations Crime Congress and the Council of Europe (COE) are two important actors because they can influence the 
direction of global police operations. As the previous chapter explained, both institutions have shaped policy making, legislation and police practices surrounding transnational policing. With all of these powers comes the responsibility to make policing more transparent and to accord rights protections a more central place in deliberations and daily policing operations. Unfortunately, Chapter Three also demonstrated that the COE in particular failed to translate its outward commitment to these issues into real, practical change. The point to recognize is that these organizations have the potential to make impactful changes. This capability needs to be acknowledged and utilized because democratic accountability of policing depends on the clout held by key players. It is for this reason that I take opposition to James Sheptycki's (2002c: 14) assertion that policing cannot become part of the solution to the problem of democratic accountability. He adds that policing by itself cannot deliver greater democracy because police agencies are points in a global system of polycentric power. Globally police institutions are part of a broader organizational set which inhibits democracy and human rights (Sheptycki, 2002c: 14). These statements are deeply flawed because they disregard the potential for police institutions to make real change to their practices.

One example of this is found in the rights-oriented changes Interpol has made to its data protection measures. Recalling from Chapter One, it is stated under Article Two of Interpol's Constitution that the organization acts 'in the spirit of the Universal Declaration of Human Rights'. In observing this piece of international law, Interpol created the 'Rules on International Police Co-operation and on the Internal Control of Interpol's Activities' to make human rights an important consideration in the processing of police data. To ensure this was made practical, Interpol set up a supervisory board 
under Article 15 of this body of rules. These measures to enhance data protection point to real changes of policing policies towards greater accountability.

Another major player in multi-agency policing is the private policing industry. Leaders of this sector arguably have the greatest capacity to make accountability a more prominent aspect of private policing and better guarantee democratic policing. Fewer layers of bureaucracy and the desire to maintain business relationships are two reasons for this. One recommendation towards greater accountability is the 'professionalization' of the private sector. The Law Commission of Canada is a particularly strong advocate of this strategy and suggests some forms that it can take:

The development of an effective and representative industry association, the enactment of minimum standards for training and the creation of oversight bodies may go a long way in ensuring that policing services are delivered in accordance to democratic values (LCC, 2002: 4).

It is fruitful to examine each of these in turn. Representative industry associations are needed because, at least in Canada, there is no national organization that represents the interests of a significant portion of the industry. This lack of coordination is due to the fact that the industry is highly diverse, competitive and its corporate structure blocks the development of a unified voice. The Commission acknowledges that although these problems are not uncommon to business, their consequences are potentially more serious for the deliverance of effective and democratic policing (LCC, 2002: 49). One solution proposed by the Law Commission is the collection of reliable statistical data about the industry. In short, private policing is at a crucial juncture and government can play a key role in helping the industry strengthen existing controls and establish new ones that support police accountability. 
The development of minimum standards for training and the licensing of all security workers can significantly improve the quality of private security services. For instance, they may help diminish 'the race to the least qualified' by imposing processes that do not always benefit the lowest bidder. In addition, they would work towards harmonizing the standards of the industry thereby equalizing the playing field and raising the overall quality of services. Again, the state can play a crucial role in bringing about these changes because they can draft policies, seek the input of the public and facilitate cooperation among diverse policing agencies.

Effective oversight is the third recommendation. A common criticism of private policing is that it does not have a system of public oversight in place. It has been argued that as security companies expand their services into areas that were previously the exclusive domain of the public police, they operate in the interest of their clients and are uninterested in and unaccountable to the people they police. Since a key component of democratic policing is reliable redress mechanisms, the Commission argues that the private police must establish such systems in order to give the public a voice in the policing processes that affect their lives.

The principal strategy needed to make these recommendations a reality is greater coordination and integration among police authorities, state governments and the other key elements I discuss in this section. Just as cooperation is taking place among police to fight crime, it can also serve to strengthen accountability mechanisms. Leadership by actors from the policing community is crucial to setting the process of cooperation in motion. Comparable to the policing commissions idea explored above, the Law Commission of Canada proposes 'policing boards' to organize and regulate security. 
These boards would not only have the power to appoint, dismiss and provide oversight to chiefs of police and senior police officers, they would also act as a hub for fostering cooperation between the public police and a host of other agencies (2002: 52). The intent would be to create partnerships with other governmental and non-governmental agencies that have important roles in maintaining public security under one umbrella.

Although this intention is commendable, not all scholars can see a positive outcome. For example, James Sheptycki (2002c: 8) contends that the diversity of the policing field makes centralized planning difficult to orchestrate and the fragmentation of the transnational political field means that there is no one institutional site from which any such orchestration could be constructed. However, policing boards would address this concern because they coordinate vertically with policing agencies under their ambit as well as horizontally with other boards. Nonetheless, Sheptycki's point highlights the challenges of regulating this field more broadly. The important point to recognize, however, is that discussion on alternatives to current mechanisms is taking place. This, perhaps, is a good starting point for more concrete action.

In sum, leaders from the policing community have the capacity to bring about greater transparency in their respective police agencies. Arguably, the internal accountability that these authorities are capable of instituting can be more effective than externally imposed regulatory controls. To this end, professionalization of the private sector, the creation of policing boards and cooperation that involves all sectors are three tactics that could prove beneficial. 


\section{The Judiciary and the Courts}

In democratic societies, the judiciary and courts are of crucial importance to the criminal justice system and transparency in policing. The decision-making and precedentsetting capacities of these institutions make them key 'safety valves' of democracies. The judiciary is charged with the role of closely regulating police power, and has substantial authority to exercise these controls, but as the previous chapter demonstrated, we are witnessing a gradual movement away from this duty. The courts have experienced similar changes. According to the Vera Institute of Justice, courts labour under a dual obligation. They must do justice in each individual case, and they must work as efficiently as possible. Since these two objectives often conflict, the challenge facing courts is to fulfill both duties at once ${ }^{13}$. The cases reviewed in Chapter Three showed that these obstacles are taking place in both the Canadian and American legal systems.

It is important to recognize that these negative outcomes are the product of internal as well as external causes. Among the internal reasons are judicial decisions that diminish rights protections. Paul De Hert (2005: 78) argues that this is the case with the European Court of Human Rights regarding the balance between police uses of technologies and privacy rights:

Most countries lack a requirement of legality (defined as 'no technology without law') with regard to criminal law enforcement. Even in countries that respect such a requirement, like the Netherlands, judges are known to give too much leeway to law enforcement authorities trying out new technologies. Judges do not like to say 'no' to human-rights-infringing technologies that help combat crime but which lack a proper legal basis.

In terms of external factors, the political climate of a state is powerful because it can influence public opinion, which in turn affects judicial decision-

\footnotetext{
${ }^{13} \mathrm{http} / / /$ www.vera.org/section4/section4_3.asp
} 
making. Major events such as the 9/11 attacks can also affect the direction of the courts. For instance, new and more stringent anti-terrorism legislation that followed these events has had an impact on how courts deal with matters of policing, technology and civil liberties. Just as the impediments to police accountability are internally and externally caused, solutions must come from these directions as well. It is noteworthy to first mention that because the judiciary and courts retain a strong level of control and sanctioning power over the police, they are important and reliable mechanisms in police oversight. I propose three steps that can be taken to address these problems.

The first is to enhance judicial oversight of the police. This requires substantial support, both financial and ideological, by the state. Non-state and civil society actors can also be instrumental in this process. The second step is alleviating some of the burdens that are interfering with court efficiency. This too requires state assistance in the form of financial and human resources. Thirdly, cooperation among the judiciary from different states is needed. As Schalken and Pronk (2002: 77) state, police cooperation such as it has developed in international practice emphasizes the importance of effective judicial cooperation. In short, the judiciary and the courts are equipped with powerful tools to render police accountable. If supported by the state, civil society and counterparts in other countries, positive change can take place.

The remainder of this section examines how non-state actors can affect accountability of transnational policing practices. These actors are of crucial importance because, individually and as a collective, their efforts can foster important transformations. Sheptycki (2002a: 336) shares this view, stating that democratic policing 
in the transnational era can only rest on the ability of non-state actors being able to gain access to, move between and render accountable policing institutions that have transformed the policing field. These actors should emphasize that the aim is to increase the effectiveness of policing in delivering peace, order and good governance.

\section{Public Participation and the Need for Civilian Oversight}

The importance of public involvement in democratic societies has been discussed at many points in this chapter. Significantly, these societies are also the most conducive to social action against police abuses of power. It is only fitting then, that the public is both empowered to and utilizes this capacity to affect how the police are regulated and by extension, to protect basic rights. This argument extends to all forms of policing because their activities affect the citizenry, often in profound ways. Thus, civilian oversight schemes are both logical and necessary. Samuel Walker has documented three such frameworks that I will explore below.

In the previous section, I argued that in light of the diverse nature of MAP, it is useful to suppose that there are multiple publics. At first, this would appear to encumber public initiatives to hold the police to account. Upon further consideration, however, the MAP field is likely to be more responsive to civilian oversight schemes that target several ongoing policing initiatives. The effect of many citizen groups active on several issues simultaneously and in conjunction with other groups, has the potential to make a bigger impact than a few organizations that are perhaps not as well coordinated or mobilized. The Vera Institute of Justice has recognized the importance of this, stating that the field of police oversight is young, without clear definitions and lacking an organization to advance best practices. To address this, the Institute set up the Police Assessment 
Resource Center (PARC) to support and assist those involved in police oversight. Although PARC involves more than just citizen groups, it points to the need to coordinate the many actors performing oversight activities.

In opposition to this, some commentators contend that the principle of public participation advocated here should take low priority among democratic values. Jones et al (1996: 192) are among these critics, stating that public involvement only seems possible in a highly stratified society in which political activity is confined to a small elite. They explain that active participation flourished in the ancient world in small societies where most people were excluded from the political process. By contrast, widespread public participation no longer seems achievable in industrial or postindustrial societies. Jones et al's (1996: 193) principal rationale for this is that getting together groups of people to discuss policing policy is an uphill struggle because the issues are often not salient enough to stimulate substantive concern. These authors agree that participation is important, but emphasize that widening involvement may not always be possible or necessary. The strong point of this argument is that it addresses practical problems of numbers and interest. What it fails to recognize, however, is the impact that citizen activism can have on policing practices. One scholar who does recognize this is Samuel Walker. He argues that there are three types of public involvement in oversight schemes (1996: 72).

The first consists of members of the public who conduct investigations of citizen complaints, often with access to internal police documents. There may or may not be parallel internal police investigations of the same complaints. Depending on the system of review in place, civilians may only be able to make recommendations as to how the 
complaint should be adjudicated, may be empowered to adjudicate the complaint but not to impose discipline or be given the power to impose discipline. In the second instance, civilians are able to review how the police department itself has adjudicated complaints and make recommendations but are not empowered to conduct independent investigations. In this case, investigations are usually carried out by police officers. Lastly, civilians audit, monitor and report on the effectiveness of the police in managing complaints but do not investigate and adjudicate individual complaints as such. Under this model, civilians have complete access to internal police documents.

At the same time that these models can increase transparency in policing, there are also many obstacles to this process. Stone and Merrick (2002: 6) identify a few of these challenges: who can be trusted to fairly and effectively investigate alleged misconduct of the police? To what degree should the discretion of police chiefs to impose or withhold discipline be subject to oversight or control by civilians? To what degree should internal investigations and disciplinary processes be transparent to public scrutiny? Though these issues are deeply problematic as they pertain to the public police, they are arguably far more pronounced in relation to private policing and multi-agency policing. Consequently, the role of the public in fostering greater transparency in policing is simultaneously complex and necessary.

\section{E. The Role of Non-Governmental Organizations}

An increasingly important part of civil society in democratic countries is the nongovernmental organization (NGO) community. In recent years, new NGOs have taken shape to respond to many of the concerns raised in this paper. For instance, the Electronic Privacy Information Center (EPIC) is an American NGO created in 1994 to "focus public 
attention on emerging civil liberties issues and to protect privacy, the First Amendment and constitutional values" (EPIC, 2006). EPIC produces publications on a range of privacy related issues, emphasizes the frailty of state data protection policies and the dangers of electronic data storage.

Another high-profile NGO that addresses similar issues is Privacy International, a British watchdog organization that is critical of the diminishing privacy that has accompanied the information age. Like EPIC, Privacy International focuses on the failings of state regulation in curtailing these negative consequences of technologization (PI, 2006). Both organizations have caused considerable controversy in recent years as they have taken a more aggressive stance on their issues of concern and mobilized a strong support base. The internet and information technologies have, paradoxically, been their primary means of communication.

A host of other non-governmental organizations have recently joined the efforts of EPIC and Privacy International. For example, the American Civil Liberties Union (ACLU) has, especially since the events of $9 / 11$, become extremely active in the area of police powers, technological tools and civil liberties. Some of the current issues that the ACLU is challenging include the Bush administration's illegal spying activities, global identity documents and a host of controversial legislation that threatens privacy rights and other constitutional protections (ACLU, 2006). Another example is the Vera Institute of Justice, an organization that has conducted several research studies around the world on democratic policing, accountability issues, civilian oversight of police and communitypolicing relations. 
These examples indicate that the NGO community is becoming increasingly vocal about issues that have serious implications for privacy matters and civil liberties more generally. Many of these actors engage with one another and have partnerships with likeminded organizations around the world. The strategy of cooperation is therefore taking hold among NGOs more noticeably than among other actors discussed here. The work of these organizations includes not only research, but also political lobbying, advocacy and watchdog activities. Based on these observations, NGO activity can be viewed as a check on policing that emerged to address the gaps in state governance. With the increasing fragmentation and diversification of the policing field, the state has been unable to regulate policing operations as it may once have.

\section{F. Tying It All Together Through a Cooperative Strategy}

Each of these types of actors has the potential to enhance democratic accountability over the police in their own right as well as together. I would like to examine the latter of these to argue that more integrated cooperation can make democratic accountability over policing a more tangible result. The Vera Institute's PARC, as mentioned above, provides a good model for this. By assisting those responsible for the oversight of police departments - monitors, law enforcement executives, civic officials, and government agencies - PARC's objective is to advance, effective and publicly accountable policing. In this sense, PARC's role is to facilitate the reform process by providing information and guidance. Also valuable is the Law Commission of Canada's policing boards framework because it would foster cooperation among both policing and non-policing actors. These are just two examples of models for making cooperation a reality among the five key actors I have identified here. 
In summary, enhancing democratic accountability of the police is possible through the cooperation and coordination of these actors. Having conceptualized them as the 'safety valves' of democracy, it is necessary that they are activated and strengthened. By converging both momentum and resources, it is possible to pave new paths for developing a comprehensive police governance and accountability model. Crucial to this strategy is technology because it facilitates communication and the exchange of knowledge. The ideas offered and evaluated here are intended to foster democratic dialogue and contribute to the larger body of recommendations for making accountability a more prominent aspect of multi-agency policing operations. At the same time that there is tremendous potential for greater police accountability, many obstacles lay ahead as diversification, fragmentation and technologization continue to occur within multiagency policing. To re-emphasize, the need is to consider how we might develop frameworks that foster collaborations among important players that have the ability to bring about greater democratic accountability within the police.

\section{Conclusion}

The rights implications of multi-agency policing and the accelerating use of surveillance technologies within this field have prompted researchers, policymakers and concerned civil society actors to ask how best to render multi-agency policing democratically accountable. In undertaking this same task, this chapter has emphasized the importance of accountability in the face of ongoing fragmentation and pluralization of the policing field. In order to translate this position into practice, cooperation among state governments, leaders from the policing community, the judiciary and the courts, the public and NGOs is critical. Borrowing this strategy from transnational crime fighting, I 
have argued that it can powerfully assist in bringing about greater transparency by assembling the momentum and resources of these key actors. In advancing this scheme, the tone of this chapter has been one of cautious optimism. Cautious because of the many roadblocks posed by the nature of the multi-agency policing field and the interplay of vested interests; optimistic because of the strong potential for change via the combined efforts of the five actors identified here. Based on the problems and possible solutions put forth in this chapter, it is hoped that there is now greater clarity on how to understand and respond to change within the fragmented, pluralized, technologized yet clearly still emergent police network. A final conclusion of this thesis is provided next. 


\section{Conclusion}

In this conclusion, I want to provide some final comments based on the analyses and arguments presented in the foregoing chapters.

Multi-agency policing is here to stay. The historical trajectory of the policing landscape from the $19^{\text {th }}$ century onward has demonstrated that this form of policing unfolded in response to political, historical, social and economic changes. Structural changes to the state, the bureaucratic autonomy of the police, 'new' criminal legislation, the expansion of transnational crime and technological innovations were the key stimulating factors identified here. Not only is multi-agency policing set to stay, it is also poised to expand and branch out because it is still an emergent field that continues to experience rapid change. A valuable research undertaking in the future would be to investigate post-9/11 policing developments vis-à-vis the history of multi-agency policing documented here.

A second conclusion relates to the place of technologies within multi-agency policing. From the earliest innovations in transportation and communications to the astounding degree of information and surveillance technologies that characterize transnational policing today, it is no wonder that technologies have come to be a fundamental feature of the policing landscape. This rate of technological advancement shows no abatement. The theoretical tools applied to analyze this phenomenon revealed that there are deeper and larger processes at work. Thus, just as the international policing landscape is set to undergo greater change and expansion, so too is the technological infrastructure that underpins it. 
Thirdly, I want to comment on the consequences for rights as a result of these developments. What I have documented here reveals a very complex picture of rights that is at once problematic and indicative of larger forces at play. My analysis in Chapter Three highlighted these complexities as they manifested in different contexts. Overall, however, there emerged a general sense that the contemporary policing landscape and its dependence on technologies have weakened rights protections today.

Finally, I have underscored the importance of greater democratic accountability within multi-agency policing as a way to address these rights implications. By proposing a strategy of cooperation among five specific actors, it is held that such an outcome is possible. Policy makers would do well to recognize the value of this approach.

The issues and problems investigated in this thesis have generated substantial debate among theorists, academics and civil society actors. The events of September 11, 2001 had a deep impact on these debates and also engendered a new set of concerns about the protection of rights. It is hoped that this thesis contributes to the discussion on changes taking place within the policing landscape, its reliance on technologies and the consequences for rights. 


\section{Bibliography}

ACLU. (2006). American Civil Liberties union. Retrieved 19 June, 2006, from http://www.aclu.org/

Aden, H. (2001). Convergence of Policing Practices and Transnational Policing in Europe. European Journal of Crime, Criminal Law and Criminal Justice, 9(2), 99-112.

Anderson, M. (1989). Policing the World: Interpol and the Politics of International Police Cooperation. New York: Oxford University Press.

Anderson, M., \& Boer, M. D. (Eds.). (1994). The Agenda for Police Cooperation. London: Printer Publishers.

Austin, L. (2001). Is Privacy a Casualty of the War on Terrorism? In P. M. Ronald Daniels, Kent Roach (Ed.), The Security of Freedom: Essays on Canada's AntiTerrorism Bill (pp. 251-265). Toronto: University of Toronto Press.

Balzer, A. (1996). International Police Cooperation: Opportunities and Obstacles. In M. Pagon (Ed.), Policing in Central and Eastern Europe: Comparing Firsthand Knowledge with Experience from the West (pp. x-z). Lubljana: College of Police and Security Studies.

Bayley, D., \& Shearing, C. (1996). The Future of Policing. Law and Society Review, 30(3), 585-606.

Bennett, C. (1996). The Public Surveillance of Personal Data: A Cross-National Analysis. In D. Lyon \& E. Zureik (Eds.), Computers, Surveillance and Privacy (pp. 237-259). Minneapolis: University of Minnesota Press.

Bigo, D. (2000). Liaison Officers in Europe: New Officers in the European Security Field. In J. Sheptycki (Ed.), Issues in Transnational Policing (pp. 67-99). London: Routledge.

Brandl, S. (2003). Back to the Future: The Implications of September 11, 2001 on Law Enforcement Practice and Policy. Ohio State Journal of Criminal Law, 1(133), 133-150.

Bratich, J. (2006). Nothing is Left Alone for too Long: Reality Programming and Control Society Subjects. Journal of Communication Inquiry, 30(1), 65-83.

Brodeur, J.-P. (2003). The Globalization of Security and Intelligence Agencies: A Report on the Canadian Intelligence Community. In J.-P. Brodeur \& D. Tollborg (Eds.), Democracy, Law and Security: Internal Security Service in Contemporary Europe (pp. 210-264). Hampshire: Ashgate Publishing Ltd.

Burbidge, S. (2005). The Governance Deficit: Reflections on the Future of Public and Private Policing in Canada. Canadian Journal of Criminology and Criminal Justice, 47(1), 63-87.

Canada. (2001). Highlights of Anti-Terrorism Act. Retrieved 30 November, 2005, from www.canada.justice.gc.ca/en/news/nr/2001/doc 27787.html

Canada. (2003). RCMP International Policing. Retrieved 17 December, 2005, from www.rcmp-grc.gc.ca/intpolicing/intpolicing e.htm

Canada. (2005). Royal Canadian Mounted Police as Point of Contact for Europol. Retrieved 8 December, 2005, from www.europol.eu.int/index.asp?page $=$ news \&news $=$ pr051124.htm 
Castells, M. (1997). The Information Age: Economy, Society and Culture, Vol. 2 - The Power of Identity. Oxford: Blackwell.

COE. (2001). Council of Europe's Convention on Cybercrime. Retrieved 18 January, 2006, from http://www.conventions.coe.int/Treaty/en/Treaties/Html/185.htm

Colbridge, T. (1997). Thermal Imaging: Much Heat But Little Light. FBI Law Enforcement Bulletin, 2004, from http://209.238.245.203/Articles/Thermal.htm

Coleman, C. (2003). Cyberspace Security: Securing Cyberspace - New Laws and Developing Strategies. Computer Law and Security Report, 19(2), 131-136.

De Hert, P. (2005). Balancing Security and Liberty Within the European Human Rights Framework. A Critical Reading of the Court's Case Law in the Light of Surveillance and Criminal Law Enforcement Strategies After 9/11. Utrecht Law Review, 1(1), 68-96.

Deflem, M. (2002a). Policing World Society. Great Britain: Oxford University Press.

Deflem, M. (2002b). Technology and the Internationalization of Policing: A Comparative-Historical Perspective. Justice Quarterly, 19(3), 453-475.

Deflem, M. (2005). History of International Police Cooperation. In R. Wright \& M. Miller (Eds.), The Encyclopedia of Criminology (pp. 795-798). New York: Routledge.

Deleuze, G. (1995). Negotiations 1972-1990. New York: Columbia University Press.

Deleuze, G., \& Guattari, F. (1987). A Thousand Plateaus. Minneapolis: University of Minnesota Press.

Den Boer, M. (2002). Towards an Accountability Regime for an Emerging European Policing Governance. Policing and Society, 12(4), 275-289.

EPIC. (2005). Data Retention. Retrieved 10 March, 2006, from http://www.epic.org/privacy/intl/data retention.html

EPIC. (2006). Electronic Privacy Information Center. Retrieved 23 June, 2006, from http://www.epic.org/epic/about.html

Ericson, R., \& Haggerty, K. (2000). The Surveillant Assemblage. British Journal of Sociology, 51(4), 605-622.

Europol. (1997). Annual Report. Retrieved 19 December, 1005, from www.europol.eu.int

Europol. (2005). Fact Sheet on Europol 2005. Retrieved 4 January, 2006, from www.europol.eu.int/index.asp?page=facts

Fijnaut, C. (2002). Introduction to the Special Issue on Police Accountability in Europe. Policing and Society, 12(4), 243-248.

Fooner, M. (1989). Interpol: Issue in World Crime and International Criminal Justice. New York: Plenum Press.

Foucault, M. (1977a). Discipline and Punish. New York: Vintage Books.

Foucault, M. (1977b). Panopticism (A. Sheridan, Trans.). In Discipline and Punish: The Birth of the Prison (pp. 195-228). New York: Vintage Books.

Foucault, M. (2003). Lecture 11 delivered on 17 March 1976 (D. Macey, Trans.). In A. Davidson (Ed.), Society Must Be Defended (pp. 239-264). New York: Picador.

GAO. (2005). Homeland Security: Some Progress Made, but Many Challenges, Remain on U.S. Visitor and Immigrant Status Indicator Technology Program. GAO-05202: United States Government Accountability Office. 
Garland, D. (1996). The Limits of the Sovereign State: Strategiesof Crime Control in Contemporary Society. British Journal of Criminology, 36(4), 445-471.

Garland, D. (2000). The Culture of High Crime Societies. British Journal of Criminology, 40(3), 347-376.

Garland, D. (2001). The Culture of Control: Crime and Social Order in Contemporary Society. Chicago: The University of Chicago Press.

Giddens, A. (1981). A Contemporary Critique of Historical Materialism: Power, Property and the State. London: The Macmillan Pres Ltd.

Glendening, M. (2002, 26 July 2002). Fight the Future for Human Rights. Tribune, Voice of the Left.

Gotlieb, C. (1996). Privacy. In D. Lyon \& E. Zureik (Eds.), Computers, Surveillance and Privacy (pp. 156-174). Minneapolis: University of Minnesota Press.

Haggerty, K., \& Ericson, R. (1999). The Militarization of Policing in the Information Age. Journal of Political and Military Sociology, 27(2), 233-256.

Heiner, B. (1995). Borderless Police? Meunster: Westfaelisches Dampfboot.

Held, D. (1987). Models of Democracy. London: Polity Press.

Huey, L., \& Rosenberg, R. (2004). Watching the Web: Thoughts on Expanding Police Surveillance Opportunities Under the Cyber-Crime Convention. Canadian Journal of Criminology and Criminal Justice, 46(5), 597-607.

Interpol. (1996a). ICPO-Interpol Constitution and General Regulations. Retrieved 16 December, 2005, from www.interpol.int/Public/ICPO/LegalMaterials/constitution/constitutionGenReg/c onstitution.asp\#art2

Interpol. (1996b). Rules on the Processing of Information for the Purposes of International Police Cooperation. Retrieved 16 December, 2005, from www.interpol.int/Public/ICPO/LegalMaterials/constitution/info/default.asp

Interpol. (2005a). About Interpol. Retrieved 14 December, 2005, from www.interpol.int/public/icpo/default.asp

Interpol. (2005b). Human Rights and the Legal Framework of Interpol's Activity. Retrieved 3 July, 2006, from http://www.interpol.int/public/ICPO/LegalMaterials/FactSheets/FS06.asp\#2

Interpol. (2005c). Interpol Crime Areas. Retrieved 18 December, 2005, from www.interpol.int

Jefferson, T., \& Grimshaw, R. (1984). Controlling the Constable: Police Accountability in England and Wales. London: Muller.

Jensen, R. (1987). The International Anti-Anarchist Conference of 1898 and the Origins of Interpol. Journal of Contemporary History, 16(2), 323-347.

Jones, R. (2000). Digital Rule. Punishment, Control and Technology. Punishment and Society, 2(1), 5-22.

Jones, T., Newburn, T., \& Smith, D. (1996). Policing and the Idea of Democracy. British Journal of Criminology, 36(2), 182-198.

Julie, R. (2000). High-tech Surveillance Tools and the Fourth Amendment: Reasonable Expectations of Privacy in the Technological Age. The American Criminal Law Review, 37(1), 127-144.

LCC. (2002). In Search of Security: The Roles of Public Police and Private Agencies, Law Commission of Canada. Ottawa: Law Commission of Canada. 
Loader, I. (2000). Plural Policing and Democratic Governance. Social \& Legal Studies, 9(3), 323-345.

Loader, I. (2002). Governing European Policing: Some Problems and Prospects. Policing and Society, 12(4), 291-305.

Loader, I., \& Walker, N. (2001). Policing as a Public Good: Reconstituting the Connections Between Policing and the State. Theoretical Criminology, 5(1), 9-35.

Loader, I., \& Walker, N. (2005). Locating the Public Interest in Transnational Policing. In A. Goldsmith \& J. Sheptycki (Eds.), Crafting Global Policing. Oxford: Hart.

Lyon, D. (1994). The Electronic Eye: The Rise of Surveillance Society. Minneapolis: University of Minnesota Press.

Lyon, D. (2001). Surveillance Society: Monitoring Everyday Life. Buckingham: Open University Press.

Lyon, D., \& Zureik, E. (1996). Surveillance, Privacy, and the New Technology. In D. Lyon \& E. Zureik (Eds.), Computers, Surveillance and Privacy (pp. 1-20). Minneapolis: University of Minnesota Press.

Manning, P. (2000). Policing New Social Spaces. In J. Sheptycki (Ed.), Issues in Transnational Policing (pp. 177-200). London: Routledge.

Marx, G. (1986). The Iron Fist and the Velvet Glove: Totalitarian Potentials Within Democratic Structures. In J. J. Short (Ed.), The Social Fabric: Dimensions and Issues. California: Sage Publications.

Marx, G. (1997). The Declining Significance of Traditional Borders (and the Appearance of New Borders) in an Age of High Technology. In P. Drogue (Ed.), Intelligent Environments (pp. 484-494). New York: Elsevier Science.

Miller, J., \& Merrick, C. (2002). Civilian Oversight of Policing: Lessons From the Literature. Paper presented at the Global Meeting on Civilian Oversight of Police, Los Angeles.

Mueller, G. (2001). Transnational Crime: Definitions and Concepts. In P. Williams \& D. Vlassis (Eds.), Combating Transnational Crime: Concepts, Activities and Responses (pp. 13-21). London: Frank Cass Publishers.

Nadelmann, E. (1993). Cops Across Border: The Internationalization of U.S. Criminal Law Enforcement. Pennsylvania: The Pennsylvania State University Press.

Norman, P. (2005). The Evolution of European Policing Strategies in Response to Transnational Crime. In J. Sheptycki \& A. Wardak (Eds.), Transnational \& Comparative Criminology (pp. 317-334). Oregon: Glass House Press.

Nunn, S. (2001). Police Technology in Cities: Changes and Challenges. Technology in Society, 23, 11-27.

Nunn, S. (2003). Seeking Tools for the War on Terror: A Critical Assessment of Emerging Technologies in Law Enforcement. Policing: An International Journal of Police Strategies \& Management, 26(3), 454-472.

O'Connor, T. (2004). Lecture on the Right to Privacy: North Carolina Wesleyan College.

Occhipinti, J. (2003). The Politics of EU Police Cooperation. Colorado: Lynne Rienner Publishers Inc.

Philipkoski, K. (1998). A Crime-Sniffing Network. Wired News Retrieved January 30, 2006, from www.wired.com/news/print/0,1294,14231,00.html

PI. (2006). Privacy International. Retrieved 15 June, 2006 
Pocar, F. (2004). New Challenges for International Rules Against Cyber-Crime. European Journal on Criminal Policy and Research, 10, 27-37.

Podgor, E. (2002). International Computer Fraud: A Paradigm for Limiting National Jurisdiction. UC Davis Law Review, 35, 267-318.

Prosser, W. (1960). Privacy. California Law Review, 48(3), 383-423.

Reiner, R. (2000). The Politics of the Police (3rd ed.). Oxford: Oxford University Press.

Rider, B. (2001). Cyber-Organised Crime: The Impact of Information Technology on Organised Crime. Journal of Financial Crime, 8(4), 322-346.

Robertson, K. (1994). Practical Police Cooperation in Europe: The Intelligence Dimension. In M. Anderson \& M. Den Boer (Eds.), Policing Across National Boundaries (pp. 106-120). London: Printer Publishers.

Rose, N. (2000). Government and Control. British Journal of Criminology, 40, 321-339.

Santiago, M. (2000). Europol and Police Cooperation in Europe. New York: The Edwin Mellen Press.

Schalken, T., \& Pronk, M. (2002). On Joint Investigation Teams, Europol and Supervision of Their Actions. European Journal of Crime, Criminal Law and Criminal Justice, 10(1), 70-82.

Secretariat, U. N. (1956). Report on the First United Nations Congress on the Prevention of Crime and Treatment of Offenders. Geneva, Switzerland: United Nations.

Secretariat, U. N. (1961). Report on the Second United Nations Congress on the Prevention of Crime and Treatment of Offenders. London, England: United Nations.

Secretariat, U. N. (1967). Report on the Third United Nations Congress on the Prevention of Crime and Treatment of Offenders. Stockholm, Sweden: United Nations.

Secretariat, U. N. (1971). Report of the Fourth United Nations Congress on the Prevention of Crime and the Treatment of Offenders. Tokyo, Japan: United Nations.

Secretariat, U. N. (1976). Report on the Fifth United Nations Congress on the Prevention of Crime and Treatment of Offenders. Geneva, Switzerland: United Nations.

Secretariat, U. N. (1981). Report on the Sixth United Nations Congress on the Prevention of Crime and Treatment of Offenders. Caracas, Venezuela: United Nations.

Secretariat, U. N. (1986). Report on the Seventh United Nations Congress on Crime Prevention and the Treatment of Offenders. Milan, Italy: United Nations.

Secretariat, U. N. (1995). Report on the Ninth United Nations Congress on Crime Prevention and the Treatment of Offenders. Cairo, Egypt: United Nations.

Secretariat, U. N. (2001). Report on the Tenth United Nations Congress on the Prevention of Crime and Treatment of Offenders. Vienna, Austria: United Nations.

Secretariat, U. N. (2006). Report on the Eleventh United Nations Congress on the Prevention of Crime and Treatment of Offenders. Bangkok, Thailand: United Nations.

Secretary-General, U. N. (2001). Effective Measures to Prevent and Control of Computer-Related Crime. Vienna: United Nations Economic and Social Council.

Shearing, C. (2001). A Nodal Conception of Governance: Thoughts on a Policing Commission. Policing and Society, 11(3-4), 259-272. 
Sheptycki, J. (1995). Transnational Policing and the Makings of a Postmodern State. British Journal of Criminology, 35(4), 613-635.

Sheptycki, J. (1997). Insecurity, risk supression and segregation. Theoretical Criminology, 1(3), 303-315.

Sheptycki, J. (1998). Policing, Postmodernism and Transnationalization. British Journal of Criminology, 38(3), 485-504.

Sheptycki, J. (2000). Policing and Human Rights: An Introduction. Policing and Society, $10(1), 1-10$.

Sheptycki, J. (2002a). Accountability Across the Policing Field: Towards a General Cartography of Accountability for Post-Modern Policing. Policing and Society, 12(4), 323-338.

Sheptycki, J. (2002b). In Search of Transnational Policing: Towards a Sociology of Global Policing. England: Ashgate Publishing Limited.

Sheptycki, J. (2002c). Postmodern Power and Transnational Policing: Democracy, The Constabulary Ethic and the Response to Global (In)Security. Paper presented at the Geneva Centre for the Democratic Control of Armed Forces (DCAF), Geneva, Switzerland.

Sheptycki, J. (2004). The Accountability of Transnational Policing Insitutions: The Strange Case of Interpol. Canadian Journal of Law and Society, 19(1), 117-134.

Stenning, P. (1995). Accountability for Criminal Justice: Selected Essays. Toronto: University of Toronto Press.

Stenning, P. (2000). Powers and Accountability of Private Police. European Journal on Criminal Policy and Research, 8(3), 325-352.

Stenning, P., \& Shearing, C. (1980). The Quiet Revolution: The Nature, Development and General Legal Implications of Private Policing in Canada. Criminal Law Quarterly, 22, 220-248.

Stone, C., \& Merrick, B. (2002). Civilian Oversight of the Police in Democratic Societies. Paper presented at the Global Meeting on Civilian Oversight of Police, Los Angeles.

Thomas, M. (2000). The Globalization of Control: The Development of Registration and Surveillance Systems in Europe. Nordisk Tidsskrift for Kriminalvidenskab, 87(3), 203-220.

Thomas, P. (2002). Legislative Responses to Terrorism. In P. Scraton (Ed.), Beyond September 11: An Anthology of Dissent (pp. 93-102). London: Pluto Press.

UN. (2002). Report on Effective Measures to Prevent and Control of Computer-Related Crime. Vienna: United Nations Economic and Social Council.

UN. (2006). Previous Congresses on the Prevention of Crime and the Treatment of Offenders: United Nations Office of Drugs and Crime.

Walker, S. (1996). Varieties of Citizen Review: The Implications of Organizational Features of Complaint Review Procedures for Accountability of the Police. American Journal of Police, 15(3), 72-73.

Walsh, R. (2006). The United States and the Development of DNA Data Banks. from http://www.privacyinternational.org/article.shtml?cmd[347] $=\mathrm{x}-347-528471$ \#uses

Warren, S., \& Brandeis, L. (1890). The Right to Privacy. Harvard Law Review, 4(5), 193-220. 


\section{Cases Cited}

R. v. Tessling, [2004] S.C.C 67

Rv. Wise, [1992] 1 S.C.R. 527

R. v. Wong, [1990] 3 S.C.R. 36

R.v. Duarte, [1990] 1 S.C.R. 30

Katz v. United States, 389 U.S. 347 (1967)

Kyllo v. United States, 533 U.S. 27 (2001)

United States v. Penny-Feeney, 773 F. Supp. 220 (D. Haw. 1991) 